Aus der Poliklinik für Präventive Zahnmedizin, Parodontologie und Kariologie (Prof. Dr. med. dent. A. Wiegand) im Zentrum für Zahn-, Mund- und Kieferheilkunde der Medizinischen Fakultät der Universität Göttingen

\title{
Zahngesundheit bei übergewichtigen und adipösen Kindern und Jugendlichen
}

\author{
INAUGURAL-DISSERTATION \\ zur Erlangung des Doktorgrades \\ für Zahnmedizin \\ der Medizinischen Fakultät der \\ Georg-August-Universität zu Göttingen
}

vorgelegt von

Alexandra Rebecca Simon

aus

Homburg

Göttingen 2020 
Dekan:

\section{Betreuungsausschuss}

Betreuer/in:

Ko-Betreuer/in:

\section{Prüfungskommission}

Referent/in:

Ko-Referent/in:

Drittreferent/in:

Datum der mündlichen Prüfung: 15.07 .2020
Prof. Dr. med. dent. A. Wiegand

Prof. Dr. med. K. Brockmann

Prof. Dr. med. dent. A. Wiegand

Prof. Dr. med. K. Brockmann

Prof. Dr. hum. biol. M. Schön 
Hiermit erkläre ich, die Dissertation mit dem Titel "Zahngesundheit bei übergewichtigen und adipösen Kindern und Jugendlichen" eigenständig angefertigt und keine anderen als die von mir angegebenen Quellen und Hilfsmittel verwendet zu haben.

Göttingen, den 31.01.2020

(Unterschrift) 
Die Daten, auf denen die vorliegende Arbeit basiert, wurden teilweise publiziert:

Tschammler C, Simon A, Brockmann K, Röbl M, Wiegand A (2019): Erosive tooth wear and caries experience in children and adolescents with obesity. J Dent $\underline{83}, 77-86$ 


\section{Inhaltsverzeichnis}

Abkürzungsverzeichnis.................................................................................. III

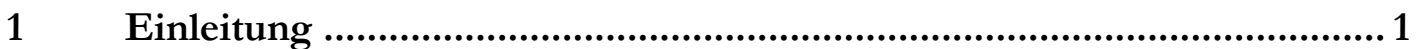

1.1 Definition und Klassifikation von Übergewicht und Adipositas im Kindes- und Jugendalter

1.2 Epidemiologische Studien zur Prävalenz von Übergewicht und Adipositas im Kindesund Jugendalter .............................................................................................................

1.3 Risikofaktoren für die Entstehung juveniler Adipositas ................................................

1.4 Zahngesundheit bei Adipositas im Kindes- und Jugendalter............................................. 5

1.4.1 Parodontalerkrankungen und Adipositas im Kindes- und Jugendalter .............................. 5

1.4.2 Karies und Adipositas im Kindes- und Jugendalter.......................................................... 6

1.4.3 Erosive Zahnhartsubstanzdefekte und Adipositas im Kindes- und Jugendalter ............11

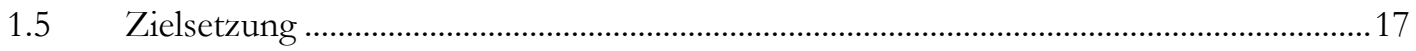

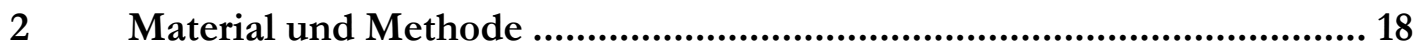

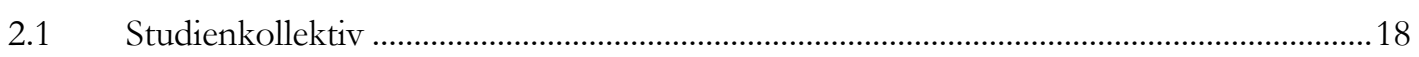

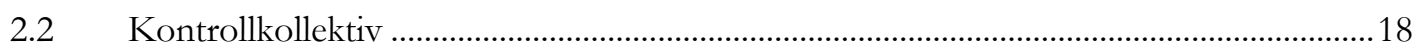

$2.3 \quad$ Fragebogen ........................................................................................................ 19

2.4 Erhebung der Body-Mass-Index-Perzentile (BMI-P) ......................................................19

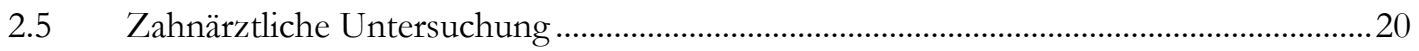

2.5.1 Zahnstatus und Erfassung von Karies....................................................................... 21

2.5.2 Erfassung von erosiven Zahnhartsubstanzdefekten.......................................................23

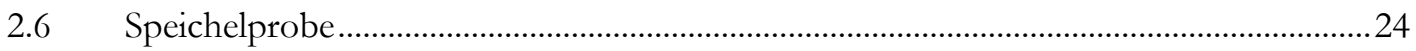

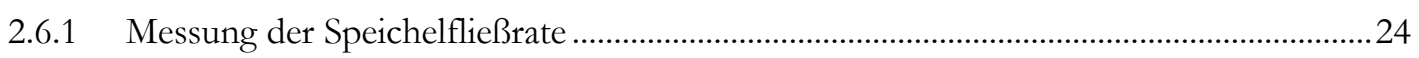

2.6.2 Messung des pH-Wertes des Speichels ..........................................................................2

2.6.3 Bestimmung der Pufferkapazität des Speichels ...............................................................25

2.7 Datenerfassung und statistische Auswertung ...............................................................26

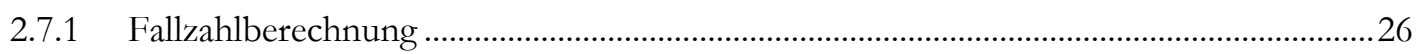

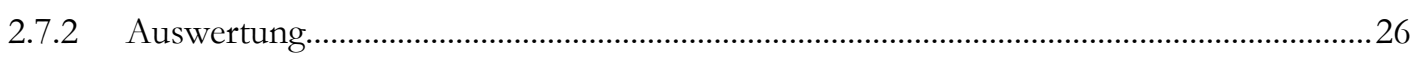

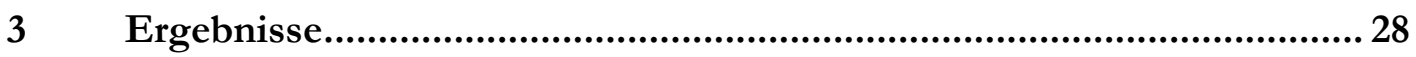

3.1 Verteilung der untersuchten Kinder und Jugendlichen nach Gewichtsklassen, Alter, Geschlecht und soziodemographischen Parametern.........................................................28

3.2 Ergebnisse der zahnärztlichen Untersuchung ...............................................................

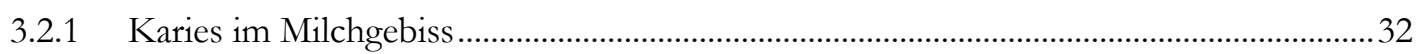

3.2.2 Karies im bleibenden Gebiss ....................................................................................... 37

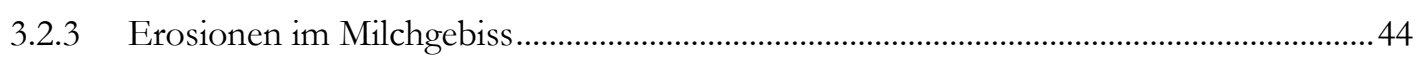

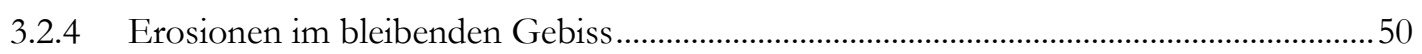

3.3 Assoziation zwischen Karies und dentalen Erosionen....................................................55

3.4 Ergebnisse der Speichelanalyse ................................................................................5

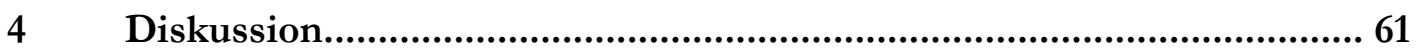




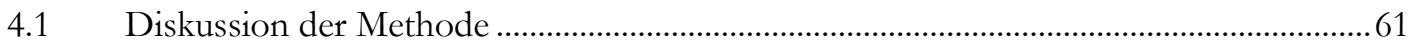

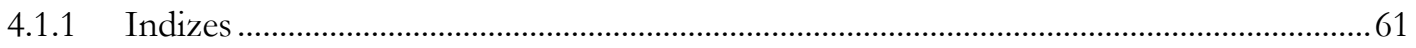

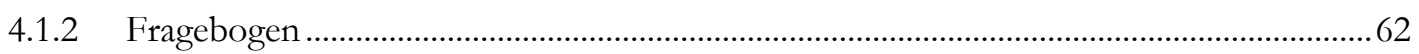

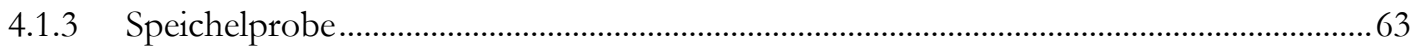

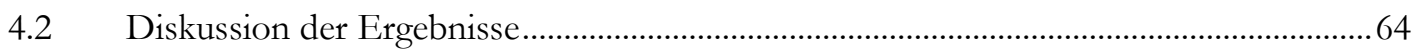

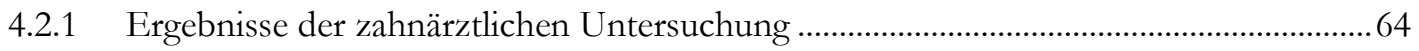

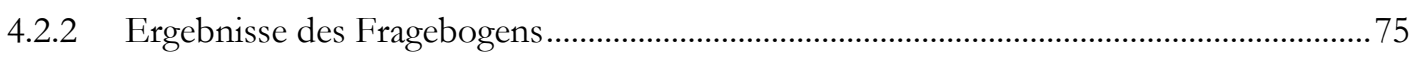

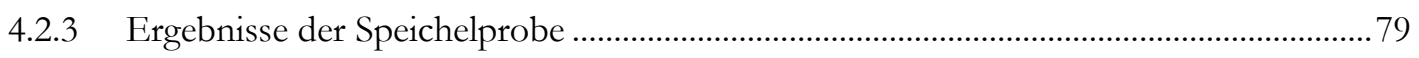

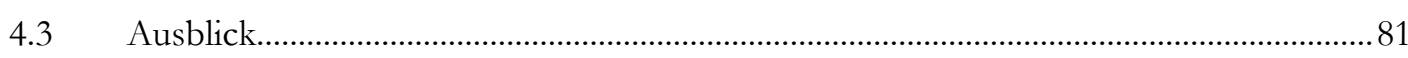

$5 \quad$ Zusammenfassung.......................................................................... 82

$6 \quad$ Anhang .......................................................................................... 84

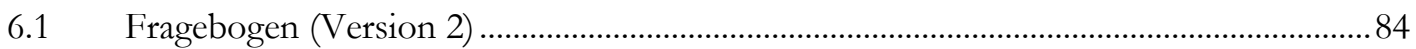

$7 \quad$ Literaturverzeichnis ................................................................... 85 


\section{Abkürzungsverzeichnis}

AGA Arbeitsgemeinschaft für Adipositas im Kindes- und Jugendalter

BMI Body-Mass-Index

DGZMK Deutsche Gesellschaft für Zahn-, Mund- und Kieferheilkunde

DMFS/dmfs Decayed Missing Filled Surfaces/ decayed missing filled surfaces

(bleibendes Gebiss/Milchgebiss)

$\mathrm{DMFT} / \mathrm{dmft}$

Decayed Missing Filled Teeth/ decayed missing filled teeth

(bleibendes Gebiss/Milchgebiss)

ECOG European Childhood Obesity Group

Gew.\% Gewichtsprozent

ICDAS International Caries Detection and Assessment System

NHANES National Health and Nutrition Examination Survey

SPZ Sozialpädiatrisches Zentrum 


\section{$1 \quad$ Einleitung}

Veränderte Lebensumstände, die mit einer Zunahme des Verbrauchs von gesüßten Getränken und hochkalorischem Essen einhergehen, stellen die Hauptursache steigender Prävalenzen für Adipositas im Kindes- und Jugendalter dar (Bawa 2005). Der Anteil übergewichtiger und adipöser Kinder und Jugendlicher stieg zwischen 1990 und 2010 von 4,2 \% auf 6,7 \% an, was einer weltweiten Anzahl von 43 Millionen betroffenen Kindern und Jugendlichen im Jahr 2010 entspricht (de Onis et al. 2010). Amerikanischen Studien zufolge decken Jugendliche im Durchschnitt 23,3 \% ihrer täglichen Kalorienzufuhr durch Erfrischungsgetränke, Säfte und Süßigkeiten (Block 2004). Der Anstieg des weltweiten Konsums kohlenhydrathaltiger Lebensmittel sowie Getränke könnte neben einem erhöhten Risiko für Übergewicht auch mit einer signifikant höheren Prävalenz für Karies und erosive Zahnhartsubstanzdefekte einhergehen, für die die Art der Ernährung und die Häufigkeit der Zufuhr bestimmter Lebensmittel bedeutende Risikofaktoren darstellen.

Karies gehört zu den häufigsten Krankheiten weltweit. Eine Vielzahl epidemiologischer Studien in Deutschland, wie die Fünfte Deutsche Mundgesundheitsstudie (DMS V) (Micheelis und Jordan 2016) und die Untersuchungen der Deutschen Arbeitsgemeinschaft für Jugendzahnpflege e. V. (Basner et al. 2017), berichten über einen deutlichen Kariesrückgang, insbesondere an Zähnen der bleibenden Dentition. Die Ursachen werden in einem gesteigerten Gesundheitsbewusstsein, verbunden mit regelmäßigeren Zahnarztbesuchen, und in einer Ausweitung der prophylaktischen Maßnahmen bereits in früheren Lebensjahren gesehen.

Trotz verbesserter Prophylaxemaßnahmen kann der deutliche Kariesrückgang für das Milchgebiss nicht bestätigt werden. Insbesondere bei Kindern bis zum dritten Lebensjahr bleibt die Prävalenz der frühkindlichen Karies (early childhood caries (ECC)) weiterhin hoch. Die Prävalenzraten in Deutschland weisen deutliche regionale Unterschiede auf und liegen zwischen $10 \%$ und $15 \%$ (Splieth et al. 2009; Treuner und Splieth 2013), unter Einbeziehung der initial kariösen Läsionen zwischen $14 \%$ und $25 \%$ (Basner et al. 2017).

Bei der Erforschung eines möglichen Zusammenhangs von Karies und Body-Mass-Index (BMI) zeigten Hayden et al. (2013) und Hooley et al. (2012) im Rahmen von Übersichtsarbeiten unterschiedliche Beobachtungen in Bezug auf Korrelationen auf, deren Ursachen in noch nicht genau geklärten ätiologischen Mechanismen, altersdemographischen Unterschieden, Interobservervarianzen und stark abweichenden sozioökonomischen Gegebenheiten der Studienländer gesucht werden (Hooley et al. 2012). 
Erosive Zahnhartsubstanzdefekte sind pathologische und chronische Zerstörungsprozesse von Schmelz und Dentin, welche durch direkte Einwirkung von Säuren exogener oder endogener Genese entstehen (Ganss 2014). Erosionen waren jedoch im Gegensatz zu Karies viele Jahre von geringem Interesse für die klinische Praxis. Die Diagnose insbesondere früher Stadien säureinduzierter Zahnhartsubstanzschädigung wurde selten gestellt, und es gab wenig geeignete Therapieansätze. Das wissenschaftliche Interesse an Erosionen erlangt jedoch zunehmend größere Bedeutung, was sich nicht zuletzt in einer steigenden Anzahl an Publikationen zu diesem Thema zeigt.

Eine auf PubMed unter MeSH terms durchgeführte Literaturrecherche ergibt aktuell jedoch nur zwei Studien, die sich mit dem Auftreten erosiver Zahnhartsubstanzdefekte bei übergewichtigen und adipösen Kindern und Jugendlichen auseinandergesetzt haben. Diese stammen aus den Vereinigten Staaten bzw. Singapur und kommen zu widersprüchlichen Ergebnissen (McGuire et al. 2009; Tong et al. 2014).

Die vorliegende Arbeit hat zum Ziel, die Prävalenz, den Schweregrad und die Lokalisation von Karies und erosiven Zahnhartsubstanzdefekten an einem Probandengut übergewichtiger und adipöser Kinder und Jugendlicher in Deutschland zu untersuchen und mit normalgewichtigen Kindern zu vergleichen.

\subsection{Definition und Klassifikation von Übergewicht und Adipositas im Kindes- und Jugendalter}

Die Deutsche Arbeitsgemeinschaft Adipositas im Kinder- und Jugendalter (AGA) definiert die Adipositas als eine chronische Erkrankung, verbunden mit einem zur Gesamtkörpermasse pathologisch erhöhten Körperfettanteil, der häufig aus einem Ungleichgewicht zwischen Energiezufuhr und Energieverbrauch resultiert (Wabitsch und Kunze 2015). Die Folgen reichen von einer eingeschränkten Lebensqualität bis hin zu einer häufig reduzierten Lebenserwartung.

Die Erkrankung bedarf einer längerfristigen interdisziplinären Behandlung, bestehend aus Ernährungs-, Bewegungs-, psychosozialer und in einigen Fällen auch pharmakologischer Therapie. Voraussetzung ist eine hohe, mitunter auch lebenslange, Compliance des Patienten.

Ein sowohl von der Childhood Group der International Obesity Task Force (IOTF) als auch der European Childhood Obesity Group (ECOG) anerkannter Index zur Klassifizierung des Gewichts bei Kindern und Jugendlichen ist der BMI, definiert als Quotient aus Körpermasse in $\mathrm{kg}$ und Körperlänge in m zum Quadrat (Quetelet 1869):

BMI $=$ Körpermasse $[\mathrm{kg}] /(\text { Körperlänge }[\mathrm{m}])^{2}$. 
Entsprechend physiologischer Änderungen der prozentualen Körperfettmasse im Kindesund Jugendalter muss zur Beurteilung des BMI stets das Alter und Geschlecht berücksichtigt werden.

Basierend auf den Daten zu Körpergröße und -gewicht von 17.147 Jungen und 17.275 Mädchen im Alter von 0 bis 18 Jahren, die zwischen 1985 und 1998 innerhalb verschiedener Regionen Deutschlands erhoben wurden, definierte Kromeyer-Hauschild et al. (2001) einheitliche Referenzperzentilwerte für Kinder und Jugendliche. So gelten Kinder und Jugendliche zwischen der 90. und 97. Perzentile als übergewichtig, Kinder mit Werten oberhalb der 97. Perzentile als adipös und oberhalb der 99,5. Perzentile als extrem adipös (KromeyerHauschild et al. 2001).

Zu weiteren Methoden der Quantifizierung und Diagnostik von Übergewicht und Adipositas gehören die Messung von Hautfaltendicken, Ultraschalluntersuchungen, aber auch komplexere Untersuchungen, wie beispielsweise Bioelektrische Impedanzanalysen (BIA) oder die Doppelröntgenabsorptiometrie zur Bestimmung der Körperzusammensetzung.

\subsection{Epidemiologische Studien zur Prävalenz von Übergewicht und Adipositas im Kindes- und Jugendalter}

Die Prävalenz von Übergewicht und Adipositas bei Kindern steigt in zahlreichen Ländern der Welt seit 1990 an (de Onis et al. 2010).

Im Rahmen einer Übersichtsarbeit wurden Studien aus 144 verschiedenen Ländern hinsichtlich der Prävalenz von Übergewicht und Adipositas bei Vorschulkindern ausgewertet. Dabei lag im Jahre 2015 der weltweite Anteil übergewichtiger und adipöser Kinder bei rund 50 Millionen, was einer weltweiten Prävalenz von 7,8 \% entspricht. Schätzungen zufolge werden im Jahre 2020 9,1 \% der Kinder weltweit übergewichtig sein. Verglichen mit den Daten der 1990er-Jahre würde dies einem Anstieg der weltweiten Prävalenz um mehr als 50 \% entsprechen (de Onis et al. 2010).

Die Ergebnisse einer standardisierten Vermessung von 14.747 Kindern und Jugendlichen im Rahmen des bundesweiten Kinder- und Jugendgesundheitssurveys (KiGGS) bestätigen den Anstieg übergewichtiger und adipöser Kinder und Jugendlicher auch in Deutschland und liefern repräsentative Informationen zur Verbreitung von Übergewicht und Adipositas unter den 3- bis 17-Jährigen. Die vom Robert-Koch-Institut von Mai 2003 bis 2006 durchgeführte Studie zeigt, dass insgesamt $15 \%$ der Untersuchten einen BMI oberhalb des 90. Perzentils aufweisen und damit als übergewichtig gelten. Nahezu 6,3\% liegen bei einem BMI oberhalb der 97. Perzentile und gelten per Definition als adipös. Werden diese Zahlen auf Deutschland 
hochgerechnet, leben ca. 1,9 Millionen übergewichtige und davon ca. 800.000 adipöse Kinder und Jugendliche in Deutschland. Die KiGGS hebt die Bedeutung der sozialen Herkunft, des Migrationshintergrundes sowie des maternalen Übergewichts als Risikofaktoren hervor. Verglichen mit den Referenzdaten der 1980er-Jahre hat sich der Anteil übergewichtiger und adipöser Kinder- und Jugendlicher in Deutschland verdoppelt (Kurth und Schaffrath Rosario 2007).

Vergleichbare Ergebnisse zeigt die Auswertung der Daten einer Teilstudie des National Health and Nutrition Examination Survey (NHANES) der Vereinigten Staaten von Amerika aus dem Jahre 2009 bis 2010. Hieraus geht hervor, dass 16,9\% der Kinder und Jugendlichen in der Altersgruppe der 2- bis 19-Jährigen übergewichtig bzw. adipös sind. Männliche Kinder und Jugendliche zeigen mit 18,6 \% eine deutlich höhere Prävalenz als weibliche Kinder und Jugendliche mit 15,0\%. Zwischen 2007 bis 2008 und 2009 bis 2010 konnte jedoch keine steigende Prävalenz verzeichnet werden (Ogden et al. 2012).

\subsection{Risikofaktoren für die Entstehung juveniler Adipositas}

Multifaktorielle Mechanismen genetischer und umweltbedingter Art werden für die Entstehung juveniler Adipositas verantwortlich gemacht. Die Hauptursachen liegen dabei in veränderten Verhaltensweisen, die sich in typischen Ernährungs- und Bewegungsmustern widerspiegeln. Der Rückgang körperlicher Freizeitaktivitäten hin zu überwiegend sitzender Freizeitbeschäftigung, wie z. B. Fernsehen oder Computer spielen (Lobstein et al. 2004), bedingt einen niedrigen Energieverbrauch. Übergewichtige Kinder und Jugendliche sind zusätzlich häufig körperlich weniger aktiv als normalgewichtige Kinder mit der Folge einer geringen Fettverbrennung. Ein weiterer begünstigender Faktor bei der Entstehung juveniler Adipositas ist nicht zuletzt der steigende Konsum zucker- und fettreicher Nahrungsmittel, die zusätzlich arm an Proteinen, Vitaminen und Spurenelementen wie Eisen und Kalzium sind (Fox et al. 2005).

Einen Überblick über die wichtigsten Adipositas-fördernden Faktoren gibt die Abbildung 1.1. 


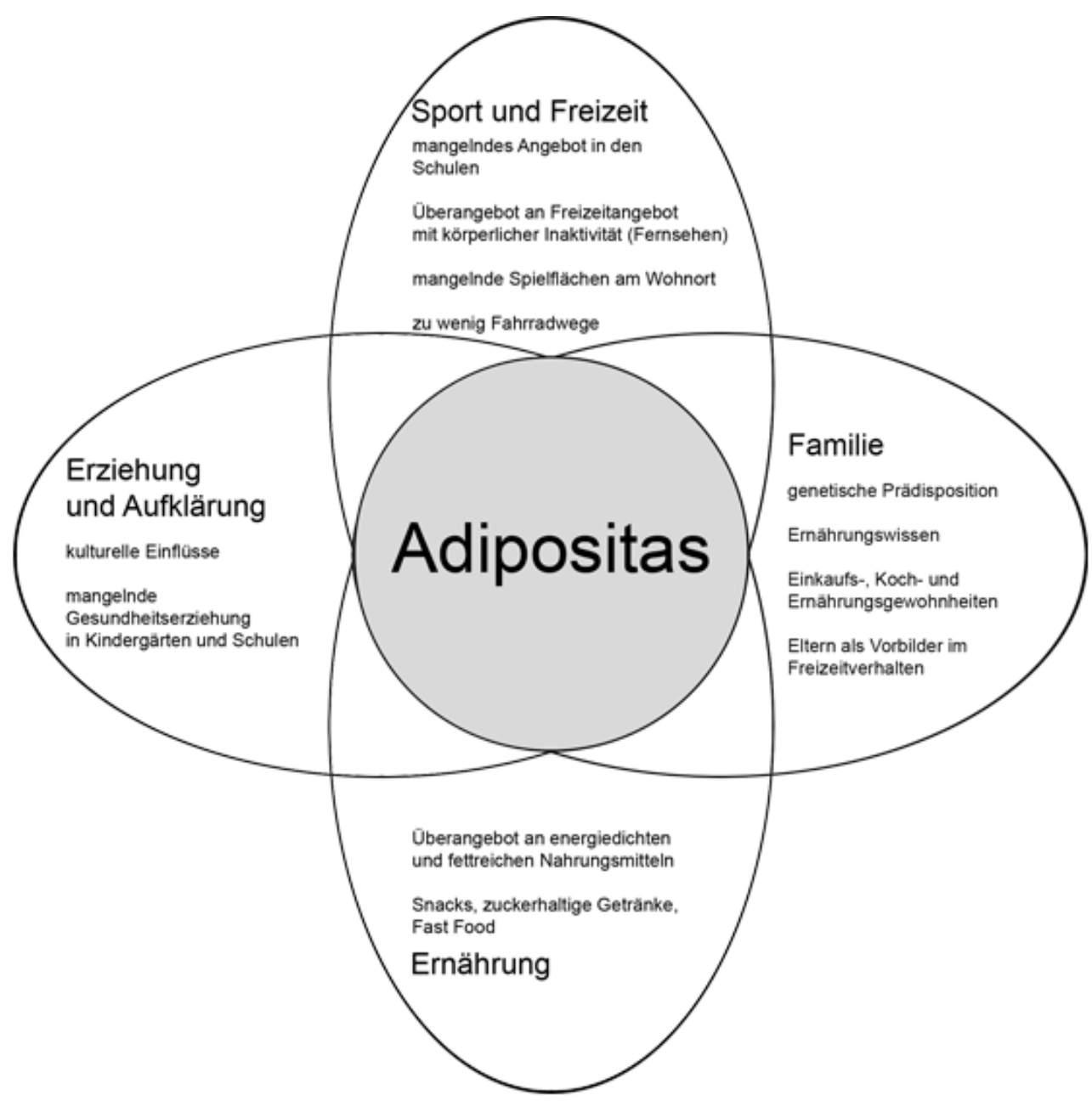

Abbildung 1.1: Adipositasfördernde Lebensbedingungen nach Wabitsch (2004)

\subsection{Zahngesundheit bei Adipositas im Kindes- und Jugendalter}

Gesundheitliche Risiken juveniler Adipositas reichen von höheren Komorbiditäten im Vergleich zu Normalgewichtigen bis hin zu einem deutlich erhöhten Morbiditäts- und Mortalitätsrisiko im Erwachsenenalter. Neben allgemeinmedizinischen Folgen, wie z. B. arterieller Hypertonie, kardiovaskulären Erkrankungen oder auch Diabetes mellitus Typ II, zeigen Betroffene häufig auch psychosoziale Folgeerkrankungen und eine erhöhte Prädisposition für zahnmedizinische Folgeerkrankungen (Alberti et al. 2004; Nadeau et al. 2011; Wabitsch 2004).

\subsubsection{Parodontalerkrankungen und Adipositas im Kindes- und Jugendalter}

Der Begriff „parodontale Erkrankungen“ beschreibt eine Gruppe entzündlicher Erkrankungen der Gingiva und des Parodonts. Das klinische Bild einer Parodontitis umfasst eine progressive Gewebezerstörung mit dem Auftreten parodontaler Taschen (erhöhte Sondierungstiefen), Attachmentverlust, Abbau des Knochens, Lockerung der betroffenen Zähne bis hin zur Exfoliation (Williams 1990). 
Parodontale Erkrankungen gehören zu den multifaktoriell bedingten Erkrankungen. Eine der Hauptursachen ihrer Entstehung liegt in parodontopathogenen Keimen, wie Aggregatibacter actinomycetemcomitans, Porphyromonas gingivalis, Tanerella forsythia, Treponema denticola oder Fusobacterium nucleatum, welche die subgingivale Plaque besiedeln und über chemotaktische Faktoren (z. B. Lipopolysaccharide, Antigene) mit dem Wirt interagieren. Für die Entstehung parodontaler Erkrankungen ist neben der bakteriellen Besiedelung also auch ein empfänglicher Wirt Voraussetzung. Die Abschilferung von Epithelzellen, die Phagozytoseaktivität der Granulozyten sowie die Spülfunktion des Speichels stehen in einem physiologischen Gleichgewicht mit den vorkommenden Mikroorganismen. Genetische aber auch Umwelt- und erworbene Risikofaktoren, wie z. B. Rauchen, Stress, Adipositas oder Diabetes mellitus, können die inflammatorische und immunologische Reaktion des Wirtes beeinträchtigen. In der Folge entsteht ein Ungleichgewicht mit Etablierung einer pathogenen Flora und der Auslösung einer Entzündungsreaktion (Page und Kornman 1997; Preshaw et al. 2004).

Adipositas wurde als signifikanter Risikofaktor für die Entstehung parodontaler Erkrankungen im Erwachsenenalter identifiziert (Moura-Grec et al. 2014). Genco et al. (2005) erklären diese Prädisposition mit der häufig im Rahmen des metabolischen Syndroms auftretenden Insulinresistenz. Die vermehrte Sekretion proinflammatorischer Adipokine und Zytokine sowie des Tumor-Nekrose-Faktors alpha (TNF- $\alpha$ ) aus dem Fettgewebe begünstigen eine gesteigerte Entzündungsbereitschaft oraler Gewebe. Die Aktivierung von Osteoklasten durch TNF- $\alpha$ und Interleukine kann das Auftreten einer starken Gewebedestruktion, gekennzeichnet durch Resorption des Alveolarknochens und Zerstörung desmodontaler Fasern, stimulieren (Nishida et al. 2005).

Umgekehrt kann die vermehrte Interleukin-1- $\beta$ - (IL-1- $\beta$ ) und Interferon- $\gamma$-Sekretion unter Parodontitis zu einer Störung des Fettstoffwechsels und somit zu einer weiteren Zunahme des Gewichts beitragen (Wood et al. 2003).

Für das Kindes- und Jugendalter liegen aktuell nur wenige Daten über einen möglichen Zusammenhang von Adipositas und einer höheren Prävalenz für Parodontitis vor. Laut Modeer et al. (2010) haben adipöse Kinder und Jugendliche verglichen mit normalgewichtigen Kindern ein höheres Risiko an chronischer Parodontitis zu erkranken.

\subsubsection{Karies und Adipositas im Kindes- und Jugendalter}

Karies und Adipositas sind multifaktoriell bedingte Erkrankungen und zeigen als gemeinsame Risikofaktoren verschiedene Ernährungsfaktoren, wie z. B. den regelmäßigen Konsum zuckerhaltiger Getränke (Bawa 2005; Ochoa et al. 2007), einen geringen Frucht- und Gemüseanteil in der Ernährung (Dye et al. 2004) und den regelmäßigen Konsum größerer Mengen 
Zucker (Hayden et al. 2013). Neben den Ernährungsfaktoren spielen zusätzlich sozioökonomische Faktoren, genetische Prädisposition, die Mundhygiene des Kindes und die Einstellung der Eltern zur Zahn- und Allgemeingesundheit eine wichtige Rolle.

Einen weiteren Risikofaktor bei der Entstehung von Karies stellt eine verminderte Speichelfließrate dar, wie sie bei adipösen Patienten auftreten kann. Als mögliche Ursache für diese Beobachtung wird eine chronische Entzündung der Speicheldrüsen, die durch eine vermehrte Synthese proinflammatorischer Adipokine und Zytokine aus dem Fettgewebe ausgelöst wird, diskutiert (Marsicano et al. 2012).

Die aktuelle Studienlage bezüglich einer Korrelation zwischen einem erhöhten Körpergewicht und dem Auftreten von Karies ist ambivalent. Während zahlreiche Studien der vergangenen Jahre einen signifikanten Zusammenhang zwischen Adipositas und kariösen Läsionen feststellen konnten (Fadel et al. 2014; Gerdin et al. 2008; Willershausen et al. 2007), konnten andere Studien keinen (Dye et al. 2004; Hooley et al. 2012) oder einen inversen Zusammenhang aufzeigen (Sanchez-Perez et al. 2010; Sharma und Hegde 2009). Die Variabilität der Ergebnisse ist häufig auf unterschiedliche soziökonomische Begebenheiten der Untersuchungsländer zurückzuführen.

\subsubsection{Definition von Karies}

Das Wort „Karies“ entstammt dem lateinischen Wort „caries“als Synonym für „Morschheit“ bzw. „Fäulnis“ und beschreibt einen Substanzverlust an Hartgewebe (Hoffmann-Axthelm 2000). Die Zahnkaries ist eine dynamische und multifaktoriell bedingte, pathologische Erkrankung der Zahnhartsubstanzen, die durch das Zusammenwirken potenziell pathogener Mikroorganismen und ökologischer Faktoren entsteht (Shellis 2012). Die häufigste und zugleich lokalisierte Erkrankung der Zahnhartgewebe kennzeichnet sich durch Phasen der Stagnation, Remission und Progression.

\subsubsection{2 Ätiologie und Lokalisation von Karies}

Die heute allgemein akzeptierte Theorie der chemisch-parasitären Kariesentstehung nach Miller wurde im Jahr 1898 erstmals vorgestellt und durch zahlreiche Wissenschaftler modifiziert. Kariogene Mikroorganismen in der Plaque produzieren bei einem Überangebot an kariogenem Substrat, wie niedermolekularen Kohlenhydraten, organische Säuren, welche bei längerem Einwirken auf die Zahnhartsubstanz zu einer Demineralisation derselben führen. Zusätzlich zu diesen vier beschriebenen Hauptfaktoren (Wirt, Plaque, kariogenes Substrat und Zeit) spielen auch sekundäre Faktoren bei der Entstehung und Progression einer kariösen Läsion eine entscheidende Rolle. 
Dazu zählen Speichelfluss- und Speichelzusammensetzung, pH-Wert und Pufferkapazität des Speichels, Immunabwehr, genetische Faktoren, Dauer und Häufigkeit der Substratzufuhr, verhaltensbezogene Komponenten, Zahnfehlstellungen und Zahnfehlbildungen (Shellis 2012).

An bestimmten Zahnflächen entsteht wegen anatomischer und morphologischer Besonderheiten häufiger Karies als an anderen. Zu diesen besonders kariesgefährdeten Bereichen (Kariesprädilektionsstellen) gehören die Zahnfissuren und -grübchen, die Approximalflächen der Zähne, das zervikale Drittel der sichtbaren Zahnkronen und freiliegende Wurzeloberflächen.

\subsubsection{Pathogenese von Karies}

Kariöse Läsionen sind das Ergebnis von De- und Remineralisationsvorgängen der Zahnhartsubstanz mit Überwiegen von Demineralisationsphasen.

Die Beschichtung der gründlich gereinigten Zahnoberflächen mit Muzinen und Glykoproteinen erfolgt durch das aquired pellicle, einer semipermeablen Membran, welche je nach Reifegrad zwischen 0,1 bis 1,0 $\mu \mathrm{m}$ dick wird. Die Pellikelkomponenten gehen aufgrund ihrer Eigenladung elektrostatische Bindungen mit Kalzium- und Phosphatgruppen des Apatits ein und sorgen so für eine starke Haftung an der Schmelzoberfläche. Die Schutzfunktion der durch Speichelproteine gebildeten Pellikel zeigt sich in einer Diffusionsbarriere für Säuren und damit der Verhinderung eines säurebedingten Mineralverlustes. Bevor eine Säure an die Zahnoberfläche gelangt, muss zunächst eine Diffusion durch die Pellikel erfolgen (Hannig und Balz 2001; Hannig und Hannig 2014; Lenander-Lumikari und Loimaranta 2000; Zahradnik et al. 1976).

Innerhalb weniger Stunden besiedeln grampositive Kokken und Aktinomyzeten sowie im weiteren Verlauf Veillonellen, Prevotella und Fusobakterien das Schmelzoberhäutchen. Durch Teilungs- und Akkumulationsvorgänge weiterer Bakterienspezies über Adhäsion und Kohäsion entwickelt sich eine hoch kariogene Plaque mit zunehmend anaerobem Charakter. Die hoch strukturierte, räumlich organisierte und verfilzte Zahnplaque, bestehend aus Speichel- und Nahrungsbestandteilen, bakteriellen Stoffwechselprodukten und Bakterienzellen, beherbergt in Abhängigkeit von ihrem Reifegrad und ihrer Lokalisation in der Mundhöhle bis zu 1.000 Bakterienspezies, welche über Gentransfer und Sekretion von Signalmolekülen interagieren (Jaroch und Kielbassa 2009).

Durch den Verzehr fermentierbarer Kohlenhydrate (Saccharose, Oligosaccharide, Glukose, Fruktose, Laktose und Stärke) wird der Säureangriff auf die Zahnhartsubstanz initiiert. Kariogene Mikroorganismen der Plaque verstoffwechseln die aufgenommenen Kohlenhydrate 
zu organischen Säuren (Laktat, Essigsäure u. a.). Eine herausragende Rolle spielt dabei der azidogene und säuretolerante Streptococcus mutans, welcher über anaerobe Glykolyse organische Säuren und mit Hilfe von Glukosyltransferasen extrazelluläre Polysaccharide (Glucane) zur Haftung an der Zahnoberfläche synthetisiert (Bender et al. 1986; Gibbons und Fitzgerald 1969; Kuramitsu 1993).

Nach entsprechend langer Einwirkzeit der Säure und beim Unterschreiten des kritischen pHWertes (Schmelz: pH 5,2 bis pH 5,7 und Dentin: pH 6,2 bis pH 6,7) kann eine Demineralisation der Zahnhartsubstanz beobachtet werden. Eine Dissoziation der organischen Säuren im Schmelzinneren bewirkt die Freisetzung von Wasserstoff-Ionen, welche folglich zum Herauslösen von Kalzium- und Phosphat-Ionen aus dem Schmelzgitter führt. Die Ionen diffundieren entlang des Konzentrationsgradienten in Richtung Plaque.

Die kariogenen Säureangriffe zeigen neben der Häufigkeit der Nahrungsmittelzufuhr sowie deren Qualität und Quantität eine ebenso große Abhängigkeit vom Faktor Zeit. So führt eine regelmäßige Zufuhr kariogener Substrate zu häufigeren und länger anhaltenden Säureattacken auf die Zahnhartsubstanz.

Individuelle Unterschiede in der Zahnstellung, Zahnhartsubstanzzusammensetzung, Oberflächenbeschaffenheit der Zähne sowie in der Qualität und Quantität des Speichels können die Entstehung dentaler Karies beeinflussen (Shellis 2012).

Der Speichel stellt eines der wichtigsten Schutzsysteme des menschlichen Körpers dar. In seiner Gesamtheit dient er der Aufrechterhaltung eines ökologischen Gleichgewichtes in der Mundhöhle und ist für die Gesunderhaltung der Zähne und Mundhöhle von eminenter Bedeutung.

Der Speichel ist eine wässrige, trübe Lösung, welche zu 99,5 \% aus Wasser besteht. In ihm sind ca. $5 \mathrm{~g} / \mathrm{l}$ anorganische und organische Substanzen gelöst. Zu den wichtigsten anorganischen Komponenten des Speichels zählen die Elektrolyte Natrium, Kalium, Kalzium, Chlorid, Bikarbonat, Phosphat, Fluorid sowie verschiedene Spurenelemente (Zink, Kupfer, Kobalt, Jod etc.). Proteine, Glykoproteine (Muzine) und Enzyme ergänzen als organische Bestandteile die Zusammensetzung (JA Young und Schneyer 1981).

Der primäre Speichel wird in den Azinuszellen der Drüsen produziert. Dabei sind die Speicheldrüsen in unterschiedlich großem $\mathrm{Maß}$ an der Produktion von unstimuliertem und stimuliertem Speichel beteiligt. Bei der Produktion des unstimulierten Speichels entfallen ca. $20 \%$ auf die Glandula parotis, etwa $65 \%$ auf die Glandula submandibularis, ca. 7 bis $8 \%$ auf die Glandula sublingualis und weniger als $10 \%$ auf die kleinen Speicheldrüsen (Edgar 1990; Humphrey und Williamson 2001; JA Young und Schneyer 1981). 
Die verschiedenen Inhaltsstoffe des Speichels erfüllen vielfältige kariesprotektive Aufgaben. Dazu gehören insbesondere die antibakterielle Aktivität durch enthaltene Antikörper, Lysozym, Laktoferrin und Laktoperoxidase sowie die Fähigkeit zur Remineralisation von Zahnhartsubstanzen. Die im Speichel enthaltenen SIgA-Antikörper sind in der Lage, das Wachstum und die Enzymaktivität des Streptococcus mutans zu hemmen und dessen Anheftung am Zahn, über Ausschaltung der enzymatischen Aktivität extrazellulärer Glukosyltransferase, zu verhindern (Hamada und Slade 1980; Marcotte und Lavoie 1998).

Der Konsum von Nahrungsmitteln steigert die Speichelfließrate und Pufferkapazität begleitet von einem Anstieg der Bikarbonatkonzentration, sodass in der Plaque freigesetzte $\mathrm{H}^{+}$Ionen entfernt werden können. Bei ausreichendem Anstieg des pH-Wertes können bei Demineralisationsprozessen freigesetzte Kalzium- und Phosphat-Ionen wieder in die Zahnoberfläche eingelagert werden (Shellis 2012). Die Fließrate und Pufferkapazität des Speichels gehören zu den wichtigsten, den Säureangriff modulierenden, Wirtsfaktoren.

Das Gleichgewicht zwischen De- und Remineralisation wird durch die Wechselwirkung zwischen bakteriellen Virulenzfaktoren (Angriffsfaktoren) und Wirtsabwehrmechanismen (Abwehrfaktoren) beeinflusst. Durch Beseitigung kariogener Mikroorganismen mit Hilfe geeigneter Prophylaxemaßnahmen kann eine initiale Kariesläsion im Schmelz arretieren und eine Remineralisierung entmineralisierter Areale erfolgen.

\subsubsection{Epidemiologische Studien zur Kariesprävalenz bei Kindern und Jugendlichen}

Epidemiologische Studien sind eine Voraussetzung, um den Mundgesundheitsstatus von Populationen zu beschreiben, die Ätiologie und Verbreitung einer Erkrankung zu klären oder um den zahnmedizinischen Versorgungsgrad in quantitativer und qualitativer Hinsicht zu beurteilen. Unter dem Begriff „Prävalenz“versteht man die Häufigkeit des Auftretens einer Erkrankung in einer Population zu einem definierten Zeitpunkt. Die Kariesprävalenz errechnet sich aus dem Quotienten aus der Anzahl der an Karies erkrankten Personen in der Population und der Gesamtzahl aller Untersuchten dieser Population.

Im Rahmen von nationalen Mundgesundheitsstudien erfasst die Arbeitsgemeinschaft für Jugendzahnpflege in Deutschland e. V. (DAJ) seit 1994 im Auftrag des Gesetzgebers die Kariesprävalenz von 6- bis 7-jährigen und 12-jährigen Kindern in Abständen von drei Jahren. Seit 2004 werden zusätzlich 15-jährige Schulkinder untersucht. Die Erhebung von Mundgesundheitsdaten von knapp 100.000 3-jährigen Kindern aus zehn verschiedenen Bundesländern erfolgte erstmalig im Jahr 2016.

Innerhalb der letzten beiden Jahrzehnte konnte eine Verbesserung der Mundgesundheit von Kindern und Jugendlichen aller Sozialschichten festgestellt werden. Lagen die mittleren 
dmft-Werte in der Altersgruppe der 6- bis 7-Jährigen im Jahre 2009 noch zwischen 1,3 (Saarland) und 2,56 (Thüringen), konnte im Jahr 2016 ein Rückgang auf 1,37 (Bayern) bis 2,31 (Sachsen-Anhalt) verzeichnet werden. Für die Schulanfänger stieg der Prozentsatz naturgesunder Gebisse von 2009 bis 2016 von $52 \%$ auf $56 \%$ an.

In der Altersgruppe der 12-Jährigen ist ein deutlicher Kariesrückgang in allen Bundesländern erkennbar. Der Anteil naturgesunder permanenter Gebisse (DMFT = 0) stieg auf 66,3\% (Bremen) bis 86,6 \% (Rheinland-Pfalz) an. Demnach verzeichnen mehr als die Hälfte aller untersuchten Jugendlichen heute kariesfreie bleibende Zähne (Basner et al. 2017).

Die Ursachen für den deutlichen Kariesrückgang in der Altersgruppe der 12-Jährigen werden in regelmäßigeren Zahnarztbesuchen und in einer Ausweitung der prophylaktischen Maßnahmen, wie Fissurenversiegelungen an bleibenden Molaren, gesehen.

Betrachtet man die Ergebnisse im Milchgebiss bei 6- bis 7-jährigen Kindern der ersten Klasse zeigt sich jedoch nur noch ein minimaler Kariesrückgang. Die Bundesländer Bremen, Rheinland-Pfalz, Sachsen und Sachsen-Anhalt verzeichneten von 2009 bis 2016 sogar steigende Prävalenzwerte. In Niedersachsen stagnierte der Anteil unversorgter Milchzähne bei 43,3 \% (Basner et al. 2017).

\subsubsection{Erosive Zahnhartsubstanzdefekte und Adipositas im Kindes- und Jugendalter}

Bis zum heutigen Tag liegen noch recht wenige Daten über den Zusammenhang zwischen BMI und einem erhöhten Auftreten von erosiven Zahnhartsubstanzdefekten bei übergewichtigen und adipösen Kindern und Jugendlichen vor. Gründe für eine mögliche Korrelation könnten einerseits in der Ernährung (regelmäßiger Konsum von Fruchtsäften und Erfrischungsgetränken, obst- und gemüsereiche Ernährung im Rahmen von Diätversuchen), in dem Auftreten einer Refluxerkrankung bei Adipositas, in einer aufgrund der Grunderkrankung veränderten Speichelzusammensetzung und Speichelmenge sowie in der Einnahme verschiedener Medikamente, wie Antihypertonika, zu finden sein.

Bisher existieren nur zwei Studien, welche sich mit diesem Thema auseinandergesetzt haben. McGuire et al. (2009) analysierten die Daten einer Teilstudie des NHANES von 2003 bis 2004, welche erstmals das Auftreten erosiver Zahnhartsubstanzdefekte berücksichtigte. Es wurden 1.962 Kinder in der Altersgruppe der 13- bis 19-Jährigen unter Anwendung des Tooth-Wear-Index (TWI) nach Smith und Knight untersucht. Bei übergewichtigen und adipösen Kindern und Jugendlichen konnte im Vergleich zu normalgewichtigen Kindern und Jugendlichen eine höhere Prävalenz erosiver Zahnhartsubstanzdefekte festgestellt werden. 
Tong et al. (2014) untersuchten die Prävalenz erosiver Zahnhartsubstanzdefekte bei Kindern zwischen dem 7. und 15. Lebensjahr. Es zeigte sich, dass adipöse Kinder signifikant mehr und schwerere Erosionen aufwiesen als die normalgewichtigen Kinder.

\subsubsection{Definition erosiver Zahnhartsubstanzdefekte}

Der Begriff „Erosion“ leitet sich von dem lateinischen Wort „erodere“- abtragen - ab. Erosive Zahnhartsubstanzdefekte sind als pathologische, chronische und lokalisierte Zerstörungsprozesse von Schmelz und Dentin definiert, welche anders als kariöse Zahnhartsubstanzdefekte durch chemische Einflüsse von Säuren ohne Beteiligung von Mikroorganismen entstehen (Pindborg 1970). Der chemische Ätzvorgang entwickelt sich unter dem Einfluss von Säuren intrinsischer (Magensäure) und/oder extrinsischer (z. B. saure Nahrungsmittel) Herkunft (Järvinen et al. 1991).

\subsubsection{Pathogenese, Ätiologie und Lokalisation erosiver Zahnhartsubstanzdefekte}

Erosive Zahnhartsubstanzdefekte entstehen durch direkte Säurewirkung, die zu einer schichtweisen Auflösung der anorganischen Zahnhartsubstanz (Demineralisation) führt. Unabhängig von der Säureart äußert sich die Demineralisation des Schmelzes zunächst durch einen Mineralverlust im Bereich der Prismenscheiden und Prismenkerne, gefolgt von einer Auflösung der interprismatischen Substanz. Im Bereich des Dentins beginnt der Prozess der Demineralisation an der Grenzfläche zwischen inter- und peritubulärem Dentin. Bei weiterem Fortschreiten folgt eine Aushöhlung und Erweiterung der Dentintubuli. Das intertubuläre Dentin wird zunehmend rauer und poröser. Das peritubuläre Dentin kann bei starker Ausprägung vollständig aufgelöst werden (Meurman et al. 1991).

Die Zone der größten Demineralisation ist bei erosiven Läsionen peripher lokalisiert und schreitet zentripetal voran (Zentner und Duschner 1996). Großflächige irreversible Zahnhartsubstanzverluste entstehen durch längere und/oder häufige Säureeinwirkung, wobei die Schwere der Ausprägung von der Stärke der Säure abhängig ist (Attin 1999).

Speichel ist eine kalzium- und phosphatübersättigte Lösung, die bei neutralem pH-Wert in der Mundhöhle ( $\mathrm{pH}$ 6,5 bis 6,9) als chemisches Gleichgewicht zwischen Kalzium- und Phosphationen sowie dem Hydroxylapatit des Schmelzes vorliegt. Wenn in Folge einer Säureexposition im Mund ein $\mathrm{pH}-$ Wertabfall unter $\mathrm{pH} 5$ erfolgt, kann eine Umwandlung der Phosphationen in die protonierte Form beobachtet werden. Kalzium- und Phosphationen diffundieren entlang des Konzentrationsgradienten aus der Zahnhartsubstanz in den Speichel, welcher dadurch zu einer an Hydroxylionen untersättigten Lösung wird. Die Hydroxylionen des Apatits, Karbonate sowie Orthophosphate werden von den Protonen der in den Schmelz 
eindringenden Säure angegriffen. Es entstehen protonisierte Karbonat- bzw. Phosphationen und Wasser durch Neutralisierung der Hydroxylionen. Innerhalb der Apatitkristalle erfolgt eine Destabilisierung des Ionengleichgewichtes und Freisetzung von Kalziumionen. Als Anionen gehen protonisierte Karbonat- und Phosphationen in Lösung. Zur Aufrechterhaltung der Elektroneutralität treten Kalziumionen in Folge einer Negativierung von Kristalloberflächen in die umgebende Lösung der Kristalle ab (Attin 1999).

Der anfänglich für den Patienten schmerzlose und nicht sichtbare destruktive Prozess einer Erosion nimmt bei ständig wiederholtem Säureangriff und Überschreiten der Neutralisationsfähigkeit des Speichels einen progredienten Verlauf mit flächenhafter Ausbreitung von der Schmelzoberfläche in die Tiefe des Dentins, gekennzeichnet mit beginnendem Auftreten von Zahnverfärbungen und schmerzhaften Hypersensitivitäten (Hotz 1987).

Klinisch zeigt sich ein Verlust der Oberflächenstruktur im Anfangsstadium in der Entstehung von glatten, matt glänzenden dellenförmigen Einsenkungen mit abgerundeter Begrenzung, die in Abhängigkeit der Ätiologie auf den vestibulären oder oralen Zahnoberflächen lokalisiert sind. Charakteristisch sind über das Niveau der umgebenden erosionsgeschädigten Zahnhartsubstanz hinausragende Füllungsränder. Mit dem Fortschreiten des erosiven Prozesses wird eine Abflachung konkaver Strukturen des Zahnes sowie eine Einebnung des Höcker-Fissuren-Reliefs beobachtet, welche folglich den vollständigen Verlust der Morphologie des Zahnes begünstigen (Ganss und Lussi 2014).

In Folge eines zusätzlichen Einwirkens abrasiver Prozesse auf die Zahnhartsubstanz kann dieser Substanzverlust beschleunigt werden (Attin 1999; Wiegand und Schlueter 2014).

\subsection{Extrinsische Faktoren}

Durch extrinsische Säureangriffe hervorgerufene Erosionen sind häufig an den Vestibulärflächen der Oberkieferfrontzähne lokalisiert und werden mit einem exzessiven Verzehr säurehaltiger Lebensmittel, Arznei- und Nahrungsergänzungsmittel, einem bestimmten Lebensstil oder einer berufsbedingten Säureexposition assoziiert (Lussi 1996).

Als erosionsauslösende Lebensmittel gelten insbesondere solche mit einem niedrigen $\mathrm{pH}$ Wert, wie z. B. Zitrusfrüchte und deren Säfte, kohlensäurehaltige Getränke, Sportlergetränke, Wein, Salatdressings und Essigprodukte. Larsen und Nyvad (1999) stellten fest, dass Nahrungsmittel, deren $\mathrm{pH}$-Wert niedriger als $\mathrm{pH} 4$ bis $\mathrm{pH}$ 5,5 ist, erosives Potential besitzen. Lussi et al. (2004) zeigten neben dem pH-Wert weitere erosionsfördernde Faktoren in Nahrungsmitteln auf. Hierbei sind insbesondere die Adhäsion der Nahrung am Zahn sowie der Phosphat-, Kalzium- und Fluoridanteil zu erwähnen. 
Beispiele für Medikamente mit einem niedrigen $\mathrm{pH}$-Wert oder einem hohen Gehalt an titrierbarer Säure sind Vitamin-C- bzw. Ascorbinsäure-haltige Präparate in Form von Kautabletten, Sirup oder Brausetabletten. Eine regelmäßige und/oder über einen längeren Zeitraum erfolgte Einnahme kann das Auftreten erosiver Läsionen an den Zähnen begünstigen (Hellwig und Lussi 2014; Schlueter und Tveit 2014).

Neben ernährungsbedingten Faktoren werden in der Literatur auch eine Reihe von Umweltfaktoren (z. B. berufsbedingte Säureexposition, gesunder Lebensstil) für die Entstehung erosiver Zahnhartsubstanzdefekte verantwortlich gemacht.

In Verbindung mit einem ausgeprägten Gesundheitsbewusstsein steht häufig ein vermehrter Verzehr von Obst und Salat, regelmäßige sportliche Betätigung und eine sehr sorgfältige Mundhygiene. Erosionen entstehen bevorzugt auf plaquefreien Oberflächen. Regelmäßiges und gründliches Zähneputzen begünstigt die Plaquereduktion und mindert die Pufferkapazität der Plaque.

Ten Bruggen Cate (1968) zeigte eine erhöhte Prävalenz für dentale Erosionen insbesondere bei Arbeitern in der Munitions-, Dynamit- und Batterieherstellung, die einer erhöhten Exposition schwefel- oder salpetersäurehaltiger Dämpfe ausgesetzt sind. In anderen Untersuchungen konnten auch bei Chemielaboranten, die beim Pipettieren mit dem Mund Säure aufnehmen, dentale Erosionen nachgewiesen werden (Levine 1973).

\subsection{Intrinsische Faktoren}

Zu den endogenen Säuren, die Auslöser von erosiven Zahnhartsubstanzdefekten sein können, gehören Magensäure oder saurer Mageninhalt. Ursächlich für den Kontakt zwischen endogenen Säuren und Zähnen sind zumeist Erkrankungen aus dem Formenkreis der gastrooesophagalen Refluxkrankheiten (gastro-oesophageal reflux disease (GORD)), Bulimia nervosa, Emesis bei chemotherapeutischer Behandlung von Tumorerkrankungen, Alkohol- und Drogenabusus sowie psychosomatische Störungen (z. B. stressinduziertes psychogenes Erbrechen) (Attin 1999).

Zahlreiche Studien zeigten, dass mehr als $90 \%$ der an Bulimia nervosa erkrankten Patienten erosive Läsionen aufweisen, von denen bis zu $64 \%$ bis in das Dentin reichen. Charakteristisch ist hierbei die Lokalisation insbesondere an den Palatinalflächen der Oberkieferfrontzähne und Okklusalflächen der Seitenzähne (Hellström 1977; Ohrn et al. 1999; Robb et al. 1995; Uhlen et al. 2014).

Palatinale Erosionen zeigen sich anfänglich in einer flächenhaften Entkalkung der Zahnhartsubstanz mit zunehmend dünneren Inzisalkanten. Bei schweren Verlaufsformen kann es zu 
einem Verlust der Vertikaldimension und einem greisenhaften Erscheinungsbild der betroffenen Patienten kommen (Lussi et al. 2005; Schlueter et al. 2006).

\subsection{Biologische Faktoren}

Der Begriff „Biologische Faktoren“ beschreibt körpereigene Einflussgrößen, welche die Entstehung dentaler Erosionen beeinflussen. Dazu zählen laut Zero (1996) und Lussi et al. (2004) insbesondere die Zusammensetzung der Zahnhartsubstanz und die Zahnstruktur, die Zahnstellung und Okklusion, der Speichel und die Anatomie der oralen Weichgewebe.

Der Speichel wird von einigen Autoren als wichtigster biologischer Faktor bei der Entstehung von Erosionen beschrieben (Buzalaf et al. 2012; Hara und Zero 2014).

Die verschiedenen Inhaltsstoffe des Speichels erfüllen vielfältige Aufgaben, die zur Prävention dentaler Erosionen beitragen. Dazu gehören insbesondere die Pufferung und Neutralisierung intrinsischer und extrinsischer Säuren, die Verdünnung und der Abtransport erosiver Substanzen aus der Mundhöhle, die Bildung der schützenden Pellikel auf der Zahnoberfläche und die Förderung der Remineralisation durch Bereitstellung von Kalzium-, Phosphat- und Fluorid-Ionen (Hara und Zero 2014; WG Young und Khan 2002).

In einer Studie von Järvinen et al. (1991) konnte ein Zusammenhang zwischen dem Auftreten erosiver Zahnhartsubstanzdefekte und einer verminderten Speichelfließrate bzw. Speichelpufferkapazität nachgewiesen werden. Eine Verminderung des Speichelflusses zeigt sich häufig als Folge einer medikamentösen Behandlung mit Anticholinergika (z. B. Antazida, Antiparkinsonmittel, Asthmamittel, Antihistaminika), Psychopharmaka (z. B. Antidepressiva, Neuroleptika, Sedativa, Tranquilizer), Antihypertonika oder auch nach einer Radiotherapie im Kopf- oder Halsbereich (Porter et al. 2004; Shiboski et al. 2007).

Schmelz und Dentin zeigen eine unterschiedliche Zusammensetzung mineralischer und organischer Bestandteile und unterscheiden sich somit in ihrem Erosionsverhalten. Das Dentin weist aufgrund seines geringeren Anteils anorganischer Komponenten sowie wegen der zahlreichen Dentinkanälchen, welche die Permeabilität deutlich erhöhen, eine höhere Anfälligkeit gegenüber Säureangriffen auf. In Folge eines Säureangriffs kann ein Verlust von anorganischem Material und die Freilegung organischer Komponenten beobachtet werden (Ganss et al. 2014; Shellis et al. 2014).

Die Stellung der Zähne im Zahnbogen, die Form eines Zahnes und seine Beziehung zum angrenzenden Weichgewebe können das Ausmaß erosiver Zahnhartsubstanzdefekte beeinflussen. Speichelfließrate, Speichelpufferkapazität und Remineralisierungseigenschaften variieren an verschiedenen Orten der Mundhöhle. Ein höheres Risiko für die Entstehung erosi- 
ver Zahnhartsubstanzdefekte zeigen Regionen, die nicht gut oder überwiegend von mukösem Speichel umspült werden. Daraus ergibt sich eine höhere Anfälligkeit der Vestibularflächen oberer Schneidezähne im Vergleich zu den Lingualflächen unterer Schneidezähne (Klimek 2008).

\subsubsection{Prävalenz erosiver Zahnhartsubstanzdefekte bei Kindern und Jugendlichen}

In den vergangenen Jahren beschäftigte sich eine Vielzahl epidemiologischer Studien mit der Prävalenz von erosiven Zahnhartsubstanzdefekten bei Kindern und Jugendlichen sowie deren Zusammenhang mit potenziellen Risikofaktoren.

Durch die Verwendung verschiedener Indizes gestaltet sich ein Vergleich der Studien jedoch häufig schwierig (Lussi und Jaeggi 2006). Im Folgenden erfolgt eine Darstellung der wichtigsten in Deutschland durchgeführten Studien:

Wiegand et al. (2006) untersuchten in den Jahren 2004/05 die Prävalenz erosiver Zahnhartsubstanzdefekte bei 463 2- bis 7-jährigen deutschen Kindergartenkindern in Göttingen. Mit steigendem Alter der Kinder konnte ein signifikanter Anstieg der Erosionsprävalenz nachgewiesen werden. Während sich in der Altersgruppe der 2- bis 3-Jährigen erosive Zahnhartsubstanzdefekte bei 23,8 \% der Untersuchten zeigten, stieg die Prävalenz in der Altersgruppe der 6- bis 7-jährigen Kinder auf 39,5 \% an. Die Auswertung von Ernährungs- und Mundhygienegewohnheiten sowie systemischer Erkrankungen zeigten keinen signifikanten Zusammenhang zum Auftreten dentaler Erosionen. Im Jahre 2014/15 ergab eine äquivalente Studie mit 775 Kindern aus 27 Göttinger Kindergärten einen deutlichen Anstieg der Prävalenz erosiver Läsionen von 31,3 \% auf 45,4 \%. Die Inzidenz der Läsionen korrelierte signifikant mit steigendem Alter der Kinder und dem regelmäßigen Konsum von Fruchtsäften oder Limonaden/Coca-Cola mehr als einmal die Woche (Tschammler et al. 2016). In beiden Studien waren Jungen deutlich häufiger betroffen als Mädchen.

Ganss et al. (2001) untersuchten von 1977 bis 19991.000 präkieferorthopädische Situationsmodelle im Hinblick auf erosive Zahnhartsubstanzdefekte. In der Altersgruppe der 8- bis 14Jährigen wiesen 70,6 \% der Zähne der ersten Dentition Anzeichen erosiver Zahnhartsubstanzschädigung auf. An den Zähnen der zweiten Dentition zeigten sich im Gegensatz zu den Milchzähnen signifikant weniger Erosionen (11,6 \%). 


\subsection{Zielsetzung}

Im Rahmen der vorliegenden Studie soll die Prävalenz, der Schweregrad und die Lokalisation von Karies und dentalen Erosionen an einem Probandengut von übergewichtigen und adipösen Kindern und Jugendlichen in der Altersgruppe von 4 bis 17 Jahren untersucht und mit normalgewichtigen Kindern verglichen werden.

Ziel dieser Studie ist es, einen möglichen Zusammenhang zwischen dem BMI und einem erhöhten Auftreten von Karies und Erosionen bei Kindern und Jugendlichen zu untersuchen. Ein besonderes Augenmerk soll dabei auf potenzielle Einflussfaktoren, wie z. B. Ernährungsgewohnheiten (Häufigkeit und Art der Zwischenmahlzeiten, bevorzugte Getränke), sozioökonomischer Hintergrund und das Vorliegen von Allgemeinerkrankungen, die potenziell mit Karies und Erosionen assoziiert werden können, gelegt werden. Die Ergebnisse der Studie sollen sowohl Zahnärzten als auch Kinderärzten helfen, mögliche Risikofaktoren schneller und eindeutig zu identifizieren und dahingehend beraten zu können. 


\section{$2 \quad$ Material und Methode}

Die Durchführung der Studie erfolgte entsprechend der Vorgaben der Deklaration von Helsinki der World Medical Association. Das Forschungsvorhaben wurde am 04.06.2015 der Ethik-Kommission der Universitätsmedizin Göttingen vorgelegt und von dieser am 08.07.2015 unter der Antragsnummer 22/6/15 genehmigt.

\subsection{Studienkollektiv}

In dieser prospektiven, nicht-interventionellen Beobachtungsstudie wurden alle Patienten zwischen 4 und 17 Jahren eingeschlossen, die im Zeitraum von Februar 2016 bis Dezember 2016 in der Adipositas-Sprechstunde der Klinik für Kinder- und Jugendmedizin ambulant und stationär vorstellig wurden. Die Durchführung erfolgte entsprechend zahnmedizinischer Standards nach ausführlicher mündlicher und schriftlicher Aufklärung über die Zielsetzung der Studie und den Ablauf der klinischen Untersuchungen. Kinder und Jugendliche mit ausschließlich Adipositas-assoziierten Erkrankungen wurden untersucht.

Folgende Ausschlusskriterien zur Teilnahme an der Studie wurden festgelegt:

- Fehlendes Einverständnis zur Teilnahme an der Studie

- Alter: jünger als 4 Jahre, älter als 17 Jahre

- Fehlende Kooperation

- Schwere Allgemeinerkrankungen, insbesondere Zustände, die mit einer vorübergehenden oder dauerhaften Einschränkung des Immunstatus oder ausgeprägten Veränderungen der motorischen und/oder kognitiven Fähigkeiten einhergehen

- Allgemeinerkrankungen, die den Speichelfluss und/oder die Speichelzusammensetzung beeinflussen (z. B. Sjögren-Syndrom)

\subsection{Kontrollkollektiv}

Zum Vergleich der Zahngesundheit übergewichtiger und adipöser Kinder und Jugendlicher mit derer normalgewichtiger Kinder und Jugendlicher wurde zusätzlich eine Kontrollgruppe ambulant und stationär vorstelliger Patienten untersucht. Die Vergleichbarkeit erhobener Daten konnte durch die Wahl gleicher Einschlusskriterien gewährleistet werden. 


\subsection{Fragebogen}

Um den Einfluss unterschiedlicher Verhaltensweisen auf die Prävalenz und das Ausmaß von Karies und Erosionen identifizieren zu können, wurden mit Hilfe eines Fragebogens die Ernährungsgewohnheiten der Kinder und Jugendlichen, ihre Zahnhygiene und das Vorliegen von weiteren möglichen Einflussfaktoren, die potenziell mit Karies und/oder Erosionen assoziiert werden können, erfragt. Ferner wurden auch demographische Daten (Alter, Geschlecht, Nationalität, Einkommen) der Patienten und Familien, denen die Patienten entstammen, erhoben.

Die Erstellung des Fragebogens erfolgte nach den Vorgaben der Weltgesundheitsorganisation (World Health Organisation (WHO)) in Anlehnung an den Fragebogen der Vierten Deutschen Mundgesundheitsstudie (Micheelis und Schiffner 2006).

Der genaue Wortlaut und Aufbau des Fragebogens kann dem Anhang entnommen werden.

\subsection{Erhebung der Body-Mass-Index-Perzentile (BMI-P)}

Die Körpergröße und das Körpergewicht des Kindes wurden tagesaktuell aus den Messungen der Adipositas-Sprechstunde übernommen. Geschultes Fachpersonal des Sozialpädiatrischen Zentrums (SPZ) vermaß und wog die Patienten unter standardisierten Bedingungen. Die Körpergröße wurde im Stehen ohne Schuhe mit Hilfe eines kalibrierten Stadiometers (Ulmer Stadiometer, Busse Design und Engineering GmbH, Elchingen, Deutschland) auf 0,1 cm genau gemessen. Die Messung des Körpergewichts wurde mittels elektronischer Waage (Modell 701, seca gmbh \& co. kg, Hamburg, Deutschland) in Unterwäsche und ohne Schuhe im Stand durchgeführt. Der Messwert wurde mit einer Genauigkeit von 0,1 kg dargestellt.

Die Arbeitsgemeinschaft Adipositas im Kindes- und Jugendalter empfiehlt, entsprechend den Vorgaben der ECOG (Poskitt 1995), bei Kindern und Jugendlichen die Verwendung von alters- und geschlechtsspezifischen Perzentilkurven für den BMI. Die Berechnung der BMI-Perzentile erfolgte mit Hilfe eines Online-Rechners des MVZ Labor Dr. Limbach \& Kollegen GbR ${ }^{1}$ nach Kromeyer-Hauschild et al. (2001). Eine Einteilung der BMI-Perzentile erfolgte entsprechend in folgende Gruppen:

- Übergewicht: BMI-Perzentile > 90 - 97

- Adipositas: BMI-Perzentile > 97 - 99,5

\footnotetext{
${ }^{1}$ https://www.labor-limbach.de/laborrechner/labor-rechner/bmi-perzentile-und-sds/; abgerufen am 06.04.2017
} 
- Extreme Adipositas: BMI-Perzentile > 99,5

Tabelle 2.1: BMI-Grenzwerte für Übergewicht (BMI > P90,0), Adipositas (BMI > P97,0) und extreme Adipositas (BMI > P99,5) bei Kindern und Jugendlichen, modifiziert nach Kromeyer-Hauschild et al. (2001)

\begin{tabular}{|c|c|c|c|c|c|c|}
\hline \multirow{2}{*}{ Alter (Jahre) } & \multicolumn{3}{|c|}{ BMI- Perzentile Jungen } & \multicolumn{3}{c|}{ BMI- Perzentile Mädchen } \\
\cline { 2 - 7 } & $\begin{array}{c}\text { Übergewicht } \\
\text { P90,0 }\end{array}$ & $\begin{array}{c}\text { Adipositas } \\
\text { P97,0 }\end{array}$ & $\begin{array}{c}\text { Extreme } \\
\text { Adipositas } \\
\text { P99,5 }\end{array}$ & $\begin{array}{c}\text { Übergewicht } \\
\text { P90,0 }\end{array}$ & $\begin{array}{c}\text { Adipositas } \\
\text { P97,0 }\end{array}$ & $\begin{array}{c}\text { Extreme } \\
\text { Adipositas } \\
\text { P99,5 }\end{array}$ \\
\hline $\begin{array}{c}4,0 \text { bis } \\
>5,0\end{array}$ & 17,6 & 18,9 & 20,9 & 17,6 & 19,0 & 21,0 \\
\hline $\begin{array}{c}5,0 \text { bis } \\
>6,0\end{array}$ & 17,7 & 19,2 & 21,5 & 17,8 & 19,4 & 21,7 \\
\hline $\begin{array}{c}6,0 \text { bis } \\
>7,0\end{array}$ & 18,0 & 19,8 & 22,4 & 18,2 & 20,0 & 22,8 \\
\hline $\begin{array}{c}7,0 \text { bis } \\
>8,0\end{array}$ & 18,7 & 20,6 & 23,8 & 18,9 & 20,9 & 24,3 \\
\hline $\begin{array}{c}8,0 \text { bis } \\
>9,0\end{array}$ & 19,4 & 21,6 & 25,5 & 19,7 & 22,0 & 26,0 \\
\hline $\begin{array}{c}9,0 \text { bis } \\
>10,0\end{array}$ & 20,1 & 22,8 & 27,3 & 20,4 & 23,0 & 27,5 \\
\hline $\begin{array}{c}10,0 \text { bis } \\
>11,0\end{array}$ & 21,0 & 23,9 & 29,2 & 21,2 & 24,0 & 28,8 \\
\hline $\begin{array}{c}11,0 \text { bis } \\
>12,0\end{array}$ & 21,8 & 25,0 & 30,6 & 22,0 & 25,0 & 29,9 \\
\hline $\begin{array}{c}12,0 \text { bis } \\
>13,0\end{array}$ & 22,6 & 25,9 & 31,7 & 22,9 & 25,9 & 30,8 \\
\hline $\begin{array}{c}13,0 \text { bis } \\
>14,0\end{array}$ & 23,4 & 26,6 & 32,5 & 23,7 & 26,7 & 31,5 \\
\hline $\begin{array}{c}14,0 \text { bis } \\
>15,0\end{array}$ & 24,0 & 27,3 & 32,8 & 24,3 & 27,3 & 31,8 \\
\hline $\begin{array}{c}15,0 \text { bis } \\
>16,0\end{array}$ & 24,7 & 27,8 & 33,0 & 24,8 & 27,8 & 32,2 \\
\hline $\begin{array}{c}16,0 \text { bis } \\
>17,0\end{array}$ & 25,2 & 28,2 & 33,1 & 25,0 & 28,3 & 32,8 \\
\hline $\begin{array}{c}17,0 \text { bis } \\
>18,0\end{array}$ & 25,7 & 28,8 & 33,6 & 25,2 & 29,3 & 34,3 \\
\hline
\end{tabular}

\subsection{Zahnärztliche Untersuchung}

Die zahnärztliche Untersuchung erfolgte standardisiert auf einem Stuhl oder einer Patientenliege im Sitzen (Abbildung 2.1). Das Untersuchungsinstrumentarium beinhaltete eine zahnärztliche, mobile Einheit mit Luftbläser (Mobile Cart 6550, DCI, Newberg, Orgeon, Vereinigte Staaten und 1420, DCI, Newberg, Oregon, Vereinigte Staaten) und ein zahnärztliches Grundbesteck, bestehend aus zahnärztlicher Sonde, Spiegel und College Pinzette. Ein an der 
Brille montiertes, dentales LED-Kopflicht (Denshine, Peking, China) ermöglichte eine gute visuelle Diagnostik. Die Dokumentation erfolgte auf standardisierten Befundbögen der Poliklinik für Präventive Zahnmedizin, Parodontologie und Kariologie.

Alle Untersuchungen wurden von einer Zahnärztin durchgeführt. Diese Zahnärztin war vor Studienbeginn intensiv geschult und analog zu zuvor durchgeführten Studien kalibriert worden (Tschammler et al. 2016; Wiegand et al. 2006).

Alle Zahnoberflächen wurden sowohl im trockenen als auch im feuchten Zustand untersucht. Das gründliche Trocknen der Zahnoberfläche erfolgte ca. fünf Sekunden mit einem Luftbläser.

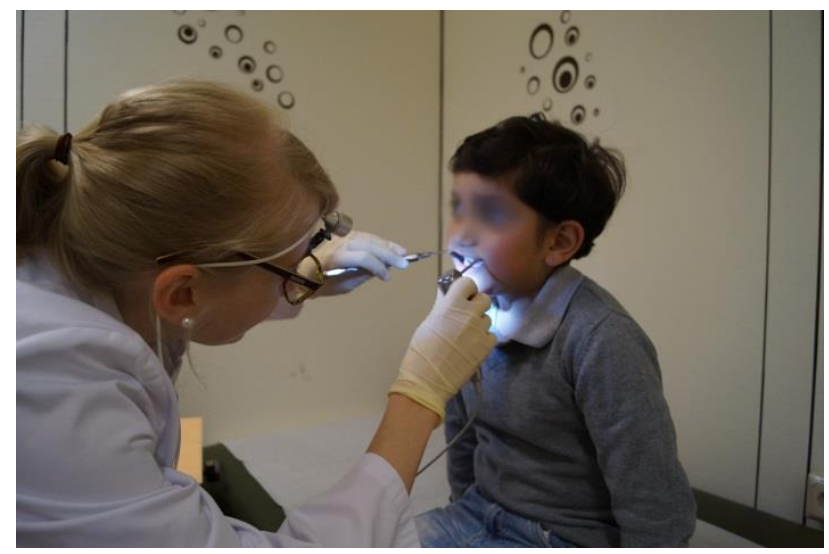

Abbildung 2.1: Zahnärztliche Untersuchung

\subsubsection{Zahnstatus und Erfassung von Karies}

Die visuelle Diagnostik kariöser Veränderungen an Okklusal- und Glattflächen der Zähne erfolgte entsprechend der Kriterien des Kariesdiagnosesystems International Caries Detection and Assessment System II (ICDAS-II) (Ismail et al. 2007). Initiale Stadien kariöser Läsionen (gelb- bis braun-weiße Farbveränderungen) und fortgeschrittene kariöse Veränderungen, gekennzeichnet durch das Auftreten dunkler Dentinschatten und/oder Kavitationen, wurden durch die Einteilung in sieben Schweregrade klassifiziert (Tabelle 2.2). Ferner wurden gefüllte und aufgrund von Karies fehlende Zähne erfasst. 
Tabelle 2.2: ICDAS-Codes für die Diagnose der okklusalen Karies nach Ismail et al. (2007)

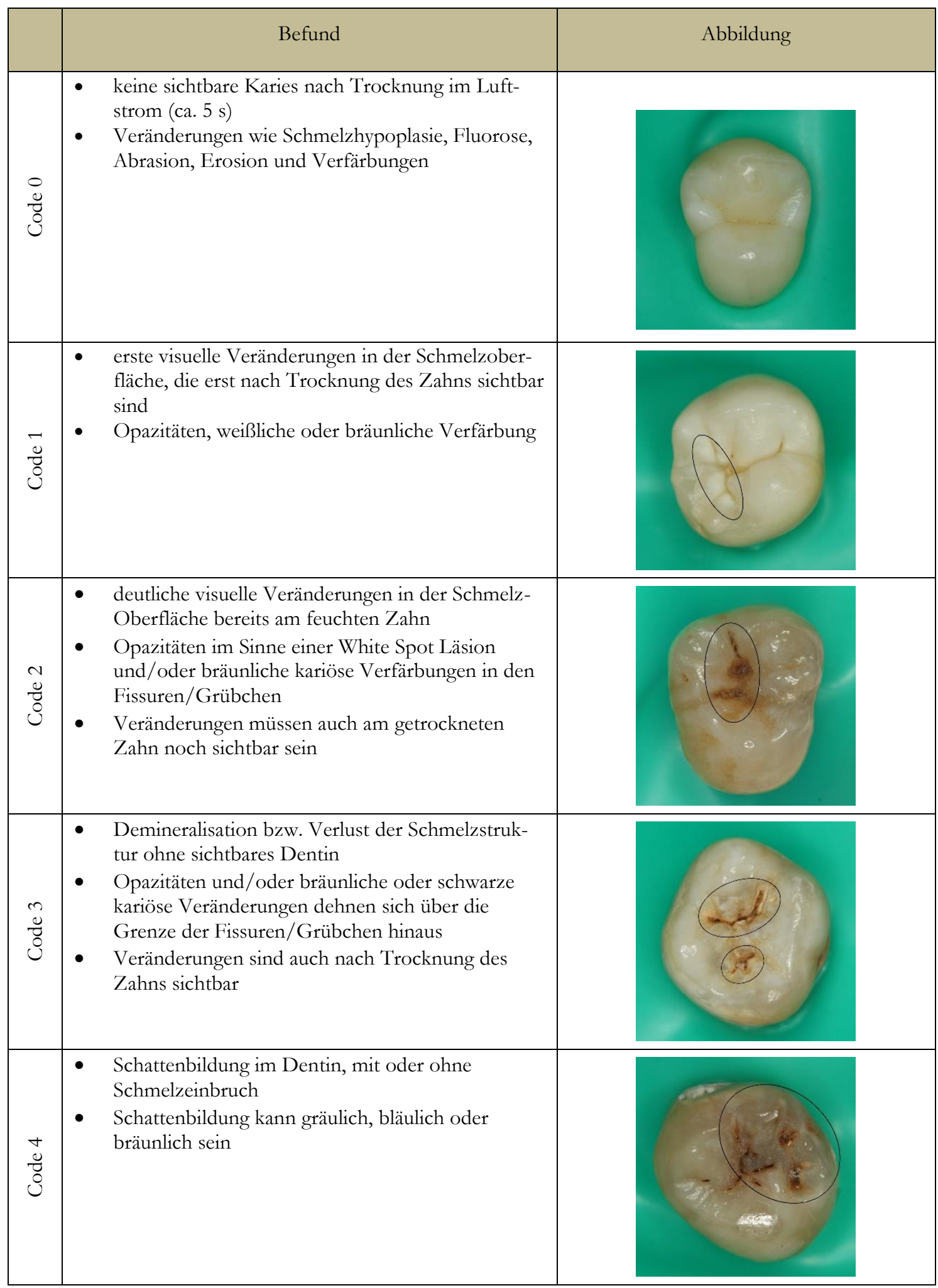




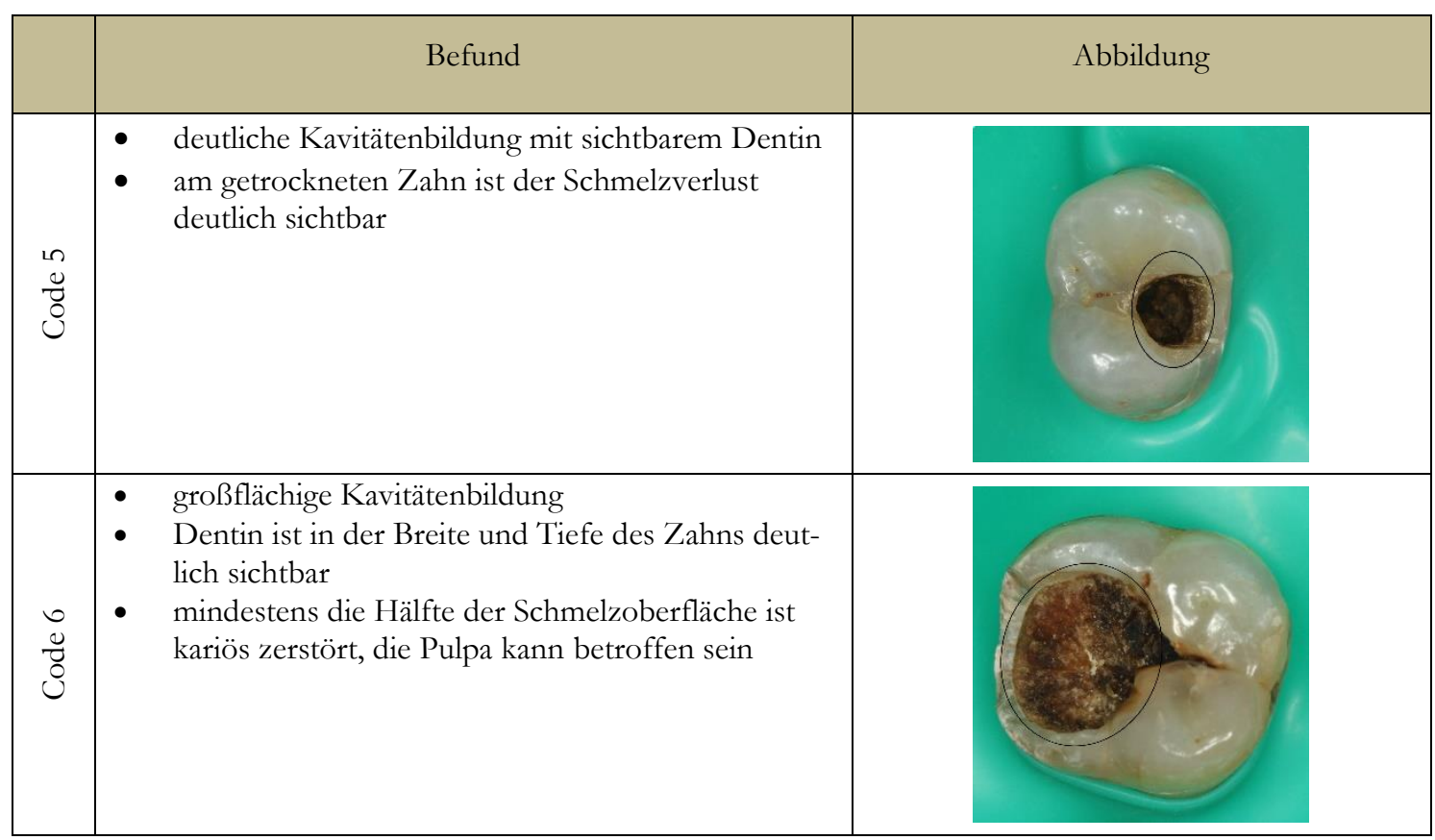

Für die statistische Auswertung erfolgte zudem die Umwandlung der ICDAS-Werte in den DMF-T-(dmf-t) bzw. D-T-(d-t)-Index. Für D/d des DMFT/dmft wurden zwei verschiedene Cut-Off-Punkte zu Grunde gelegt: D/d1 (ICDAS 0: gesund/ ICDAS 1-6: Karies) und D/d3 (ICDAS 0-2: gesund/ ICDAS 3-6: Karies).

Die Indizes beziehen sich dabei im bleibenden Gebiss auf 28 Zähne ohne Berücksichtigung der dritten Molaren. Beim Vorliegen eines Milchgebisses wurde der dmf-t- bzw. d-t-Index verwendet, im Wechselgebiss der Index für bleibende Zähne.

\subsubsection{Erfassung von erosiven Zahnhartsubstanzdefekten}

Erosive Läsionen wurden mit Hilfe des Basic-Erosive-Wear-Examination-Index (BEWEIndex) dokumentiert.

Tabelle 2.3: Kriterien zur Einordnung dentaler Erosionen, modifiziert nach Bartlett et al. (2008)

\begin{tabular}{|c|c|}
\hline Schweregrad & \\
\hline Grad 0 & kein erosiver Zahnhartsubstanzverlust \\
\hline Grad 1 & beginnender Verlust der Oberflächenstruktur \\
\hline Grad 2* & $\begin{array}{r}\text { klar ersichtlicher Verlust von Zahnhartsubstanz; } \\
\text { weniger als } 50 \% \text { der Oberfläche betroffen }\end{array}$ \\
\hline Grad 3* & $\begin{array}{l}\text { ausgeprägter Verlust von Zahnhartsubstanz; } \\
\text { mehr als } 50 \% \text { der Oberfläche betroffen }\end{array}$ \\
\hline
\end{tabular}

*Bei Grad 2 und 3 häufige Mitbeteiligung des Dentins. 
Die Erhebung des BEWE-Index (Tabelle 2.3) erfolgte durch Untersuchung jedes Zahnes unter Ausschluss der dritten Molaren. Zur besseren Vergleichbarkeit der Schweregrade wurde zudem der BEWE-Summenwert errechnet. Dieser ergibt sich durch Addition der jeweils höchsten Werte aller Sextanten. Mit Hilfe der errechneten Summe zwischen null und achtzehn lassen sich vier verschiedene Schweregrade dentaler Erosionen unterscheiden. Ein BEWE-Summenwert zwischen null und zwei bedeutet keine Anfälligkeit für dentale Erosionen, Werte zwischen drei und acht eine geringe, zwischen neun und dreizehn eine mittlere Anfälligkeit und Summenwerte über vierzehn eine hohe Anfälligkeit für erosive Läsionen.

\subsection{Speichelprobe}

Bei Einwilligung durch den Erziehungsberechtigten in die Abgabe der Speichelprobe und ausreichender Compliance des Patienten erfolgte im Anschluss an die zahnärztliche Untersuchung die Entnahme einer unstimulierten und stimulierten Speichelprobe.

\subsubsection{Messung der Speichelfließrate}

Die Messung erfolgte unter standardisierten Bedingungen. In Vorbereitung auf die Messung wurde, in Ermangelung eines Waschbeckens, der in der Mundhöhle befindliche Speichel geschluckt. In einem ruhigen Raum, bei leicht nach vorne gebeugtem Kopf, spuckte der Patient dann über einen Zeitraum von fünf Minuten den anfallenden Speichel in einen kalibrierten Plastikbecher. Im Anschluss wurde mit Hilfe einer Küchenwaage (Produkt KS 22, Beurer, Ulm, Deutschland), nach Abzug der Leermenge des Bechers, die Menge des gesammelten Speichels in $\mathrm{g}$ gemessen und die Fließrate in $\mathrm{ml}$ pro Minute errechnet. Dabei wurde die Dichte des Speichels mit der von Wasser gleichgesetzt. Zudem wurde die Fünf-MinutenFließrate in $\mathrm{ml}$ auf der Skala des Bechers abgelesen.

Der Begriff „unstimulierter Speichel“ bezeichnet die Gesamtmenge des ohne äußere Stimulation von den Speicheldrüsen sezernierten Speichels. Die unstimulierte Speichelfließrate liegt physiologisch zwischen 0,3 und 0,4 ml/min. Unter dem Begriff „stimulierter Speichel“ versteht man den durch Einwirkung von Geschmacks- oder Geruchreizen bzw. mechanischen Reizen sezernierten Speichel. Speichelfließraten von mehr als $5 \mathrm{ml}$ in fünf Minuten gelten als physiologisch (Dawes 1996; Humphrey und Williamson 2001).

Zur Bestimmung der stimulierten Speichelfließrate wurde der Patient aufgefordert ein Paraffin-Pellet (CRT®, ivoclar vivadent clincal, Schaan, Liechtenstein) weich zu kauen, den zu Beginn der Messung in der Mundhöhle befindlichen Speichel zu schlucken und anschlieBend, unter ständigem Kauen des Pellets, den über fünf Minuten produzierten Speichel in 
einem Plastikbecher zu sammeln. Die Messung der Speichelmenge und der stimulierten Speichelfließrate erfolgte analog zur Bestimmung der unstimulierten Speichelfließrate.

\subsubsection{Messung des $\mathrm{pH}-$ Wertes des Speichels}

Die Bestimmung des Speichel-pH-Wertes erfolgte mittels eines pH-Meters (Checker ${ }^{\circledR}$ 1, HANNA ${ }^{\circledR}$ instruments, Vöhringen, Deutschland) mit einer Auflösung von 0,01 und einer Genauigkeit von $\pm 0,2 \mathrm{pH}$ bei $20^{\circ} \mathrm{C}$.

Vor erstmaliger Verwendung des pH-Meters wurde die Elektrode entsprechend den Herstellerangaben nach Entfernung der Schutzkappe bis zur Stabilisierung der Anzeige ca. $4 \mathrm{~cm}$ tief in eine Pufferlösung mit pH 7,01 getaucht und mit Hilfe des mitgelieferten Kalibrierungsschraubenziehers der $\mathrm{pH}$ 7-Trimmer auf 7,01 justiert. Nach gründlichem Abspülen der Elektrode mit destilliertem Wasser wurde der Vorgang für eine Pufferlösung mit pH 4,01 wiederholt. Einmal pro Monat wurde diese Kalibrierung durch eine speziell geschulte medizinisch-technische Assistentin der Poliklinik Präventive Zahnmedizin, Parodontologie und Kariologie der Universitätsmedizin Göttingen erneut durchgeführt.

Vor Beginn des Messvorgangs wurde die Schutzkappe entfernt und um die Glaselektrode befindliche Kristalle mit destilliertem Wasser (Herstellung mit Bi-Destillierapparat 2104, GFL Gesellschaft für Labortechnik mbH, Burgwedel, Deutschland) abgespült. Nach vollständigem Eintauchen der Elektrode in die Messprobe und nach einmaligem Umrühren zur Vermeidung einer Phasenbildung sowie zum Ausgleich lokaler Konzentrationsschwankungen wurde der $\mathrm{pH}$-Wert der jeweiligen Speichelprobe abgelesen. Zur Vermeidung jeglicher Kontaminierung erfolgte im Anschluss an den Messvorgang das Abspülen der Elektrode mit destilliertem Wasser. Die feuchte und aufrechte Lagerung der Elektrode in der Schutzkappe erfolgte entsprechend der Herstellerangaben in einigen Tropfen einer Elektroden-Aufbewahrungslösung (HI 70300, HANNA® instruments, Vöhringen, Deutschland).

\subsubsection{Bestimmung der Pufferkapazität des Speichels}

Im Speichel enthaltene Puffersysteme sind in der Lage, die für die Zähne gefährlichen Säuren zu neutralisieren. Die Pufferkapazität gibt an, in welchem Umfang eine Neutralisation stattfindet.

Im Rahmen dieser Studie fanden zur Bestimmung der Pufferkapazität speziell beschichtete, industriell genormte Teststreifen Verwendung (Saliva-Check BUFFER, GC Germany, Bad Homburg, Deutschland). Diese wurden zu Beginn der Messung aus der Folienverpackung entnommen und mit der Testseite nach oben auf eine saugfähige Papierunterlage gelegt. Mit Hilfe einer Pipette erfolgte die Benetzung aller drei Testfelder mit jeweils einem Tropfen des 
gesammelten Speichels. Im Anschluss wurde der Teststreifen umgedreht, sodass überschüssiger Speichel von dem saugfähigen Tuch aufgenommen und eine Verfälschung des Testergebnisses durch Aufquellen des Streifens verhindert werden konnte. Der sichtbare Farbumschlag wurde nach zwei Minuten abgelesen und die Pufferkapazität anhand der vom Hersteller mitgelieferten Tabelle bestimmt.

\subsection{Datenerfassung und statistische Auswertung}

Die deskriptive und explorative statistische Auswertung erfolgte mit Hilfe des Programms R (Version 3.2.2, www.r-project.com). Das Signifikanzniveau wurde auf $\mathrm{p}<0,05$ festgelegt. Die Normalverteilung der Daten wurde mittels Shapiro-Wilk-Test überprüft.

\subsubsection{Fallzahlberechnung}

Die Fallzahlberechnung erfolgte entsprechend einer Studie, in der die Prävalenzrate erosiver Läsionen bei normalgewichtigen (40,1 \%) und adipösen Kindern (83,6 \%) ermittelt wurde (Tong et al. 2014).

Unter der Annahme von $\alpha=0,05$ und einer Zielkraft von $80 \%$ ergab der $\mathrm{Chi}^{2}$-Test eine Mindest-Stichprobengröße von 23 pro Gruppe (http://biomath.info/power/chsq.htm).

\subsubsection{Auswertung}

Die statistische Auswertung erfolgte mit der Software R (Version 3.2.2, www.r-project.com). Das Signifikanzniveau wurde für alle Analysen auf $\mathrm{p}<0,05$ festgelegt. Alle statistischen Analysen wurden sowohl auf Zahn- (Milchzähne; bleibende Zähne) als auch auf Patientenebene (Kinder mit Milchzähnen; Kinder mit bleibenden Zähnen) durchgeführt.

Die Prävalenz von erosiven Läsionen und Karies(erfahrung) wurde separat für Milchzähne und bleibende Zähne (Zahnebene) sowie auf Patientenebene getrennt für Kinder mit Milchzähnen (Milch- und Wechselgebiss) und Kinder mit bleibenden Zähnen (bleibendes Gebiss und Wechselgebiss) bestimmt. Der Vergleich zwischen normalgewichtigen, übergewichtigen, adipösen und extrem adipösen Kindern und Jugendlichen erfolgte mittels Chi ${ }^{2}$-Test mit Bonferroni-Korrektur.

Zur Analyse des Schweregrades dentaler Erosionen, wurde der höchste BEWE-Score für jeden Zahn ermittelt und anschließend der BEWE-Summenwert durch die Addition der jeweils höchsten Punktzahl jedes Sextanten errechnet. Der statistische Vergleich von BEWEScore pro Zahn, BEWE-Summenwert pro Patient und dem prozentualen Anteil betroffener Zähne zwischen den Gewichtsgruppen (Normalgewicht, Übergewicht, Adipositas, extreme Adipositas) erfolgte mittels Kruskal-Wallis-Tests mit Post-hoc-Analyse. 
Die ICDAS-Werte wurden in DMFT/dmft-Werte umgewandelt, wobei auch gefüllte Zähne oder aufgrund von Karies fehlende Zähne berücksichtigt wurden. Für D/d des DMFT/dmft wurden zwei verschiedene Cut-Off-Punkte zu Grunde gelegt: D/d1 (ICDAS 0: gesund/ ICDAS 1-6: Karies) und D/d3 (ICDAS 0-2: gesund/ ICDAS 3-6: Karies). Der DMFT/dmft-Wert und der prozentuale Anteil betroffener Zähne pro Patient wurden unter Verwendung von Kruskal-Wallis-Tests mit Post-hoc-Analyse zwischen den Gruppen verglichen. Logistische (Prävalenzen) und lineare (Schweregrade) Regressionsanalysen wurden durchgeführt um den möglichen Einfluss von BMI-Perzentilen und anderen Faktoren (demographische Daten, Essgewohnheiten, Mundhygienefaktoren, Fluoridversorgung etc.) auf die Prävalenz und den Schweregrad dentaler Erosionen und Karieserfahrung zu identifizieren (stepAIC, $\mathrm{p}<0,05)$.

Die Bestimmung eines möglichen Zusammenhangs zwischen dentalen Erosionen und Karieserfahrung erfolgte mittels $\mathrm{Chi}^{2}$-Tests (Prävalenz zu Prävalenz) und Spearman-Korrelationsanalysen (Schweregrad zu Schweregrad). Die Interpretation der Korrelationskoeffizienten erfolgte nach Cohen (Cohen 1988).

Der statistische Vergleich der Speichelparameter (pH-Wert, Fließrate und Pufferkapazität in Ruhe und stimuliert) zwischen den Gewichtsgruppen wurde mittels Kruskal-Wallis-Tests mit Post-hoc-Analyse durchgeführt. 


\section{Ergebnisse}

In Zusammenarbeit der Poliklinik für Präventive Zahnmedizin, Parodontologie und Kariologie und der Klinik für Kinder- und Jugendmedizin wurden insgesamt 223 Kinder und Jugendliche im Alter von vier bis siebzehn Jahren in Hinblick auf das Vorhandensein von erosiven Zahnhartsubstanzdefekten und kariösen Läsionen sowie deren Zusammenhang mit Ernährungsgewohnheiten, Mundhygieneverhalten, sozioökonomischen Faktoren und Allgemeinerkrankungen untersucht.

In Vorbereitung der Studie wurde die Untersucherin intensiv kalibriert. Zur Validierung des Kalibrierungsprozesses erfolgte die Bestimmung der Inter- und Intraobserverreliabilität in einer Untergruppe von 23 (573 Zähne) bzw. 29 (712 Zähne) Kindern- und Jugendlichen.

Die ermittelten Kappa-Werte für den BEWE-Index $\left(\boldsymbol{\mathcal { H }}_{\text {inter }}=0,906 ; \boldsymbol{\mathcal { H }}_{\text {intra }}=0,950\right)$ und den ICDAS-Index $\left(\boldsymbol{H}_{\text {inter }}=0,676 ; \boldsymbol{\varkappa}_{\text {intra }}=0,779\right)$ sprechen für eine sehr gute Validität.

\subsection{Verteilung der untersuchten Kinder und Jugendlichen nach Gewichtsklassen, Alter, Geschlecht und soziodemographischen Parametern}

Die Einteilung des untersuchten Kollektivs erfolgte gemäß der Empfehlung der AGA anhand von geschlechts- und altersspezifischen BMI-Perzentilen in normalgewichtige, übergewichtige, adipöse und extrem adipöse Probanden. Insgesamt wurden 12,1 \% der Kinder und Jugendlichen als übergewichtig eingestuft, 41,3\% als adipös und 22,9 \% als extrem adipös (Tabelle 3.1).

Die Verteilung zwischen Mädchen $(\mathrm{n}=112 ; 50,2 \%)$ und Jungen $(\mathrm{n}=111 ; 49,8 \%)$ ist in der Gesamtstichprobe annähernd gleich. Der Anteil der 4- bis 6-jährigen Kinder betrug 18,4 \%, der Anteil der 7- bis 11-jährigen Kinder belief sich auf 42,6 \%, der der über 12-Jährigen auf $39,0 \%$. 
Tabelle 3.1: Verteilung der untersuchten Kinder und Jugendlichen nach Gewichtsklassifikation, Geschlecht und Alter

\begin{tabular}{|c|c|c|c|c|}
\hline & $\begin{array}{l}\text { Anzahl } \\
\mathrm{n}(\%)\end{array}$ & $\begin{array}{c}\text { Anteil Jungen } \\
\mathrm{n}(\%)\end{array}$ & $\begin{array}{c}\text { Anteil Mädchen } \\
\mathrm{n}(\%)\end{array}$ & $\begin{array}{c}\text { Alter, } \\
\mathrm{M} \pm \mathrm{SD}\end{array}$ \\
\hline $\begin{array}{c}\text { Normalgewicht } \\
\text { (BMI-Perzentile } \\
10-90)\end{array}$ & $53(23,8 \%)$ & $32(60,4 \%)$ & $21(39,6 \%)$ & $9,4 \pm 3,7$ \\
\hline $\begin{array}{c}\text { Übergewicht } \\
\text { (BMI-Perzentile } \\
90-97)\end{array}$ & $27(12,1 \%)$ & $12(44,4 \%)$ & $15(55,6 \%)$ & $10,6 \pm 3,1$ \\
\hline $\begin{array}{c}\text { Adipositas } \\
\text { (BMI-Perzentile } \\
97-99,5)\end{array}$ & $92(41,3 \%)$ & $44(47,8 \%)$ & $48(52,2 \%)$ & $10,3 \pm 2,9$ \\
\hline $\begin{array}{c}\text { Extreme } \\
\text { Adipositas } \\
\text { (BMI-Perzentile } \\
>99,5)\end{array}$ & $51(22,9 \%)$ & $23(45,1 \%)$ & $28(54,9 \%)$ & $10,5 \pm 3,9$ \\
\hline Gesamt & $223(100,0 \%)$ & $111(49,8 \%)$ & $112(50,2 \%)$ & $10,2 \pm 3,4$ \\
\hline
\end{tabular}

M: Mittelwert; SD: Standardabweichung

Der überwiegende Teil untersuchter Probanden war zum Zeitpunkt der Untersuchung zwischen 7 und 11 Jahre alt (43,0\%).

In den Altersgruppen der 4- bis 6-Jährigen und über 12-Jährigen überwog der Anteil der Mädchen, während in der Altersgruppe der 7- bis 11-Jährigen der Anteil männlicher Probanden $(46,4 \%)$ überwog.

Bei 22,9\% der untersuchten Kinder und Jugendlichen wurde ein Migrationshintergrund angegeben (Tabelle 3.2). Die am häufigsten genannten Herkunftsländer der untersuchten Probanden und ihrer Familien waren in absteigender Reihenfolge Türkei, Italien, Amerika, Serbien, Kosovo, Russland, Polen, Vietnam, China und Griechenland. 
Tabelle 3.2: Verteilung der Probanden mit Migrationshintergrund innerhalb der Gewichtsklassen

\begin{tabular}{|c|c|}
\hline & $\begin{array}{c}\text { Migrationshintergrund } \\
\mathrm{n}(\%)\end{array}$ \\
\hline $\begin{array}{c}\text { Normalgewicht } \\
\text { (BMI-Perzentile 10 - 90) }\end{array}$ & $11(20,8 \%)$ \\
\hline $\begin{array}{c}\text { Übergewicht } \\
\text { (BMI-Perzentile 90 - 97) }\end{array}$ & $7(25,9 \%)$ \\
\hline $\begin{array}{c}\text { Adipositas } \\
(\text { BMI-Perzentile } 97-99,5)\end{array}$ & $21(22,8 \%)$ \\
\hline $\begin{array}{c}\text { Extreme Adipositas } \\
(\text { BMI-Perzentile }>99,5)\end{array}$ & $12(23,5 \%)$ \\
\hline Gesamt & $51(22,9 \%)$ \\
\hline
\end{tabular}

Die Ermittlung der Sozialschichtzugehörigkeit der untersuchten Probanden erfolgte anhand des monatlichen Netto-Haushaltseinkommens der Familien (Bundeszentrale für politische Bildung). Eine Zuordnung konnte für 177 Kinder (79,4 \%) vorgenommen werden. Bei den übrigen 46 Kindern und Jugendlichen (20,6\%) konnte keine Zuordnung erfolgen, da ihre Eltern keine Angaben zum Einkommen machten. Der größte Anteil der an der Studie teilnehmenden Probanden wurde mit einem monatlichen Netto-Haushaltseinkommen bis $1.749 €$ der unteren Sozialschicht zugeordnet (32,3\%). Der mittleren Sozialschicht entstammten mit 19,3\% die wenigsten Kinder (Tabelle 3.3). 
Tabelle 3.3: Verteilung der Gesamtstichprobe nach monatlichem Netto-Haushaltseinkommen

\begin{tabular}{|c|c|c|c|}
\hline & $\begin{array}{c}<50 €-1.749 € \\
\mathrm{n}(\%)\end{array}$ & $\begin{array}{c}1.750 €-2.749 € \\
\mathrm{n}(\%)\end{array}$ & $\begin{array}{c}2.750 €->5.000 € \\
\mathrm{n}(\%)\end{array}$ \\
\hline $\begin{array}{c}\text { Normalgewicht } \\
\text { (BMI-Perzentile 10-90) }\end{array}$ & $18(25,0 \%)$ & $7(16,3 \%)$ & $11(17,7 \%)$ \\
\hline $\begin{array}{c}\text { Übergewicht } \\
\text { (BMI-Perzentile 90-97) }\end{array}$ & $5(6,9 \%)$ & $6(14,0 \%)$ & $21(33,9 \%)$ \\
\hline $\begin{array}{c}\text { Adipositas } \\
\text { (BMI-Perzentile 97 - }\end{array}$ & $30(41,7 \%)$ & $20(46,5 \%)$ & $10(16,1 \%)$ \\
\hline 99,5$)$ & $19(26,4 \%)$ & $10(23,3 \%)$ & $62(27,8 \%)$ \\
\hline $\begin{array}{c}\text { Extreme Adipositas } \\
(\text { BMI-Perzentile }>99,5)\end{array}$ & $72(32,3 \%)$ & $43(19,3 \%)$ & \\
\hline
\end{tabular}

Bei der Frage nach Allgemeinerkrankungen gaben insgesamt 45,0 \% $(\mathrm{n}=101)$ der untersuchten Kinder und Jugendlichen eine Grunderkrankung an. Die am häufigsten genannten Allgemeinerkrankungen der untersuchten Probanden waren in absteigender Reihenfolge arterielle Hypertonie, metabolisches Syndrom, Asthma bronchiale und Reflux.

Der Anteil von untersuchten Probanden mit metabolischem Syndrom machte 13,9 \% $(\mathrm{n}=31)$ aus.

\subsection{Ergebnisse der zahnärztlichen Untersuchung}

Insgesamt wurden 223 Kinder und Jugendliche mit 5.586 Zähnen untersucht. Davon wiesen 140 Patienten Milchzähne ( $\mathrm{n}=1.476$; Altersdurchschnitt 8,3 \pm 2,6 Jahre) und 207 Kinder und Jugendliche Zähne der bleibenden Dentition ( $\mathrm{n}=4.110$; Altersdurchschnitt 10,6 \pm 3,1 Jahre) auf.

Unter den Patienten mit Milchzähnen waren 38 von normalem Gewicht (27,1 \%), 15 übergewichtige (10,7 \%), 61 adipöse (43,6 \%) und 26 extrem adipöse Patienten (18,6 \%). Die mittlere BMI-Perzentile betrug $88,8 \pm 18,8$. 


\subsubsection{Karies im Milchgebiss}

\subsubsection{Kariesprävalenz und Karieserfahrung}

Zahnebene

Bei 81,3 \% der untersuchten Milchzähne konnte kein Anzeichen für eine kariöse Läsion festgestellt werden $\left(\mathrm{d}_{1-6} \mathrm{mft}=0\right)$. Invasiv behandlungsbedürftige kariöse Läsionen fanden sich bei 13,9\% der untersuchten Milchzähne $\left(\mathrm{d}_{3-6} \mathrm{mft}>0\right)$.

Die Karieserfahrung an den Milchzähnen nahm innerhalb der Gewichtsgruppen zu. So verzeichneten die Milchzähne adipöser und extrem adipöser Kinder signifikant höhere Prävalenzraten als die Milchzähne der normalgewichtigen Kinder (Tabelle 3.4).

Tabelle 3.4: Karieserfahrung (n, \%) nach zwei verschiedenen Cut-Off-Punkten: d1 und d3

\begin{tabular}{|c|c|c|}
\hline & \multicolumn{2}{|c|}{ Milchzähne } \\
\hline & $\begin{array}{c}\text { Karieserfahrung }\left(\mathrm{d}_{1-6} \mathrm{mft}>0\right) \\
\mathrm{n}(\%)\end{array}$ & $\begin{array}{c}\text { Karieserfahrung }\left(\mathrm{d}_{3-6} \mathrm{mft}>0\right) \\
\mathrm{n}(\%)\end{array}$ \\
\hline $\begin{array}{l}\text { Normalgewicht } \\
\text { (BMI-Perzentile } 10 \text { - 90) }\end{array}$ & $54(10,9 \%)$ & $36(7,2 \%)$ \\
\hline $\begin{array}{c}\text { Übergewicht } \\
\text { (BMI-Perzentile } 90 \text { - 97) }\end{array}$ & $21(13,9 \%)$ & $15(9,9 \%)$ \\
\hline $\begin{array}{c}\text { Adipositas } \\
\text { (BMI-Perzentile } 97 \text { - 99,5) }\end{array}$ & $127(23,6 \%)$ & $103(19,1 \%)$ \\
\hline $\begin{array}{c}\text { Extreme Adipositas } \\
(\text { BMI-Perzentile }>99,5)\end{array}$ & $78(25,0 \%)$ & $54(17,3 \%)$ \\
\hline Gesamt & $280(18,7 \%)$ & $208(13,9 \%)$ \\
\hline
\end{tabular}

\subsection{Patientenebene}

Bei 42,9 \% der untersuchten Kinder und Jugendlichen mit Milchzähnen lagen kariesfreie Gebisse vor $\left(\mathrm{d}_{1-6 \mathrm{mft}}=0\right)$. Invasiv behandlungsbedürftige kariöse Läsionen fanden sich bei $44,3 \%\left(\mathrm{~d}_{3-6} \mathrm{mft}>0\right)$. Die Karieserfahrung innerhalb der verschiedenen Gewichtsgruppen kann der Tabelle 3.5 entnommen werden. Die Kariesprävalenz $\left(\mathrm{d}_{1-6} \mathrm{mft}>0\right)$ bei adipösen und extrem adipösen Kindern war im Vergleich zu normalgewichtigen Kindern erhöht, dieser Unterschied war jedoch nicht signifikant $(p>0,05)$. 
Deutliche Unterschiede in der Kariesprävalenz ließen sich zwischen den verschiedenen Altersgruppen feststellen. Zu beobachten war eine deutliche Abnahme der naturgesunden Gebisse mit steigendem Alter. Während in der Altersgruppe der 4- bis 6-Jährigen noch 46,3 \% der Gebisse kariesfrei waren, wiesen unter den 7- bis 11-jährigen Kindern nur noch 38,1 \% ein kariesfreies Gebiss auf $\left(\mathrm{d}_{1-6} \mathrm{mft}=0\right)$. So war auch eine Zunahme des durchschnittlichen $\mathrm{d}_{1-6} \mathrm{mft}-$ Wertes von 2,0 auf 2,2 zu beobachten.

Tabelle 3.5: Karieserfahrung ( $\mathrm{n}, \%)$ und Schweregrad (dmft, $\mathrm{M} \pm \mathrm{SD}$ ) nach zwei verschiedenen Cut-OffPunkten: $\mathrm{d} 1$ und $\mathrm{d} 3$

\begin{tabular}{|c|c|c|c|c|}
\hline & \multicolumn{4}{|c|}{ Kinder mit Milchzähnen } \\
\hline & $\begin{array}{c}\text { Karieserfahrung } \\
\left(\mathrm{d}_{1-6} \mathrm{mft}>0\right) \\
\mathrm{n}(\%)\end{array}$ & $\begin{array}{l}\text { Schweregrad } \\
\qquad \begin{array}{l}\left(\mathrm{d}_{1-6} \mathrm{mft}\right) \\
\mathrm{M} \pm \mathrm{SD}\end{array}\end{array}$ & $\begin{array}{c}\text { Karieserfahrung } \\
\left(\mathrm{d}_{3-6 \mathrm{mft}}>0\right) \\
\mathrm{n}(\%)\end{array}$ & $\begin{array}{l}\text { Schweregrad } \\
\qquad \begin{array}{l}\left(\mathrm{d}_{3-6} \mathrm{mft}\right) \\
\mathrm{M} \pm \mathrm{SD}\end{array}\end{array}$ \\
\hline $\begin{array}{c}\text { Normalgewicht } \\
\text { (BMI-Perzentile } 10 \text { - 90) }\end{array}$ & $19(50,0 \%)$ & $1,4 \pm 2,2$ & $15(39,5 \%)$ & $0,9 \pm 1,9$ \\
\hline $\begin{array}{c}\text { Übergewicht } \\
\text { (BMI-Perzentile } 90 \text { - 97) }\end{array}$ & $8(53,3 \%)$ & $1,5 \pm 2,1$ & $4(26,7 \%)$ & $1,1 \pm 2,2$ \\
\hline $\begin{array}{c}\text { Adipositas } \\
\text { (BMI-Perzentile } 97-99,5)\end{array}$ & $34(55,7 \%)$ & $2,1 \pm 2,8$ & $28(45,9 \%)$ & $1,7 \pm 2,5$ \\
\hline $\begin{array}{c}\text { Extreme Adipositas } \\
(\text { BMI-Perzentile }>99,5)\end{array}$ & $19(73,1 \%)$ & $2,9 \pm 2,9$ & $15(57,7 \%)$ & $2,0 \pm 2,6$ \\
\hline Gesamt & $80(57,1 \%)$ & $2,0 \pm 2,7$ & $62(44,3 \%)$ & $1,5 \pm 2,3$ \\
\hline
\end{tabular}

M: Mittelwert; SD: Standardabweichung

d1 (ICDAS 0: gesund/ ICDAS 1-6: Karies); d3 (ICDAS 0-2: gesund/ ICDAS 3-6: Karies)

Unter dem Begriff Karieserfahrung versteht man die Summe kariöser, aufgrund von Karies gefüllter oder wegen Karies entfernter Zähne. Das Ausmaß der Karieserfahrung wurde anhand des dmft-Index für zwei verschiedene Cut-Off-Punkte analysiert. Der durchschnittliche $\mathrm{d}_{1-\mathrm{G}} \mathrm{mft}-\mathrm{Wert}$ lag innerhalb der Gruppe mit Milchzähnen bei 2,0 \pm 2,7 betroffenen Zähnen.

Bei der geschlechtsspezifischen Differenzierung des Kariesbefalls waren die Mittelwerte der Mädchen 2,0 ( $\pm 2,7)$ vergleichbar mit denen der Jungen 2,0 ( $\pm 2,6)$. 
3.2.1.2 Einflussparameter auf die Kariesprävalenz und den Schweregrad von Karies

Die potenzielle Einflussnahme anamnestisch erhobener Risikofaktoren auf das Auftreten und die Schwere von Karies wurde auf Zahn- und Patientenebene mittels Regressionsanalysen statistisch analysiert.

Die Einflussnahme möglicher Risikofaktoren auf die Kariesprävalenz wurde im Rahmen logistischer Regressionsanalysen untersucht. Der Einfluss auf die Schwere der Erkrankung konnte mit linearen Regressionsanalysen bestimmt werden. Die zu untersuchenden Risikofaktoren wurden als unabhängige Variablen für die Berechnung herangezogen.

Zahnebene

Für die Milchzähne konnten ein höherer BMI $(\mathrm{p}<0,001)$, steigendes Alter $(\mathrm{p}<0,001)$, sozioökonomische Faktoren (Hintergrund, monatliches Netto-Haushaltseinkommen) sowie Zahnputzgewohnheiten $(\mathrm{p}<0,001)$ als Risikofaktoren für das Auftreten von Karies $\left(\mathrm{d}_{1-6} \mathrm{mft}>0\right)$ identifiziert werden. Die Milchzähne der Kinder mit Migrationshintergrund hatten demnach ein 1,5-fach höheres Risiko kariöse Läsionen aufzuweisen als die Milchzähne der Kinder ohne Migrationshintergrund ( $p=0,046$; OR: 1,453).

Mit zunehmenden BEWE-Werten sowie einem monatlichen Netto-Haushaltseinkommen über 2.750 € sank das Risiko für Karieserfahrung an den Milchzähnen hingegen $(p<0,001)$. Der Schweregrad kariöser Läsionen nahm mit ungünstigen Mundhygienegewohnheiten $(<2 /$ Tag, $<2$ Minuten, $\mathrm{p}<0,001)$, abnehmenden BEWE-Werten $(\mathrm{p}<0,001)$ sowie sozialen und ökonomischen Faktoren zu (Risikofaktoren: monatliches Netto-Haushaltseinkommen unter 2.750 €, zunehmende Anzahl an Geschwistern, Migrationshintergrund) (Tabelle 3.6). 


\subsection{Patientenebene}

In der patientenbezogenen Auswertung zeigte sich der Faktor „Art der Zahnpasta“ $(p=0,003)$ als Hauptrisikofaktor auf das absolute Auftreten von Karies $\left(\mathrm{d}_{1-6 \mathrm{mft}}>0\right)$. So hatten Kinder und Jugendliche, welche eine Zahnpasta mit niedrigerem Fluoridgehalt als von der Deutschen Gesellschaft für Zahn-, Mund- und Kieferheilkunde (DGZMK) empfohlen verwendeten, ein höheres Risiko für kariöse Läsionen (Tabelle 3.6).

Kinder aus Familien mit einem monatlichen Netto-Haushaltseinkommen $\geq 2.750 €$ verzeichneten ein signifikant geringeres Risiko für kariöse Läsionen verglichen mit Kindern aus Familien mit einem monatlichen Netto-Haushaltseinkommen $<2.750 €\left(\mathrm{~d}_{1-6} \mathrm{mft}>0\right)$.

Tabelle 3.6: Risikofaktoren mit signifikantem Einfluss auf die Karieserfahrung und den Schweregrad kariöser Läsionen (zahn- und patientenbezogene Auswertung)

\begin{tabular}{|c|c|c|}
\hline & & Risikofaktoren \\
\hline 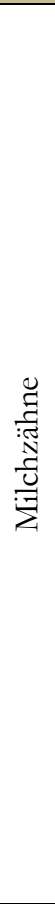 & $\begin{array}{l}\text { Prävalenz Karieserfahrung } \\
\qquad\left(\mathrm{d}_{1-6} \mathrm{mft}>0\right)\end{array}$ & 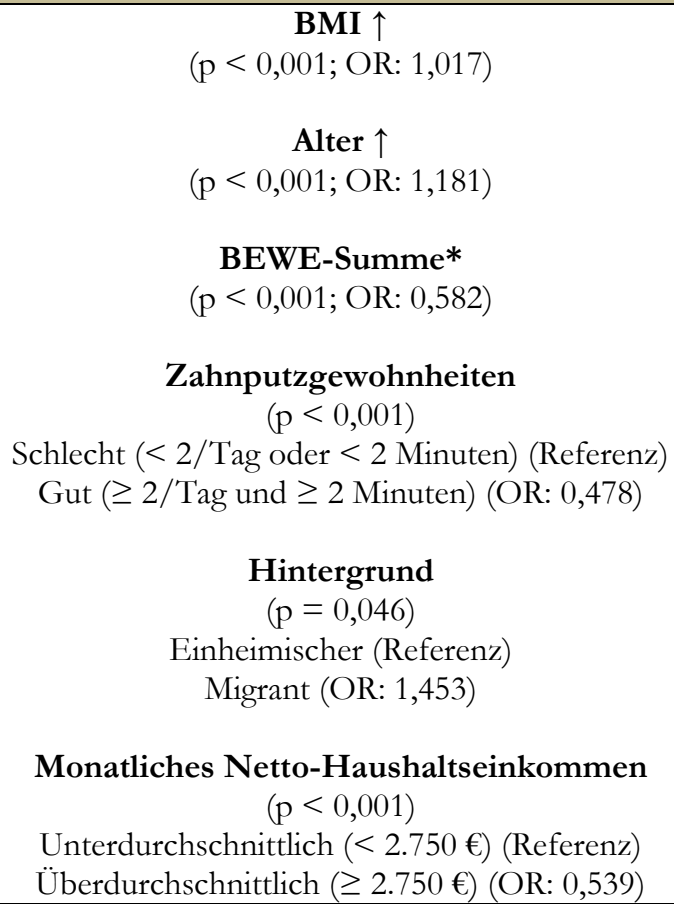 \\
\hline
\end{tabular}




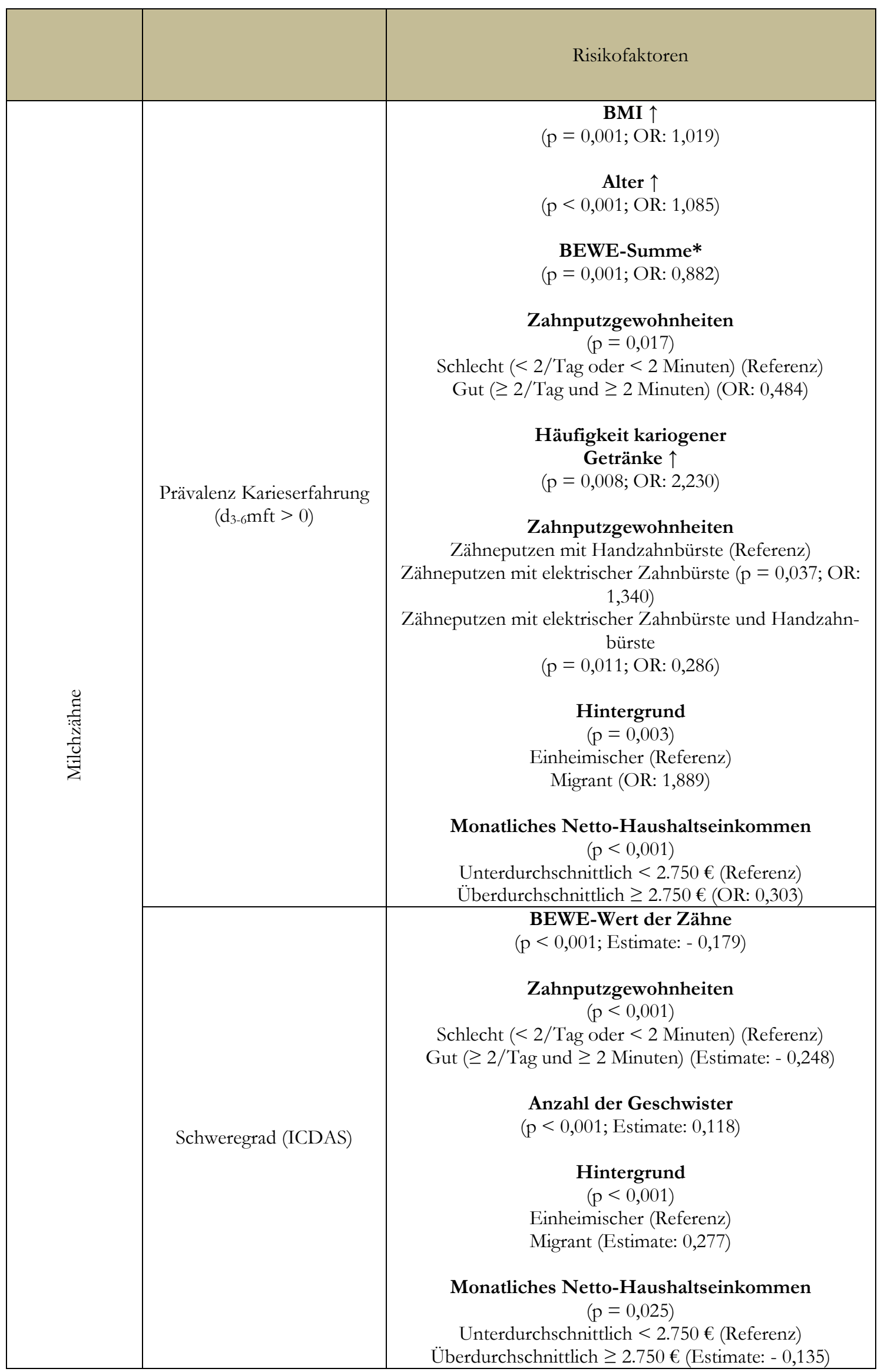




\begin{tabular}{|c|c|c|}
\hline & & Risikofaktoren \\
\hline \multirow{6}{*}{ 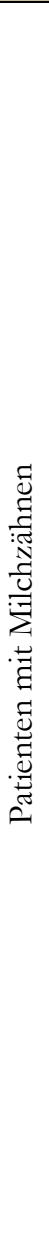 } & $\begin{array}{l}\text { Prävalenz Karieserfahrung } \\
\qquad\left(\mathrm{d}_{1-6} \mathrm{mft}>0\right)\end{array}$ & $\begin{array}{l}\text { Verwendung von Zahnpasta mit einem Fluoridgehalt } \\
\text { entsprechend der DGZMK-Empfehlung } \\
\qquad(p=0,003) \\
\text { Altersgerecht und höher (Referenz) } \\
\text { Niedriger als empfohlen (OR: 3,595) } \\
\text { Monatliches Netto-Haushaltseinkommen } \\
\quad(p=0,021) \\
\text { Unterdurchschnittlich }<2.750 €(\text { Referenz) } \\
\text { Überdurchschnittlich } \geq 2.750 €(\text { OR: } 0,362)\end{array}$ \\
\hline & $\begin{array}{l}\text { Prävalenz Karieserfahrung } \\
\qquad\left(\mathrm{d}_{3-6} \mathrm{mft}>0\right)\end{array}$ & $\begin{array}{l}\text { Verwendung von Zahnpasta mit einem Fluoridgehalt } \\
\text { entsprechend der DGZMK-Empfehlung } \\
\qquad(p=0,015) \\
\text { Altersgerecht und höher (Referenz) } \\
\text { Niedriger als empfohlen (OR: } 2,935) \\
\text { Monatliches Netto-Haushaltseinkommen } \\
(p=0,003) \\
\text { Unterdurchschnittlich }<2.750 €(\text { Referenz) } \\
\text { Überdurchschnittlich } \geq 2.750 €(\text { OR: } 0,260)\end{array}$ \\
\hline & $\begin{array}{l}\text { Betroffen Zähne/Patient } \\
\qquad\left(\% ; \mathrm{d}_{1-6} \mathrm{mft}>0\right)\end{array}$ & $\begin{array}{c}\text { Alter } \uparrow \\
(p=0,006 ; \text { Estimate: } 0,028)\end{array}$ \\
\hline & $\begin{array}{l}\text { Betroffen Zähne/Patient } \\
\qquad\left(\% ; \mathrm{d}_{3-6} \mathrm{mft}>0\right)\end{array}$ & $\begin{array}{c}\text { Alter } \uparrow \\
(p=0,023 ; \text { Estimate: } 0,020) \\
\text { Anzahl der Geschwister } \uparrow \\
(p=0,043 \text {; Estimate: } 0,038)\end{array}$ \\
\hline & Schweregrad $\left(\mathrm{d}_{1-6} \mathrm{mft}>0\right)$ & $\begin{array}{c}\text { Alter } \uparrow \\
(\mathrm{p}=0,027 ; \text { Estimate: } 0,194)\end{array}$ \\
\hline & Schweregrad $\left(\mathrm{d}_{3-6} \mathrm{mft}>0\right)$ & - \\
\hline
\end{tabular}

p: p-Wert, OR: Odds Ratio

*Die Karieserfahrung und der Schweregrad kariöser Läsionen stieg für abnehmende BEWE-Summenwerte.

\subsubsection{Karies im bleibenden Gebiss}

\subsubsection{Kariesprävalenz und Karieserfahrung}

\subsection{Zahnebene}

An den Zähnen der bleibenden Dentition fanden sich bei 15,6 \% kariöse Läsionen $\left(\mathrm{D}_{1-6} \mathrm{MFT}>0\right)$, von denen 2,7 \% invasiv behandlungsbedürftig waren $\left(\mathrm{D}_{3-6} \mathrm{MFT}>0\right)$.

Die Karieserfahrung an den bleibenden Zähnen nahm innerhalb der Gewichtsgruppen zu. So verzeichneten die bleibenden Zähne adipöser und extrem adipöser Kinder signifikant höhere Prävalenzraten als die bleibenden Zähne der normalgewichtigen Kinder ( $\left.\mathrm{D}_{1-6} \mathrm{MFT}>0\right)$ (Tabelle 3.7). 
Tabelle 3.7: Karieserfahrung (n, \%) nach zwei verschiedenen Cut-Off-Punkten: D1 und D3

\begin{tabular}{|c|c|c|}
\hline & \multicolumn{2}{|c|}{ Bleibende Zähne } \\
\hline & $\begin{array}{c}\text { Karieserfahrung } \\
\left(\mathrm{D}_{1-6} \mathrm{MFT}>0\right) \\
\mathrm{n}(\%)\end{array}$ & $\begin{array}{c}\text { Karieserfahrung } \\
\left(\mathrm{D}_{3-6} \mathrm{MFT}>0\right) \\
\mathrm{n}(\%) \\
\end{array}$ \\
\hline $\begin{array}{c}\text { Normalgewicht } \\
\text { (BMI-Perzentile } 10 \text { - 90) }\end{array}$ & $68(8,8 \%)$ & $30(3,9 \%)$ \\
\hline $\begin{array}{c}\text { Übergewicht } \\
\text { (BMI-Perzentile } 90 \text { - 97) }\end{array}$ & $62(11,6 \%)$ & $9(1,7 \%)$ \\
\hline $\begin{array}{c}\text { Adipositas } \\
\text { (BMI-Perzentile } 97 \text { - 99,5) }\end{array}$ & $326(18,0 \%)$ & $40(2,2 \%)$ \\
\hline $\begin{array}{c}\text { Extreme Adipositas } \\
(\text { BMI-Perzentile }>99,5)\end{array}$ & $186(18,7 \%)$ & $30(3,0 \%)$ \\
\hline Gesamt & $642(15,6 \%)$ & $109(2,7 \%)$ \\
\hline
\end{tabular}

D1 (ICDAS 0: gesund/ ICDAS 1-6: Karies); D3 (ICADS 0-2: gesund/ ICDAS 3-6: Karies)

\subsection{Patientenebene}

Kinder und Jugendliche mit bleibenden Zähnen verzeichneten eine Kariesprävalenz von 60,4 \% ( $\mathrm{D}_{1-6} \mathrm{MFT}>0$ ). Invasiv behandlungsbedürftige kariöse Läsionen fanden sich bei 24,2\% $\left(\mathrm{d}_{3-6} \mathrm{mft}>0\right)$. Bei 39,6\% der untersuchten Kinder und Jugendlichen lagen kariesfreie Gebisse vor $\left(\mathrm{D}_{1-6} \mathrm{MFT}=0\right)$.

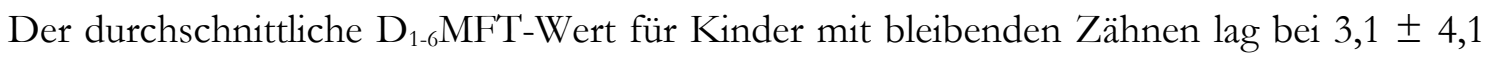
betroffenen Zähnen.

Auch im bleibenden Gebiss schnitten Mädchen bei der geschlechtsspezifischen Differenzierung des $\mathrm{D}_{1-6} \mathrm{MFT}$-Wertes besser ab als Jungen und verzeichneten somit weniger schwere kariöse Läsionen. Der Unterschied war jedoch nicht signifikant ( $p>0,05)$.

Innerhalb der Gewichtsgruppen konnte ein signifikanter Anstieg des durchschnittlichen $\mathrm{D}_{1-6}$ MFT-Werts von 1,5 \pm 3,3 für die normalgewichtigen Kinder auf 4,1 \pm 4,8 für extrem adipöse Kinder verzeichnet werden (Tabelle 3.8).

Auch für Kinder und Jugendliche mit bleibenden Zähnen ließen sich deutliche Unterschiede in der Kariesprävalenz zwischen den verschiedenen Altersgruppen feststellen. Während in der Altersgruppe der 4- bis 6-Jährigen noch 84,0 \% der Gebisse kariesfrei waren, wiesen unter den 7- bis 11-jährigen Kindern nur noch 37,9 \% ein kariesfreies Gebiss auf (Tabelle 3.9). 
Tabelle 3.8: Karieserfahrung (n, \%) und Schweregrad (DMFT, M \pm SD) nach zwei verschiedenen Cut-OffPunkten: D1 und D3

\begin{tabular}{|c|c|c|c|c|}
\hline \multirow{2}{*}{} & \multicolumn{3}{|c|}{ Kinder mit bleibenden Zähnen } \\
\cline { 2 - 5 } & $\begin{array}{c}\text { Karieserfahrung } \\
\left(\mathrm{D}_{1-6} \mathrm{MFT}>0\right) \\
\mathrm{n}(\%)\end{array}$ & $\begin{array}{c}\text { Schweregrad } \\
\left(\mathrm{D}_{1-6 \mathrm{MFT}}\right. \\
\mathrm{M} \pm \mathrm{SD}\end{array}$ & $\begin{array}{c}\text { Karieserfahrung } \\
\left(\mathrm{D}_{3-6 \mathrm{MFT}>0)} \mathrm{n}(\%)\right.\end{array}$ & $\begin{array}{c}\text { Schweregrad } \\
\left(\mathrm{D}_{3-6} \text { MFT }\right) \\
\mathrm{M} \pm \mathrm{SD}\end{array}$ \\
\hline $\begin{array}{c}\text { Normalgewicht } \\
\text { (BMI-Perzentile 10 - 90) }\end{array}$ & $16(34,8 \%)$ & $1,5 \pm 3,3$ & $10(21,7 \%)$ & $0,7 \pm 2,0$ \\
\hline $\begin{array}{c}\text { Übergewicht } \\
\text { (BMI-Perzentile 90 - 97) }\end{array}$ & $15(60,0 \%)$ & $2,5 \pm 3,2$ & $6(24,0 \%)$ & $0,4 \pm 0,8$ \\
\hline $\begin{array}{c}\text { Adipositas } \\
\text { (BMI-Perzentile 97 - 99,5) }\end{array}$ & $63(69,2 \%)$ & $3,6 \pm 4,2$ & $23(25,3 \%)$ & $0,4 \pm 0,9$ \\
\hline $\begin{array}{c}\text { Extreme Adipositas } \\
\text { (BMI-Perzentile > 99,5) }\end{array}$ & $31(68,9 \%)$ & $4,1 \pm 4,8$ & $11(24,4 \%)$ & $0,7 \pm 1,5$ \\
\hline
\end{tabular}

M: Mittelwert; SD: Standardabweichung

D1 (ICDAS 0: gesund/ ICDAS 1-6: Karies); D3 (ICDAS 0-2: gesund/ ICDAS 3-6: Karies) 
Tabelle 3.9: Karieserfahrung ( $\mathrm{n}, \%$ ) nach zwei verschiedenen Cut-Off-Punkten: D1 und D3 innerhalb verschiedener Altersgruppen

\begin{tabular}{|c|c|c|c|}
\hline & $\begin{array}{c}\text { Anzahl gesamt } \\
\mathrm{n}(\%)\end{array}$ & $\begin{array}{c}\text { Anzahl mit Karies } \\
\left(\mathrm{D}_{1-6} \mathrm{MFT}>0\right) \\
\mathrm{n}(\%)\end{array}$ & $\begin{array}{c}\text { Anzahl mit Karies } \\
\left(\mathrm{D}_{3-6} \mathrm{MFT}>0\right) \\
\mathrm{n}(\%)\end{array}$ \\
\hline 4- bis 6-Jährige & $25(12,1 \%)$ & $4(16,0 \%)$ & $0(0,0 \%)$ \\
\hline 7- bis 11-Jährige & $95(45,9 \%)$ & $59(62,1 \%)$ & $19(20,0 \%)$ \\
\hline$\geq$ 12-Jährige & $87(42,0 \%)$ & $62(71,3 \%)$ & $31(35,6 \%)$ \\
\hline Gesamt & $207(100,0 \%)$ & $125(60,4 \%)$ & $50(24,2 \%)$ \\
\hline
\end{tabular}

D1 (ICDAS 0: gesund/ ICDAS 1-6: Karies) und D3 (ICDAS 0-2: gesund/ ICDAS 3-6: Karies)

3.2.2.2 Einflussparameter auf die Kariesprävalenz und den Schweregrad von Karies

Die potenzielle Einflussnahme anamnestisch erhobener Risikofaktoren auf das Auftreten und die Schwere von Karies wurde auf Zahn- und Patientenebene mittels Regressionsanalysen statistisch analysiert.

\subsection{Zahnebene}

Für die bleibenden Zähne konnten ein höherer BMI ( $p=0,006)$, steigendes Alter $(p<0,001)$, das Geschlecht ( $p<0,001)$, der häufige Konsum kariogener Getränke ( $p=0,003)$, eine steigende Anzahl an Geschwistern $(\mathrm{p}=0,030)$, ein vorliegender Migrationshintergrund $(\mathrm{p}<0,001)$ und das monatliche Netto-Haushaltseinkommen $(\mathrm{p}<0,001)$ als Risikofaktoren für das Auftreten von Karies $\left(\mathrm{D}_{1-6} \mathrm{MFT}>0\right)$ identifiziert werden. Demnach hatten die bleibenden Zähne der Kinder mit Migrationshintergrund ein 1,5-fach höheres Risiko kariöse Läsionen aufzuweisen als die Zähne der Kinder ohne Migrationshintergrund.

Der Schweregrad kariöser Läsionen nahm mit steigendem Alter $(\mathrm{p}<0,001)$, dem Vorliegen eines weiblichen Geschlechts ( $\mathrm{p}<0,001)$, einem häufigen Konsum kariogener Getränke ( $p=0,003)$, in Abhängigkeit der verwendeten Zahnbürste (elektrische und Handzahnbürste, $\mathrm{p}=0,014)$ sowie mit dem Vorliegen eines Migrationshintergrundes $(\mathrm{p}<0,001) \mathrm{zu}$. Kinder aus Familien mit einem monatlichen Netto-Haushaltseinkommen $\geq 2.750 €$ verzeichneten signifikant weniger schwere kariöse Läsionen (Tabelle 3.10). 


\subsection{Patientenebene}

In der Gruppe mit bleibenden Zähnen konnte neben dem BMI ( $p=0,007)$, ein steigendes Alter $(p<0,001)$ und das Vorliegen eines Migrationshintergrundes $(p=0,038)$ als statistisch signifikante Risikofaktoren ermittelt werden ( $\mathrm{D}_{1-6} \mathrm{MFT}>0$, Tabelle 3.10).

Deutliche Zusammenhänge zeigten sich zwischen dem Alter und dem Auftreten kariöser Läsionen. Das Risiko kariöse Zahnhartsubstanzdefekte zu entwickeln stieg pro Lebensjahr um den Faktor 1,3 ( $\mathrm{p}<0,001$; OR: 1,273).

Auf dem Cut-off-point D1 zeigte sich, dass in der Gruppe der Kinder mit bleibenden Zähnen Prävalenz, Schweregrad und Prozentsatz der betroffenen Zähne bei adipösen und extrem adipösen Kindern im Vergleich zu den normalgewichtigen Kindern signifikant erhöht war.

In Bezug auf die Schwere der Erkrankung $\left(\mathrm{D}_{1-6} \mathrm{MFT}>0\right)$ zeigten sich bei Kindern und Jugendlichen mit bleibenden Zähnen neben dem BMI $(\mathrm{p}=0,019)$ die Faktoren „Alter“ ( $p<0,001)$ und „Geschlecht“ ( $p=0,029)$ als signifikante Einflussfaktoren (Tabelle 3.10).

Dabei haben ältere Kinder ein signifikant höheres Risiko für schwerere kariöse Läsionen als Kinder jüngeren Alters $(p<0,001)$. 
Tabelle 3.10: Risikofaktoren mit signifikantem Einfluss auf die Karieserfahrung und den Schweregrad kariöser Läsionen (zahn- und patientenbezogene Auswertung)

\begin{tabular}{|c|c|c|}
\hline & Variable & Risikofaktoren \\
\hline \multirow[t]{2}{*}{ 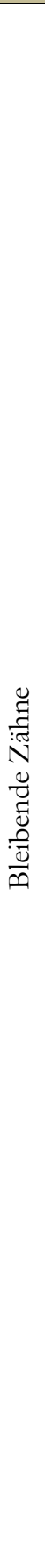 } & $\begin{array}{c}\text { Prävalenz } \\
\text { Karieserfahrung } \\
\left(\mathrm{D}_{1-6} \mathrm{MFT}>0\right)\end{array}$ & 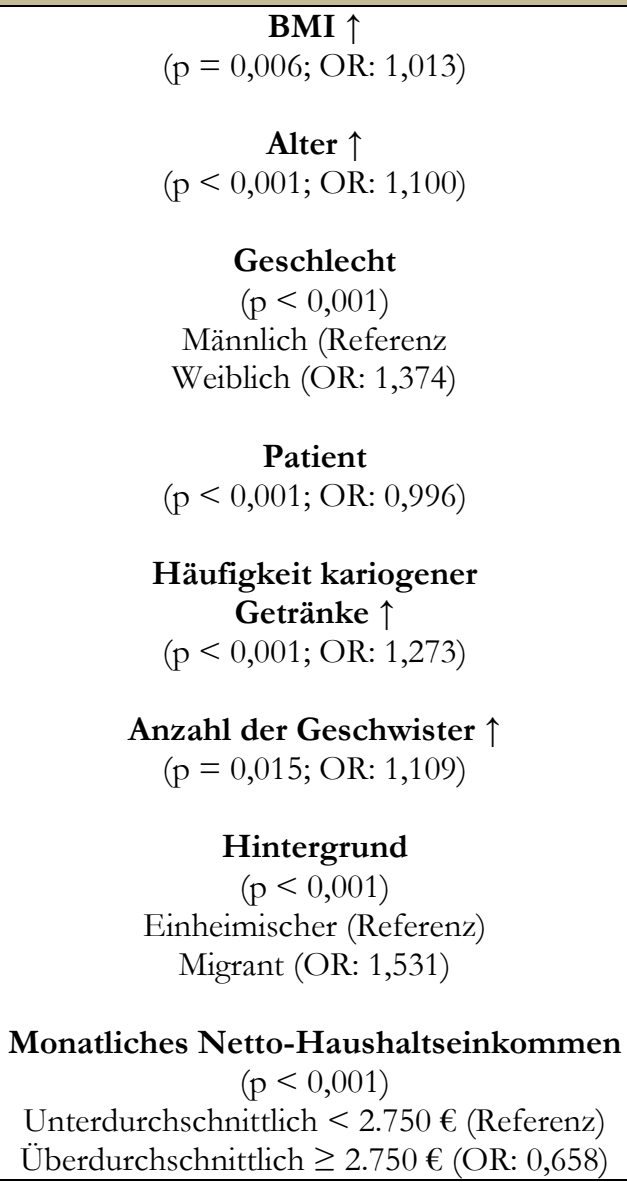 \\
\hline & $\begin{array}{c}\text { Prävalenz } \\
\text { Karieserfahrung } \\
\left(\mathrm{D}_{3-6} \mathrm{MFT}>3\right)\end{array}$ & $\begin{array}{c}\text { Alter } \uparrow \\
(\mathrm{p}<0,001 ; \text { OR: } 1,266) \\
\text { Anzahl der Geschwister } \uparrow \\
(\mathrm{p}<0,001 ; \text { OR: } 1,478) \\
\text { Hintergrund } \\
(\mathrm{p}=0,017) \\
\text { Einheimischer (Referenz) } \\
\text { Migrant (OR: 1,614) } \\
\text { Monatliches Netto-Haushaltseinkommen } \\
(\mathrm{p}=0,007) \\
\text { Unterdurchschnittlich }<2.750 €(\text { Referenz) } \\
\text { Überdurchschnittlich } \geq 2.750 €(\text { OR: } 0,347)\end{array}$ \\
\hline
\end{tabular}




\begin{tabular}{|c|c|c|}
\hline & Variable & Risikofaktoren \\
\hline 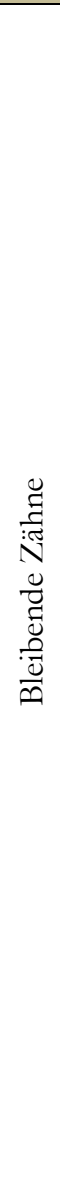 & Schweregrad (ICDAS) & 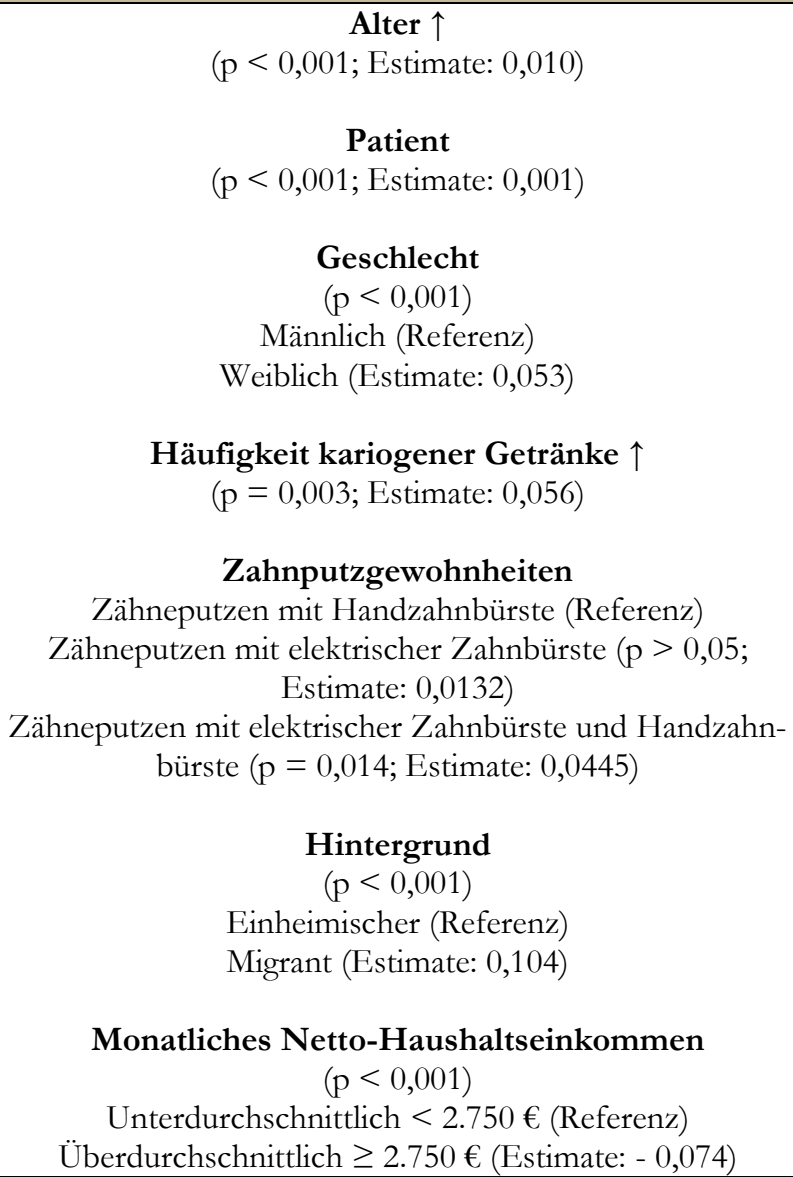 \\
\hline \multirow{2}{*}{ 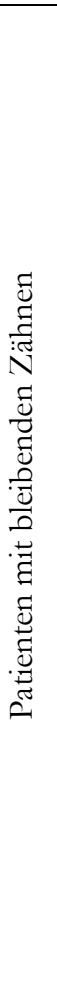 } & $\begin{array}{c}\text { Prävalenz } \\
\text { Karieserfahrung } \\
\left(\mathrm{D}_{1-6} \mathrm{MFT}>0\right)\end{array}$ & $\begin{array}{c}\text { BMI } \uparrow \\
(\mathrm{p}=0,007 ; \text { OR: } 1,027) \\
\text { Alter } \uparrow \\
(\mathrm{p}<0,001 ; \text { OR: } 1,273) \\
\text { Hintergrund } \\
(\mathrm{p}=0,038) \\
\text { Einheimischer (Referenz) } \\
\text { Migrant (OR: 2,812) } \\
\text { Monatliches Netto-Haushaltseinkommen } \\
(\mathrm{p}=0,011) \\
\text { Unterdurchschnittlich }<2.750 €(\text { Referenz) } \\
\text { Überdurchschnittlich } \geq 2.750 €(\text { OR: } 0,382)\end{array}$ \\
\hline & $\begin{array}{c}\text { Prävalenz } \\
\text { Karieserfahrung } \\
\left(\mathrm{D}_{3-6} \mathrm{MFT}>3\right)\end{array}$ & $\begin{array}{c}\text { Alter } \uparrow \\
(p<0,001 ; \text { OR: 1,315) } \\
\text { Anzahl der Geschwister } \uparrow \\
(p=0,034 \text {; OR: 1,431) } \\
\text { Monatliches Netto-Haushaltseinkommen } \\
(p=0,024) \\
\text { Unterdurchschnittlich }<2.750 €(\text { Referenz }) \\
\text { Überdurchschnittlich } \geq 2.750 €(\text { OR: } 0,324)\end{array}$ \\
\hline
\end{tabular}




\begin{tabular}{|c|c|c|}
\hline & Variable & Risikofaktoren \\
\hline \multirow{4}{*}{ 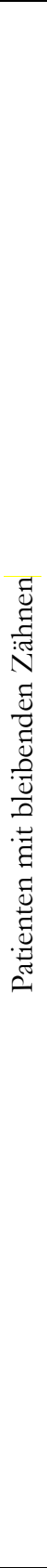 } & $\begin{array}{c}\text { Betroffene } \\
\text { Zähne/Patient } \\
\left(\% ; \text { D }_{1-6} \text { MFT }>0\right)\end{array}$ & $\begin{array}{c}\text { BMI } \uparrow \\
(\mathrm{p}=0,044 ; \text { Estimate: } 0,001) \\
\text { Alter } \uparrow \\
(\mathrm{p}<0,001 ; \text { Estimate: } 0,017) \\
\text { Geschlecht } \\
(\mathrm{p}=0,025) \\
\text { Männlich (Referenz) } \\
\text { Weiblich (Estimate: } 0,047) \\
\text { Anzahl der Geschwister } \uparrow \\
(\mathrm{p}=0,024 ; \text { Estimate: } 0,021)\end{array}$ \\
\hline & $\begin{array}{c}\text { Betroffene } \\
\text { Zähne/Patient } \\
\left(\% ; \text { D }_{3-6} \mathrm{MFT}>3\right)\end{array}$ & $\begin{array}{c}\text { Alter } \uparrow \\
(\mathrm{p}=0,002 ; \text { Estimate: } 0,003) \\
\text { Anzahl der Geschwister } \uparrow \\
(\mathrm{p}<0,001 ; \text { Estimate: } 0,010) \\
\text { Hintergrund } \\
(\mathrm{p}=0,021) \\
\text { Einheimischer (Referenz) } \\
\text { Migrant (Estimate: } 0,019) \\
\\
\text { Monatliches Netto-Haushaltseinkommen } \\
(\mathrm{p}=0,025) \\
\text { Unterdurchschnittlich }<2.750 €(\text { Referenz) } \\
\text { Überdurchschnittlich } \geq 2.750 €(\text { Estimate: }-0,015)\end{array}$ \\
\hline & $\begin{array}{c}\text { Schweregrad } \\
\left(\mathrm{D}_{1-6} \mathrm{MFT}>0\right)\end{array}$ & $\begin{array}{c}\text { BMI } \uparrow \\
(\mathrm{p}=0,019 ; \text { Estimate: } 0,037) \\
\text { Alter } \uparrow \\
(\mathrm{p}<0,001 ; \text { Estimate: } 0,754) \\
\text { Geschlecht } \\
(\mathrm{p}=0,029) \\
\text { Männlich (Referenz) } \\
\text { Weiblich (Estimate: } 1,312)\end{array}$ \\
\hline & $\begin{array}{c}\text { Schweregrad } \\
\left(\mathrm{D}_{3-6} \mathrm{MFT}>3\right)\end{array}$ & $\begin{array}{c}\text { Alter } \uparrow \\
(p<0,001 ; \text { Estimate: } 0,341) \\
\text { Anzahl der Geschwister } \uparrow \\
(p<0,001 ; \text { Estimate: } 0,357)\end{array}$ \\
\hline
\end{tabular}

p-Wert, OR: Odds Ratio

\subsubsection{Erosionen im Milchgebiss}

\subsubsection{Prävalenz dentaler Erosionen}

\subsubsection{1}

Zahnebene

An den Milchzähnen konnten in 34,1 \% der Fälle Erosionen nachgewiesen werden. Die Prävalenz erosiver Läsionen nahm innerhalb der Gewichtsgruppen signifikant zu $(p<0,001)$. Während 24,7 \% der Milchzähne normalgewichtiger Kinder dentale Erosionen aufwiesen, 
verzeichneten die Milchzähne der adipösen Kinder bereits in 41,7 \% Anzeichen erosiver Läsionen (Tabelle 3.11).

\subsection{Patientenebene}

Von den untersuchten Kindern mit Milchzähnen wiesen 75,0 \% Anzeichen erosiver Läsionen auf (Tabelle 3.11). Ein Großteil der Kinder bei denen dentale Erosionen nachgewiesen wurden, hatten ein bis fünf betroffene Zähne $(n=69 ; 49,3 \%), 36$ Kinder wiesen sechs bis zehn betroffene Zähne auf (25,7 \%) und nur bei 2,1 \% (n=3) der Kinder konnten erosive Defekte an mehr als zehn Zähnen nachgewiesen werden.

\subsubsection{Schweregrad, Lokalisation und Verteilung dentaler Erosionen}

\subsection{Zahnebene}

Der durchschnittliche BEWE-Summenwert für die Milchzähne lag bei 0,5 \pm 0,8.

\subsection{Patientenebene}

Die Mehrheit der untersuchten Kinder mit Milchzähnen zeigte eine geringe Anfälligkeit für dentale Erosionen (BEWE-Summenwert zwischen drei und acht, $\mathrm{n}=71 ; 64,1 \%$ ). Keine Anfälligkeit für dentale Erosionen im Milchgebiss zeigte sich bei 57 (40,7 \%) der untersuchten Probanden mit BEWE-Summenwerten zwischen null und zwei. Ein kleiner Anteil der untersuchten Kinder wies eine mittlere Anfälligkeit für erosive Läsionen auf (BEWE-Summenwerte zwischen neun und dreizehn, $\mathrm{n}=8$; 3,6 \%). Schwere erosive Zahnhartsubstanzdefekte mit BEWE-Summenwerten über 14 konnten nur bei einem der untersuchten Probanden nachgewiesen werden.

Der durchschnittliche BEWE-Summenwert lag bei 3,5 \pm 3,1 (Tabelle 3.11). 
Tabelle 3.11: Prävalenz und Schweregrad dentaler Erosionen im Milch- und Wechselgebiss

\begin{tabular}{|c|c|c|c|c|}
\hline \multirow{2}{*}{} & \multicolumn{2}{|c|}{ Milchzähne } & \multicolumn{2}{c|}{$\begin{array}{c}\text { Kinder und Jugendliche mit } \\
\text { Milchzähnen }\end{array}$} \\
\cline { 2 - 5 } & Prävalenz (\%) & $\begin{array}{c}\text { BEWE- } \\
\text { Summe } \\
\text { (M } \pm \text { SD })\end{array}$ & Prävalenz (\%) & $\begin{array}{c}\text { BEWE- } \\
\text { Summe } \\
\text { (M } \pm \text { SD) }\end{array}$ \\
\hline $\begin{array}{c}\text { Normalgewicht } \\
\text { (BMI-Perzentile 10 - 90) }\end{array}$ & $123(24,7 \%)$ & $0,4 \pm 0,8$ & $24(63,2 \%)$ & $3,2 \pm 3,5$ \\
\hline $\begin{array}{c}\text { Übergewicht } \\
\text { (BMI-Perzentile 90 - 97) }\end{array}$ & $55(36,4 \%)$ & $0,5 \pm 0,8$ & $13(86,7 \%)$ & $3,7 \pm 3,1$ \\
\hline $\begin{array}{c}\text { Adipositas } \\
\text { (BMI-Perzentile 97 - 99,5) }\end{array}$ & $224(41,7 \%)$ & $0,6 \pm 0,8$ & $47(77,0 \%)$ & $3,4 \pm 3,0$ \\
\hline $\begin{array}{c}\text { Extreme Adipositas } \\
\text { (BMI-Perzentile > 99,5) }\end{array}$ & $108(34,6 \%)$ & $0,5 \pm 0,7$ & $21(80,8 \%)$ & $3,4 \pm 2,7$ \\
\hline
\end{tabular}

M: Mittelwert; SD: Standardabweichung

Der Anteil dentaler Erosionen im Ober- und Unterkiefer war vergleichbar (OK: 50,7 \%, UK: $49,3 \%)$.

Kinder mit Milchzähnen verzeichneten die höchste Erosionsprävalenz an den Eckzähnen (Zahn 53: 65,7\%; Zahn 63: 61,9\%), gefolgt von den zweiten unteren Milchmolaren (Zahn 75: 50,5\%).

Im Unterkiefer wiesen die Zähne der rechten Kieferhälfte eine höhere Erosionsprävalenz (28,2 \%) auf als die Zähne der linken Kieferhälfte (23,6 \%) (Abbildung 3.1). 
-BEWE 3 BEWE 2 BEWE 1

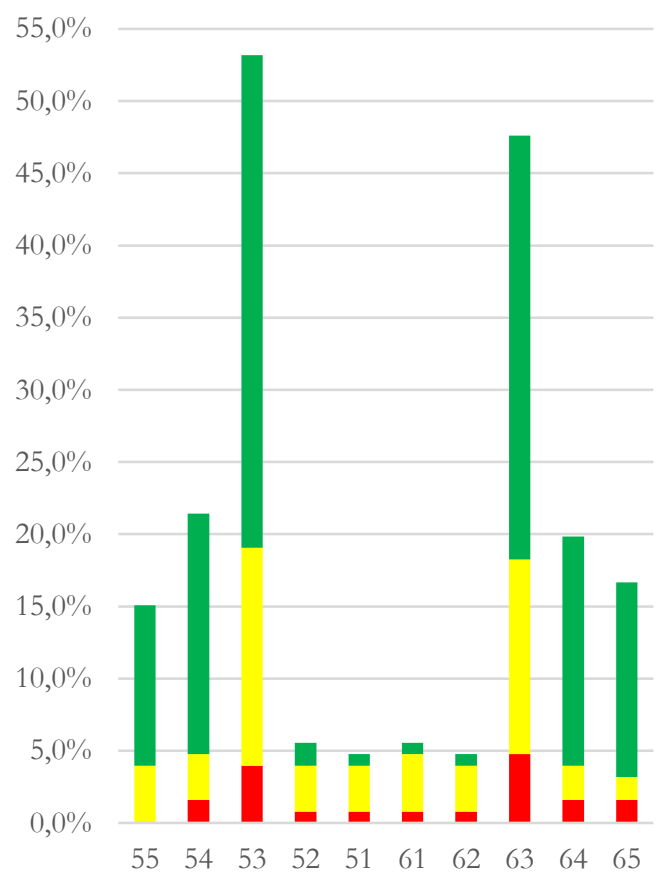

A

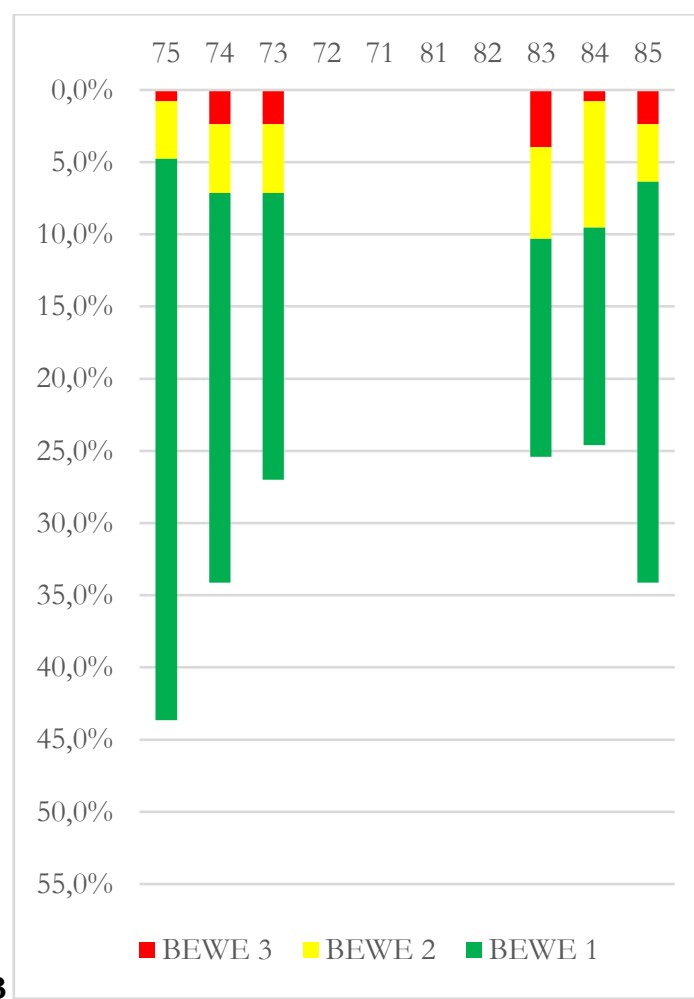

C

-BEWE 3 BEWE 2 BEWE 1

$10,0 \%$

$9,0 \%$

$8,0 \%$

$7,0 \%$

$6,0 \%$

$5,0 \%$

$4,0 \%$

$3,0 \%$

$2,0 \%$

$1,0 \%$

$0,0 \%$

48474645444342413132333435363738

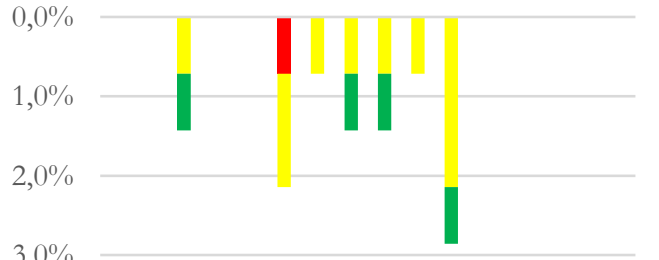

$3,0 \%$

$4,0 \%$

$5,0 \%$

$6,0 \%$

$7,0 \%$

$8,0 \%$

$9,0 \%$

$10,0 \%$

-BEWE 3 BEWE 2 BEWE 1

D

Abbildung 3.1: Prävalenz und Schweregrad dentaler Erosionen an den verschiedenen Zähnen bei Patienten mit Milch- und Wechselgebiss: (A) Milchzähne (Oberkiefer), (B) Milchzähne (Unterkiefer), (C) Bleibende Zähne (Oberkiefer), (D) Bleibende Zähne (Unterkiefer) 
3.2.3.3 Einflussparameter auf die Erosionsprävalenz und den Schweregrad dentaler Erosionen

\subsection{Zahnebene}

Die analytische Auswertung zeigte, dass ein höherer BMI das Risiko für das Auftreten dentaler Erosionen erhöht (Tabelle 3.12). Darüber hinaus wurden ein höheres Alter $(p<0,001)$, das Geschlecht und der Hintergrund als Hauptrisikofaktoren identifiziert.

Kinder aus Migrantenfamilien zeigten ein 0,7-fach geringeres Risiko für das Auftreten von dentalen Erosionen als Kinder und Jugendliche ohne Migrationshintergrund $(p=0,010$; OR: 0,678). Auch zeigten Mädchen im Vergleich zu Jungen ein signifikant geringeres Risiko für das Auftreten von erosiven Zahnhartsubstanzdefekten ( $p=0,011$; OR: 0,737).

Hauptrisikofaktoren für die Schwere dentaler Erosionen waren ein zunehmender BMI $(p=0,011)$ und ein steigendes Alter $(p<0,001)$. Mädchen verzeichneten signifikant weniger schwere Erosionen als Jungen ( $p<0,001$; Estimate: - 0,249).

Für die Milchzähne zeigte sowohl die Prävalenz als auch der Schweregrad dentaler Erosionen einen inversen Zusammenhang mit den jeweiligen ICDAS-Werten der Zähne: Milchzähne mit kariösen Läsionen hatten ein geringeres Risiko für das Auftreten von dentalen Erosionen $(\mathrm{p}<$ 0,001; OR: 0,668). Lagen dennoch Erosionen vor, so fielen diese in der Regel weniger schwer aus als bei kariesfreien Zähnen ( $\mathrm{p}<0,001$; Estimate: - 0,102).

\subsection{Patientenebene}

Kinder mit Milchzähnen zeigten bei höherem BMI ein signifikant höheres Risiko für das Auftreten dentaler Erosionen ( $\mathrm{p}=0,015$; OR: 1,025).

Hauptrisikofaktor für die Schwere dentaler Erosionen war für Kinder mit Milchzähnen die Verwendung einer Zahnpasta, deren Fluoridkonzentration geringer ist als von der DGZMK empfohlen ( $\mathrm{p}=$ 0,004; Estimate: 1,539).

Der Prozentsatz der von Erosionen betroffenen Zähne stieg in der Gruppe mit Milchzähnen für Kinder mit metabolischem Syndrom ( $p=0,046$; Estimate: 0,171) sowie für ältere Kinder $(\mathrm{p}<0,001 ;$ Estimate 0,042) an. 
Tabelle 3.12: Risikofaktoren mit signifikantem Einfluss auf die Prävalenz und den Schweregrad dentaler Erosionen (zahn- und patientenbezogene Auswertung)

\begin{tabular}{|c|c|c|}
\hline & Variable & Risikofaktoren \\
\hline \multirow[t]{2}{*}{ 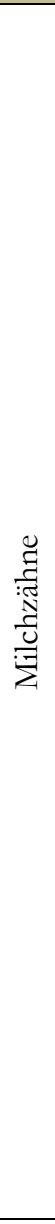 } & $\begin{array}{l}\text { Prävalenz für dentale } \\
\text { Erosionen }\end{array}$ & $\begin{array}{c}\text { BMI } \uparrow \\
(\mathrm{p}<0,001 ; \text { OR: } 1,013) \\
\text { Alter } \uparrow \\
(\mathrm{p}<0,001 ; \text { OR: } 1,381) \\
\text { Geschlecht } \\
(\mathrm{p}=0,011) \\
\text { Männlich (Referenz) } \\
\text { Weiblich (OR: } 0,737) \\
\text { Hintergrund } \\
(\mathrm{p}=0,010) \\
\text { Einheimischer }(\text { Referenz) } \\
\text { Migrant }(\text { OR: } 0,678) \\
\text { ICDAS-Wert } \\
(\mathrm{p}<0,001 ; \text { OR: } 0,668)\end{array}$ \\
\hline & BEWE-Summe & $\begin{array}{c}\text { BMI } \uparrow \\
(p=0,011 \text {; Estimate: } 0,002) \\
\text { Alter } \uparrow \\
(p<0,001 \text {; Estimate: } 0,103) \\
\text { Geschlecht } \\
(p<0,001) \\
\text { Männlich (Referenz) } \\
\text { Weiblich (Estimate: }-0,249) \\
\text { ICDAS-Wert } \\
(p<0,001 \text {; Estimate: }-0,102)\end{array}$ \\
\hline \multirow{3}{*}{ 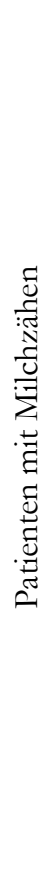 } & $\begin{array}{c}\text { Prävalenz für dentale } \\
\text { Erosionen }\end{array}$ & $\begin{array}{c}\text { BMI } \uparrow \\
(\mathrm{p}=0,015 ; \text { OR: } 1,025)\end{array}$ \\
\hline & $\begin{array}{c}\text { Betroffene } \\
\text { Zähne/Patient (\%) }\end{array}$ & $\begin{array}{c}\text { Metabolisches Syndrom } \\
(\mathrm{p}=0,046 ; \text { Estimate: } 0,171) \\
\text { Alter } \uparrow \\
(\mathrm{p}<0,001 ; \text { Estimate: } 0,042) \\
\text { Hintergrund } \\
(\mathrm{p}=0,017) \\
\text { Einheimischer }(\text { Referenz }) \\
\text { Migrant }(\text { Estimate: }-0,150)\end{array}$ \\
\hline & $\begin{array}{c}\text { Schweregrad } \\
\text { (BEWE-Summe) }\end{array}$ & $\begin{array}{c}\text { Geschlecht } \\
(\mathrm{p}=0,024) \\
\text { Männlich (Referenz) } \\
\text { Weiblich (Estimate: }-1,165) \\
\text { Verwendung von Zahnpasten mit einem Fluoridgeh- } \\
\text { alt entsprechend der DGZMK-Empfehlung } \\
(\mathrm{p}=0,004) \\
\text { Altersgerecht oder höher (Referenz) } \\
\text { Niedriger als empfohlen (Estimate: } 1,539)\end{array}$ \\
\hline
\end{tabular}




\subsubsection{Erosionen im bleibenden Gebiss}

\subsubsection{Prävalenz dentaler Erosionen}

Zahnebene

An den bleibenden Zähnen konnten in 2,3 \% der Fälle dentale Erosionen nachgewiesen werden, wovon $11,6 \%$ bis in das Dentin reichten.

Die Prävalenz erosiver Läsionen nahm innerhalb der Gewichtsgruppen signifikant zu. Während nur 1,0 \% der bleibenden Zähne normalgewichtiger Kinder dentale Erosionen aufwiesen, verzeichneten die bleibenden Zähne der adipösen Kinder bereits in 2,3 \% der Fälle Anzeichen erosiver Läsionen (Tabelle 3.13).

\subsection{Patientenebene}

Von den untersuchten Kindern mit bleibenden Zähnen wiesen 17,4 \% Anzeichen erosiver Läsionen auf (Tabelle 3.13).

Ein Großteil der Kinder bei denen erosive Zahnhartsubstanzdefekte nachgewiesen wurden, hatten ein bis fünf betroffene Zähne ( $\mathrm{n}=30 ; 14,4 \%$ ), fünf Kinder wiesen sechs bis zehn betroffene Zähne auf (2,9\%) und nur bei einem Kind konnten erosive Defekte an mehr als zehn Zähnen nachgewiesen werden.

\subsubsection{Schweregrad, Lokalisation und Verteilung dentaler Erosionen}

Zahnebene

Der durchschnittliche BEWE-Summenwert lag für die bleibenden Zähne bei 0,0 \pm 0,3.

Patientenebene

Die Mehrheit der untersuchten Kinder mit bleibenden Zähnen zeigte keine (BEWE-Summenwert zwischen null und zwei, $\mathrm{n}=119 ; 57,5 \%$ ) oder eine geringe Anfälligkeit für dentale Erosionen (BEWE-Summenwert zwischen drei und acht, $\mathrm{n}=77 ; 37,2 \%$ ), während ein kleiner Anteil der untersuchten Probanden eine mittlere Anfälligkeit für erosive Läsionen aufwies (BEWE-Summenwert zwischen neun und dreizehn, $\mathrm{n}=10 ; 4,8 \%$ ). BEWE-Summenwerte über 14 wies einer der untersuchten Probanden auf.

Der durchschnittliche BEWE-Summenwert lag bei 0,4 \pm 1,3. 
Tabelle 3.13: Prävalenz und Schweregrad dentaler Erosionen im bleibenden Gebiss und Wechselgebiss

\begin{tabular}{|c|c|c|c|c|}
\hline \multirow{2}{*}{} & \multicolumn{2}{|c|}{ Bleibende Zähne } & \multicolumn{2}{c|}{$\begin{array}{c}\text { Kinder und Jugendliche mit } \\
\text { bleibenden Zähnen }\end{array}$} \\
\cline { 2 - 5 } & Prävalenz (\%) & $\begin{array}{c}\text { BEWE- } \\
\text { Summe } \\
(\mathrm{M} \pm \text { SD })\end{array}$ & $\begin{array}{c}\text { PEẄ̈alenz (\%) } \\
\text { Summe } \\
\text { (M } \pm \text { SD) }\end{array}$ \\
\hline $\begin{array}{c}\text { Normalgewicht } \\
\text { (BMI-Perzentile 10-90) }\end{array}$ & $8(1,0 \%)$ & $0,0 \pm 0,2$ & $2(4,3 \%)$ & $0,1 \pm 0,3$ \\
\hline $\begin{array}{c}\text { Übergewicht } \\
\text { (BMI-Perzentile 90 - 97) }\end{array}$ & $2(0,4 \%)$ & $0,0 \pm 0,1$ & $1(4,0 \%)$ & $0,1 \pm 0,4$ \\
\hline $\begin{array}{c}\text { Adipositas } \\
\text { (BMI-Perzentile 97 - 99,5) }\end{array}$ & $42(2,3 \%)$ & $0,0 \pm 0,3$ & $20(22,0 \%)$ & $0,5 \pm 1,1$ \\
\hline $\begin{array}{c}\text { Extreme Adipositas } \\
\text { (BMI-Perzentile }>99,5)\end{array}$ & $43(4,3 \%)$ & $0,1 \pm 0,3$ & $13(28,9 \%)$ & $1,0 \pm 2,0$ \\
\hline
\end{tabular}

M: Mittelwert; SD: Standardabweichung

Anders als bei Patienten mit Milchzähnen fanden sich bei Patienten mit bleibenden Zähnen mehr Erosionen im Unterkiefer. Im Unterkiefer lag die Erosionsprävalenz bei 50,3 \% ( $\mathrm{n}=273$ betroffene Zähne), im Oberkiefer dagegen nur bei 49,7 \%.

Kinder mit bleibender Dentition zeigten die stärkste Erosionsprävalenz an den unteren Eckzähnen (Zahn 43: 7,6 \%), gefolgt von den oberen seitlichen Schneidezähnen (Zahn 22: $5,9 \%)$.

Ebenso wie bei Kindern mit Milchzähnen zeigte sich bei Kindern mit bleibenden Zähnen in der linken unteren Kieferhälfte eine niedrigere Erosionsprävalenz (44,7 \%) als in der rechten unteren Kieferhälfte (56,0 \%) (Abbildung 3.2). 
- BEWE 3 BEWE 2 BEWE 1

$55,0 \%$

$50,0 \%$

$45,0 \%$

$40,0 \%$

$35,0 \%$

$30,0 \%$

$25,0 \%$

$20,0 \%$

$15,0 \%$

$10,0 \%$

$5,0 \%$

$0,0 \%$

A
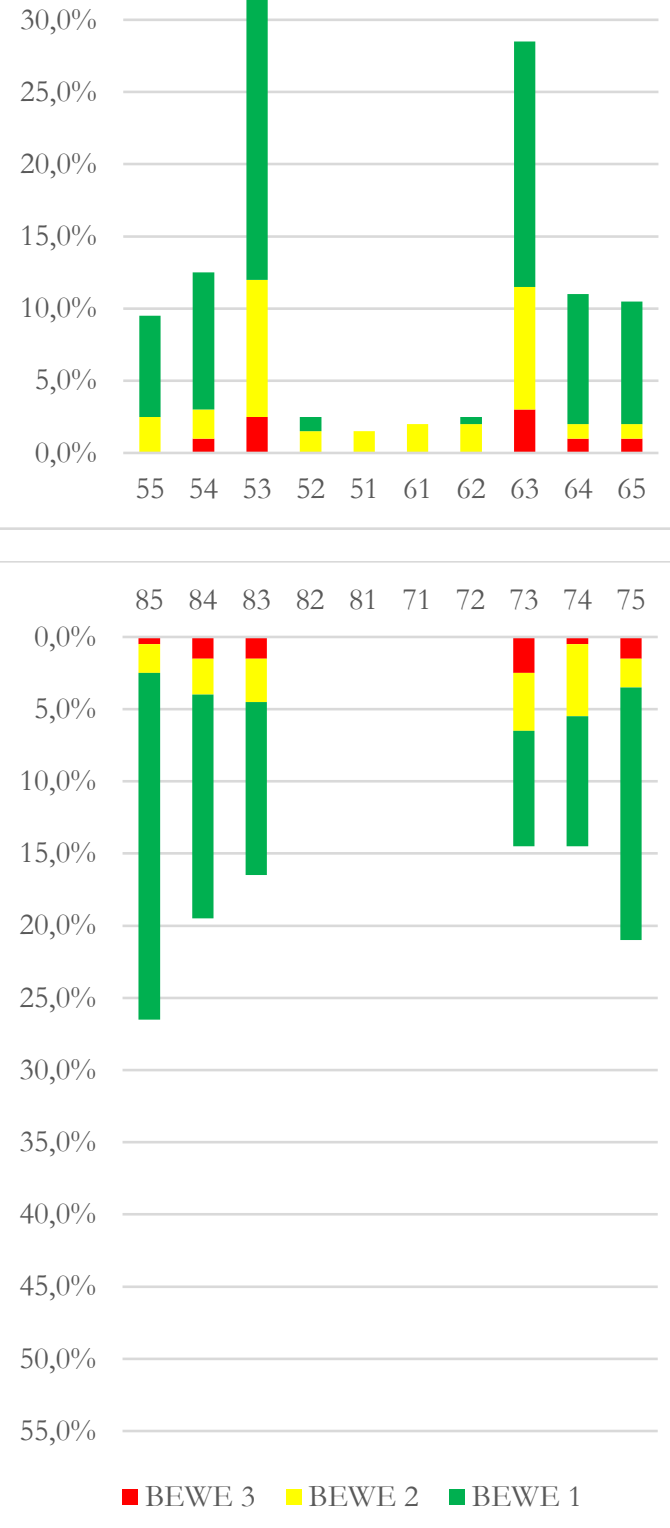

B

C

ロBEWE 3 BEWE 2 BEWE 1

$10,0 \%$

$9,0 \%$

$8,0 \%$

$7,0 \%$

$6,0 \%$

$5,0 \%$

$4,0 \%$

$3,0 \%$

$2,0 \%$

$1,0 \%$

$0,0 \%$

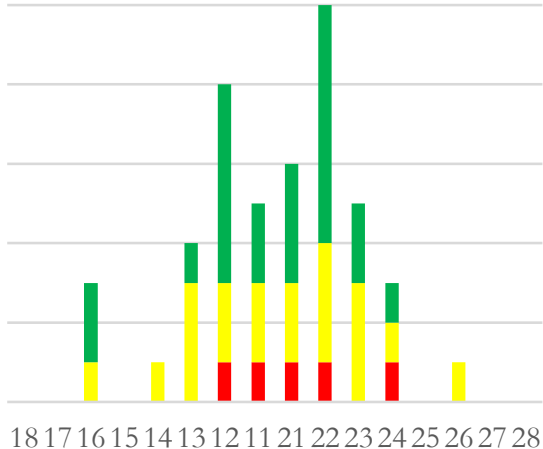

48474645444342413132333435363738

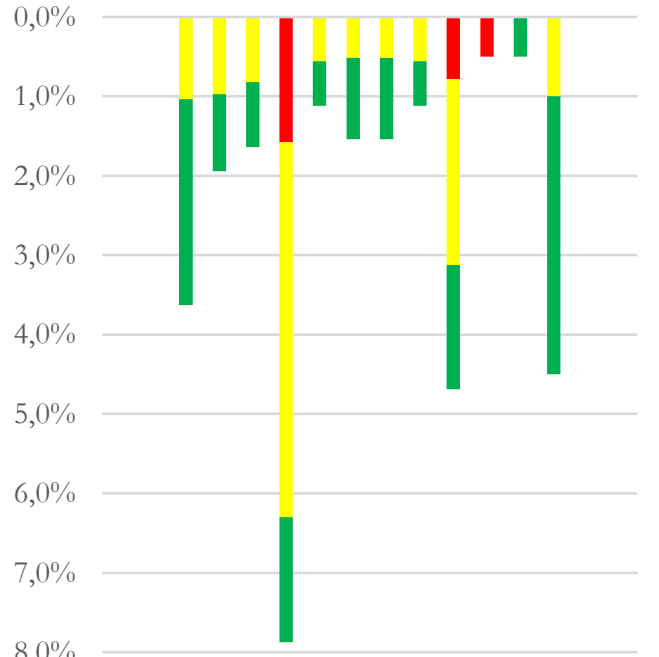

$9,0 \%$

$10,0 \%$

-BEWE 3 BEWE 2 BEWE 1

D

Abbildung 3.2. Prävalenz und Schweregrad dentaler Erosionen an den verschiedenen Zähnen bei Patienten im bleibenden Gebiss und Wechselgebiss: (A) Milchzähne (Oberkiefer), (B) Milchzähne (Unterkiefer), (C) Bleibende Zähne (Oberkiefer), (D) Bleibende Zähne (Unterkiefer) 
3.2.4.3 Einflussparameter auf die Erosionsprävalenz und den Schweregrad dentaler Erosionen

\subsection{Zahnebene}

In der explorativen Analyse konnten die Faktoren „Hintergrund“, „Häufigkeit erosiver Getränke“ und „Zahnputzgewohnheiten“ als signifikante Einflussfaktoren auf das Auftreten dentaler Erosionen an den bleibenden Zähnen nachgewiesen werden (Tabelle 3.14).

Hauptrisikofaktoren für die Schwere dentaler Erosionen waren ein steigendes Alter ( $p<0,001$; Estimate: 0,027), der Konsum erosiver Zwischenmahlzeiten ( $p=0,024$; Estimate: 0,087), eine steigende Anzahl an Geschwistern ( $p<0,001$; Estimate: 0,153) und das Vorliegen eines Migrationshintergrundes ( $p<0,001$; Estimate: 0,284).

\subsection{Patientenebene}

Hauptrisikofaktoren für das Auftreten dentaler Erosionen bei Kindern mit bleibenden Zähnen waren ein höherer BMI ( $p=0,045$; OR: 1,041) sowie ein steigendes Alter ( $p=0,002$; OR: 1,240$)$.

Hauptrisikofaktor für die Schwere dentaler Erosionen war für Kinder mit bleibenden Zähnen der Konsum erosiver Zwischenmahlzeiten ( $p=0,034$; Estimate: 1,500).

Der Prozentsatz der von Erosionen betroffenen Zähne stieg in der Gruppe mit bleibenden Zähnen für Kinder mit einem erhöhten BMI ( $p=0,039$; Estimate: 0,001). 
Tabelle 3.14: Risikofaktoren mit signifikantem Einfluss auf die Prävalenz und den Schweregrad dentaler Erosionen (zahn- und patientenbezogene Auswertung)

\begin{tabular}{|c|c|c|}
\hline & Variable & Risikofaktoren \\
\hline \multirow{2}{*}{ 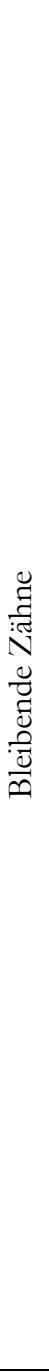 } & $\begin{array}{l}\text { Prävalenz für dentale } \\
\text { Erosionen }\end{array}$ & $\begin{array}{c}\text { Hintergrund } \\
(\mathrm{p}=0,010) \\
\text { Einheimischer (Referenz) } \\
\text { Migrant (OR: 2,013) } \\
\text { Häufigkeit erosiver Getränke } \\
(\mathrm{p}=0,049) \\
\text { Nie oder nicht mehr als wenige Mal pro Woche (Referenz) } \\
\text { Täglich oder mindestens mehrmals wöchentlich } \\
\text { (OR: 4,074) } \\
\text { Zahnputzgewohnheiten } \\
\text { Zähneputzen mit Handzahnbürste (Referenz) } \\
\text { Zähneputzen mit elektrischer Zahnbürste ( }>\text { >0,05; } \\
\text { OR: 0,649) } \\
\text { Zähneputzen mit elektrischer Zahnbürste und Handzahn- } \\
\text { bürste ( } \mathrm{p}=0,021 ; \text { OR: } 1,952)\end{array}$ \\
\hline & $\begin{array}{c}\text { Schweregrad } \\
\text { (BEWE-Summe) }\end{array}$ & $\begin{array}{c}\text { Alter } \uparrow \\
(p<0,001 ; \text { Estimate: } 0,027) \\
\text { Patient } \\
(p=0,003 \text {; Estimate: } 0,010) \\
\text { Art der Zwischenmahlzeiten } \\
(p=0,024) \\
\text { Nicht erosiv (Referenz) } \\
\text { Erosiv (Estimate: } 0,087) \\
\text { Anzahl Geschwister } \uparrow \\
(p<0,001 ; \text { Estimate: } 0,153) \\
\text { Hintergrund } \\
(p<0,001) \\
\text { Einmheimischer (Referenz) } \\
\text { Migrant (Estimate: } 0,284)\end{array}$ \\
\hline \multirow{2}{*}{ 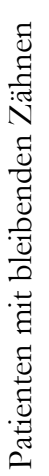 } & $\begin{array}{l}\text { Prävalenz für dentale } \\
\text { Erosionen }\end{array}$ & $\begin{array}{c}\text { BMI } \uparrow \\
(p=0,045 ; \text { OR: } 1,041) \\
\text { Alter } \uparrow \\
(p=0,002 ; \text { OR: } 1,240)\end{array}$ \\
\hline & $\begin{array}{l}\text { Betroffene Zähne/Patient } \\
(\%)\end{array}$ & $\begin{array}{c}\text { BMI } \uparrow \\
(p=0,039 ; \text { Estimate: } 0,001)\end{array}$ \\
\hline
\end{tabular}




\begin{tabular}{|c|c|c|}
\hline & Variable & Risikofaktoren \\
\hline 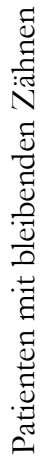 & $\begin{array}{c}\text { Schweregrad } \\
\text { (BEWE-Summe) }\end{array}$ & $\begin{array}{l}\text { Art der Zwischenmahlzeiten } \\
\qquad(p=0,034) \\
\text { Nicht erosiv (Referenz) } \\
\text { Erosiv (Estimate: } 1,500)\end{array}$ \\
\hline
\end{tabular}

p: p-Wert, OR: Odds Ratio

\subsection{Assoziation zwischen Karies und dentalen Erosionen}

Für (extrem) adipöse Kinder und Jugendliche mit Milchzähnen wurde sowohl auf Zahn- als auch auf Patientenebene eine inverse Beziehung zwischen erosiver Zahnhartsubstanzschädigung und Karies festgestellt. Ein schwacher Zusammenhang zwischen dentalen Erosionen und Karies konnte für normal- und übergewichtige Kinder und Jugendliche mit Milchzähnen auf Zahnebene ermittelt werden ( $\left.p=0,037 ; \mathrm{r}_{\mathrm{sp}}=-0,084\right)$. Im Vergleich zu Kindern ohne Karieserfahrung verzeichneten Kinder mit Karieserfahrung demnach höhere Prävalenzraten für erosive Zahnhartsubstanzdefekte.

Betrachtet man die bleibende Dentition konnte für normal- und übergewichtige Kinder und Jugendliche keiner $\left(\mathrm{D}_{1-6} \mathrm{MFT}>0, \mathrm{p}=0,008, \phi=0,007\right)$ oder nur ein geringer $\left(\mathrm{D}_{1-6}>0\right.$, $\mathrm{p}<0,001, \phi=0,132)$ direkter Zusammenhang zwischen dentalen Erosionen und Karies ermittelt werden. Für Kinder und Jugendliche mit (extremer) Adipositas waren sowohl auf Zahn- als auch auf Patientenebene dentale Erosionen und Karies assoziiert $(p \leq 0,005$; $\phi=0,110$ bis 0,267$)$ (Tabelle 3.15). 
Tabelle 3.15: Korrelation zwischen Prävalenz/Schweregrad von Karies und dentalen Erosionen auf Zahn- und Patientenebene für Patienten mit Normalgewicht bzw. Übergewicht und Adipositas bzw. extremer Adipositas

\begin{tabular}{|c|c|c|c|c|}
\hline & & Variable & $\begin{array}{l}\text { Normalgewicht } \\
\text { und } \\
\text { Übergewicht }\end{array}$ & $\begin{array}{l}\text { Adipositas } \\
\text { und } \\
\text { extreme } \\
\text { Adipositas } \\
\end{array}$ \\
\hline \multirow{5}{*}{ 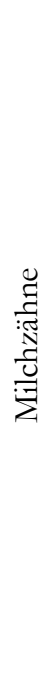 } & \multirow{4}{*}{ Erosionsprävalenz } & $\begin{array}{l}\text { Karieserfahrung } \\
\quad\left(\mathrm{d}_{1-6} \mathrm{mft}>0\right)\end{array}$ & $p>0,05$ & $\mathrm{p}>0,05$ \\
\hline & & $\begin{array}{l}\text { Karieserfahrung } \\
\quad\left(\mathrm{d}_{3-6} \mathrm{mft}>0\right)\end{array}$ & $\mathrm{p}>0,05$ & $p>0,05$ \\
\hline & & $\begin{array}{l}\text { Kariesprävalenz } \\
\qquad\left(\mathrm{d}_{1-6}>0\right)\end{array}$ & $p>0,05$ & $\begin{array}{c}\mathrm{p}<0,001 \\
\phi=0,139 *\end{array}$ \\
\hline & & $\begin{array}{l}\text { Kariesprävalenz } \\
\qquad\left(\mathrm{d}_{3-6}>0\right)\end{array}$ & $\mathrm{p}>0,05$ & $\mathrm{p}>0,05$ \\
\hline & $\begin{array}{l}\text { Schweregrad } \\
\text { (BEWE) }\end{array}$ & $\begin{array}{l}\text { Schweregrad } \\
\text { (ICDAS) }\end{array}$ & $\begin{aligned} \mathrm{p} & =0,037 \\
\mathrm{r}_{\mathrm{Sp}} & =-0,084\end{aligned}$ & $\begin{array}{c}\mathrm{p}<0,001 \\
\mathrm{r}_{\mathrm{Sp}}=-0,144\end{array}$ \\
\hline \multirow{8}{*}{ 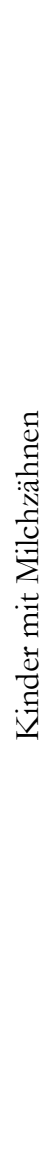 } & \multirow{4}{*}{ Erosionsprävalenz } & $\begin{array}{l}\text { Karieserfahrung } \\
\quad\left(\mathrm{d}_{1-6} \mathrm{mft}>0\right)\end{array}$ & $\mathrm{p}>0,05$ & $\mathrm{p}>0,05$ \\
\hline & & $\begin{array}{l}\text { Karieserfahrung } \\
\quad\left(\mathrm{d}_{3-6} \mathrm{mft}>0\right)\end{array}$ & $\mathrm{p}>0,05$ & $\begin{array}{c}\mathrm{p}=0,036 \\
\phi=0,244^{*}\end{array}$ \\
\hline & & $\begin{array}{l}\text { Kariesprävalenz } \\
\qquad\left(\mathrm{d}_{1-6}>0\right)\end{array}$ & $\mathrm{p}>0,05$ & $\mathrm{p}>0,05$ \\
\hline & & $\begin{array}{l}\text { Kariesprävalenz } \\
\qquad\left(\mathrm{d}_{3-6}>0\right)\end{array}$ & $\mathrm{p}>0,05$ & $\begin{array}{c}\mathrm{p}=0,034 \\
\phi=0,244^{*}\end{array}$ \\
\hline & \multirow{4}{*}{$\begin{array}{l}\text { Schweregrad } \\
\text { (BEWE) }\end{array}$} & $\mathrm{d}_{1-6 \mathrm{mft}}$ & $\mathrm{p}>0,05$ & $\mathrm{p}>0,05$ \\
\hline & & $\mathrm{d}_{3-6} \mathrm{mft}$ & $p>0,05$ & $\mathrm{p}>0,05$ \\
\hline & & $\begin{array}{c}\text { Betroffene Zähne pro } \\
\text { Patient } \\
\left(\%, \mathrm{~d}_{1-6} \mathrm{mft}\right)\end{array}$ & $p>0,05$ & $p>0,05$ \\
\hline & & $\begin{array}{c}\text { Betroffene Zähne pro } \\
\text { Patient } \\
\left(\%, \mathrm{~d}_{3-6 \mathrm{mft})}\right.\end{array}$ & $\mathrm{p}>0,05$ & $\mathrm{p}>0,05$ \\
\hline
\end{tabular}




\begin{tabular}{|c|c|c|c|c|}
\hline & & Variable & $\begin{array}{l}\text { Normalgewicht } \\
\text { und } \\
\text { Übergewicht }\end{array}$ & $\begin{array}{l}\text { Adipositas } \\
\text { und } \\
\text { extreme } \\
\text { Adipositas } \\
\end{array}$ \\
\hline \multirow{5}{*}{ 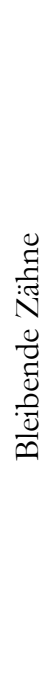 } & \multirow{4}{*}{ Erosionsprävalenz } & $\begin{array}{c}\text { Karieserfahrung } \\
\left(\mathrm{D}_{1-6} \mathrm{MFT}>0\right)\end{array}$ & $\begin{array}{l}\mathrm{p}=0,008 \\
\phi=0,077\end{array}$ & $\begin{array}{l}\mathrm{p}=0,009 \\
\phi=0,050\end{array}$ \\
\hline & & $\begin{array}{c}\text { Karieserfahrung } \\
\left(\mathrm{D}_{1-6} \mathrm{MFT}>0\right)\end{array}$ & $\mathrm{p}>0,05$ & $\begin{array}{l}\mathrm{p}<0,001 \\
\phi=0,262\end{array}$ \\
\hline & & $\begin{array}{l}\text { Kariesprävalenz } \\
\qquad\left(\mathrm{D}_{1-6}>0\right)\end{array}$ & $\begin{array}{l}\mathrm{p}<0,001 \\
\phi=0,132\end{array}$ & $\begin{array}{l}\mathrm{p}<0,001 \\
\phi=0,110\end{array}$ \\
\hline & & $\begin{array}{l}\text { Kariesprävalenz } \\
\quad\left(\mathrm{D}_{3-6}>0\right)\end{array}$ & $\mathrm{p}>0,05$ & $\begin{array}{l}\mathrm{p}<0,001 \\
\phi=0,248\end{array}$ \\
\hline & $\begin{array}{l}\text { Schweregrad } \\
\text { (BEWE) }\end{array}$ & $\begin{array}{l}\text { Schweregrad } \\
\text { (ICDAS) }\end{array}$ & $\mathrm{p}>0,05$ & $\mathrm{p}>0,05$ \\
\hline \multirow{8}{*}{ 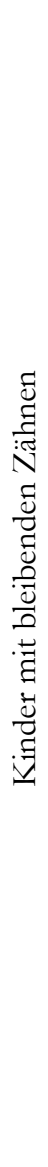 } & \multirow{4}{*}{ Erosionsprävalenz } & $\begin{array}{c}\text { Karieserfahrung } \\
\left(\mathrm{D}_{1-6} \mathrm{MFT}>0\right)\end{array}$ & $\mathrm{p}>0,05$ & $\mathrm{p}>0,05$ \\
\hline & & $\begin{array}{c}\text { Karieserfahrung } \\
\left(\mathrm{D}_{3-6} \mathrm{MFT}>0\right)\end{array}$ & $\mathrm{p}>0,05$ & $\begin{array}{l}\mathrm{p}=0,005 \\
\phi=0,267\end{array}$ \\
\hline & & $\begin{array}{l}\text { Kariesprävalenz } \\
\left(\mathrm{D}_{1-6}>0\right)\end{array}$ & $\mathrm{p}>0,05$ & $\mathrm{p}>0,05$ \\
\hline & & $\begin{array}{l}\text { Kariesprävalenz } \\
\qquad\left(\mathrm{D}_{3-6}>0\right)\end{array}$ & $\mathrm{p}>0,05$ & $\mathrm{p}>0,05$ \\
\hline & \multirow{4}{*}{$\begin{array}{l}\text { Schweregrad } \\
\text { (BEWE) }\end{array}$} & $\mathrm{D}_{1-6} \mathrm{MFT}$ & $\mathrm{p}>0,05$ & $\mathrm{p}>0,05$ \\
\hline & & $\mathrm{D}_{3-6} \mathrm{MFT}$ & $\mathrm{p}>0,05$ & $\begin{array}{l}\mathrm{p}=0,005 \\
\mathrm{r}_{\mathrm{Sp}}=0,243\end{array}$ \\
\hline & & $\begin{array}{c}\text { Betroffene Zähne pro } \\
\text { Patient } \\
\left(\%, \mathrm{D}_{1-6} \mathrm{MFT}\right)\end{array}$ & $\mathrm{p}>0,05$ & $\mathrm{p}>0,05$ \\
\hline & & $\begin{array}{c}\text { Betroffene Zähne pro } \\
\text { Patient } \\
\left(\%, \mathrm{D}_{3-6} \mathrm{MFT}\right)\end{array}$ & $\mathrm{p}>0,05$ & $\begin{array}{l}\mathrm{p}=0,009 \\
\mathrm{r}_{\mathrm{Sp}}=0,222\end{array}$ \\
\hline
\end{tabular}

p: p-Wert, $\mathrm{r}_{\mathrm{Sp}}$ : Spearman-Korrelation, $\phi$ : Phi-Koeffizient *inverse Korrelation 


\subsection{Ergebnisse der Speichelanalyse}

Die Einwilligung zur Entnahme einer Speichelprobe lag bei 223 Kindern vor. Aufgrund der häufig altersbedingt eingeschränkten Compliance einiger Patienten konnten jedoch nur bei 75 Kindern und Jugendlichen unstimulierte und stimulierte Speichelproben gewonnen werden.

Tabelle 3.16 gibt einen Überblick über die Speichelparameter in den einzelnen Gewichtsgruppen.

Tabelle 3.16: Speichelfließrate, Speichel-pH-Wert und Pufferkapazität des unstimulierten und stimulierten Speichels bei normalgewichtigen, übergewichtigen, adipösen und extrem adipösen Kindern und Jugendlichen

\begin{tabular}{|c|c|c|c|c|c|c|c|c|c|c|c|c|}
\hline & \multicolumn{2}{|c|}{$\begin{array}{l}\text { Speichel- } \\
\text { fließrate } \\
{[\mathrm{ml}] \text { in }} \\
\text { Ruhe }\end{array}$} & \multicolumn{2}{|c|}{$\begin{array}{l}\text { Stimulierte } \\
\text { Speichel- } \\
\text { fließrate } \\
\text { [ml] }\end{array}$} & \multicolumn{2}{|c|}{$\begin{array}{l}\text { Speichel- } \\
\text { pH-Wert in } \\
\text { Ruhe }\end{array}$} & \multicolumn{2}{|c|}{$\begin{array}{l}\text { Stimulierter } \\
\text { Speichel- } \\
\text { pH-Wert }\end{array}$} & \multicolumn{2}{|c|}{$\begin{array}{l}\text { Pufferkapa- } \\
\text { zität in } \\
\text { Ruhe }\end{array}$} & \multicolumn{2}{|c|}{$\begin{array}{c}\text { Stimulierte } \\
\text { Pufferka- } \\
\text { pazität }\end{array}$} \\
\hline & 光. & $\begin{array}{l}3 \\
1+ \\
0\end{array}$ & $\frac{2}{2}$ & $\begin{array}{l}3 \\
1+ \\
0\end{array}$ & $\frac{2}{2}$ & $\begin{array}{l}3 \\
1+ \\
0\end{array}$ & 岗 & $\begin{array}{l}2 \\
1+ \\
0\end{array}$ & 疋 & $\begin{array}{l}2 \\
1+ \\
\Leftrightarrow\end{array}$ & 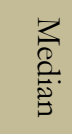 & $\begin{array}{l}3 \\
1+ \\
6\end{array}$ \\
\hline $\begin{array}{c}\text { Speichelproben } \\
\text { normalgewichtiger } \\
\text { Kinder und } \\
\text { Jugendlicher } \\
(\mathrm{n}=12 ; 16,2 \%)\end{array}$ & 0,6 & $\begin{array}{l}0,7 \\
\pm \\
0,5\end{array}$ & 1,4 & $\begin{array}{l}1,5 \\
\pm \\
0,6\end{array}$ & 7,6 & $\begin{array}{l}7,5 \\
\pm \\
0,4\end{array}$ & 7,7 & $\begin{array}{l}7,6 \\
\pm \\
0,3\end{array}$ & 8,0 & $\begin{array}{l}9,2 \\
\pm \\
1,8\end{array}$ & 12,0 & $\begin{array}{l}10,2 \\
\pm \\
3,1\end{array}$ \\
\hline $\begin{array}{l}\text { Speichelproben } \\
\text { übergewichtiger } \\
\text { Kinder und } \\
\text { Jugendlicher } \\
(\mathrm{n}=11 ; 14,9 \%)\end{array}$ & 0,6 & $\begin{array}{l}0,7 \\
\pm \\
0,5\end{array}$ & 1,0 & $\begin{array}{l}1,3 \\
\pm \\
0,7\end{array}$ & 7,3 & $\begin{array}{l}7,2 \\
\pm \\
0,3\end{array}$ & 7,4 & $\begin{array}{l}7,4 \\
\pm \\
0,2\end{array}$ & 8,0 & $\begin{array}{l}7,2 \\
\pm \\
1,7\end{array}$ & 12,0 & $\begin{array}{l}10,2 \\
\pm \\
2,0\end{array}$ \\
\hline $\begin{array}{l}\text { Speichelproben } \\
\text { adipöser Kinder } \\
\text { und Jugendlicher } \\
(\mathrm{n}=33 ; 44,6 \%)\end{array}$ & 0,6 & $\begin{array}{l}0,7 \\
\pm \\
0,4\end{array}$ & 1,2 & $\begin{array}{c}1,3 \\
\pm \\
0,5\end{array}$ & 7,3 & $\begin{array}{c}7,3 \\
\pm \\
0,3\end{array}$ & 7,5 & $\begin{array}{c}7,5 \\
\pm \\
0,3\end{array}$ & 8,0 & $\begin{array}{c}7,7 \\
\pm \\
2,7\end{array}$ & 12,0 & $\begin{array}{c}10,1 \\
\pm \\
2,3\end{array}$ \\
\hline $\begin{array}{l}\text { Speichelproben } \\
\text { extrem adipöser } \\
\text { Kinder und } \\
\text { Jugendlicher } \\
(\mathrm{n}=18 ; 24,3 \%)\end{array}$ & 0,6 & $\begin{array}{c}0,6 \\
\pm \\
0,5\end{array}$ & 1,4 & $\begin{array}{c}1,5 \\
\pm \\
0,4\end{array}$ & 7,1 & $\begin{array}{c}7,1 \\
\pm \\
0,3\end{array}$ & 7,3 & $\begin{array}{c}7,2 \\
\pm \\
0,2\end{array}$ & 8,0 & $\begin{array}{c}7,4 \\
\pm \\
2,2\end{array}$ & 12,0 & $\begin{array}{c}10,3 \\
\pm \\
2,8\end{array}$ \\
\hline Gesamt & 0,6 & $\begin{array}{c}0,7 \\
\pm \\
0,4\end{array}$ & 1,4 & $\begin{array}{c}1,4 \\
\pm \\
0,5\end{array}$ & 7,3 & $\begin{array}{c}7,3 \\
\pm \\
0,3\end{array}$ & 7,4 & $\begin{array}{c}7,4 \\
\pm \\
0,3\end{array}$ & 8,0 & $\begin{array}{c}7,8 \\
\pm \\
2,3\end{array}$ & 12,0 & $\begin{array}{c}10,2 \\
\pm \\
2,3\end{array}$ \\
\hline
\end{tabular}


In Bezug auf die Speichelfließrate sowie die Pufferkapazität gab es keine signifikanten Unterschiede zwischen den Gewichtsgruppen ( $\mathrm{p}>0,05)$.

In Bezug auf den Speichel-pH-Wert zeigten sich signifikante Unterschiede zwischen den normalgewichtigen und extrem adipösen Kindern und Jugendlichen ( $\mathrm{p}_{\text {Ruhe }}=0,016$, $\mathrm{pstimu-}$ liert $=0,003)$.

Tabelle 3.17 und 3.18 zeigen eine Auflistung der verschiedenen Speichelparameter für Probanden mit und ohne Karies sowie für Probanden mit und ohne Erosionen.

Tabelle 3.17: Vergleich der Ergebnisse der Speichelproben bei Kindern mit und ohne Karieserfahrung $\left(\mathrm{D}_{1-6} \mathrm{MFT} / \mathrm{d}_{1-6} \mathrm{mft}>0\right)$

\begin{tabular}{|c|c|c|c|c|c|c|c|c|c|c|c|c|}
\hline & \multicolumn{2}{|c|}{$\begin{array}{l}\text { Speichel- } \\
\text { fließrate } \\
{[\mathrm{ml}] \text { in }} \\
\text { Ruhe }\end{array}$} & \multicolumn{2}{|c|}{$\begin{array}{c}\text { Stimulierte } \\
\text { Speichel- } \\
\text { fließrate } \\
\text { [ml] }\end{array}$} & \multicolumn{2}{|c|}{$\begin{array}{l}\text { Speichel- } \\
\text { pH-Wert in } \\
\text { Ruhe }\end{array}$} & \multicolumn{2}{|c|}{$\begin{array}{l}\text { Stimulierter } \\
\text { Speichel- } \\
\text { pH-Wert }\end{array}$} & \multicolumn{2}{|c|}{$\begin{array}{c}\text { Pufferkapa- } \\
\text { zität in } \\
\text { Ruhe }\end{array}$} & \multicolumn{2}{|c|}{$\begin{array}{c}\text { Stimulierte } \\
\text { Pufferkapa- } \\
\text { zität }\end{array}$} \\
\hline & 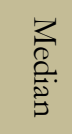 & $\begin{array}{l}3 \\
1+ \\
0\end{array}$ & 疋 & $\begin{array}{l}2 \\
1+ \\
0\end{array}$ & 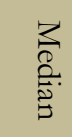 & $\begin{array}{l}3 \\
1+ \\
0\end{array}$ & 交 & $\begin{array}{l}2 \\
1+ \\
0\end{array}$ & $\frac{2}{2}$ & $\begin{array}{l}3 \\
1+ \\
6\end{array}$ & 光. & $\begin{array}{l}3 \\
1+ \\
0\end{array}$ \\
\hline $\begin{array}{l}\text { Kinder mit } \\
\text { Karies } \\
(\mathrm{n}=25)\end{array}$ & 0,7 & $\begin{array}{c}0,7 \\
\pm \\
0,4\end{array}$ & 1,5 & $\begin{array}{l}1,5 \\
\pm \\
0,5\end{array}$ & 7,2 & $\begin{array}{l}7,2 \\
\pm \\
0,3\end{array}$ & 7,4 & $\begin{array}{l}7,4 \\
\pm \\
0,3\end{array}$ & 8,0 & $\begin{array}{l}7,3 \\
\pm \\
2,4\end{array}$ & 11,5 & $\begin{array}{l}10,1 \\
\pm \\
2,1\end{array}$ \\
\hline $\begin{array}{c}\text { Kinder ohne } \\
\text { Karies } \\
(n=50)\end{array}$ & 0,6 & $\begin{array}{c}0,6 \\
\pm \\
0,4\end{array}$ & 1,4 & $\begin{array}{l}1,3 \\
\pm \\
0,6\end{array}$ & 7,3 & $\begin{array}{l}7,3 \\
\pm \\
0,2\end{array}$ & 7,5 & $\begin{array}{l}7,5 \\
\pm \\
0,3\end{array}$ & 8,0 & $\begin{array}{l}8,2 \\
\pm \\
2,3\end{array}$ & 12,0 & $\begin{array}{c}10,2 \\
\pm \\
2,5\end{array}$ \\
\hline
\end{tabular}

M: Mittelwert; SD: Standardabweichung 
Tabelle 3.18: Vergleich der Ergebnisse der Speichelproben bei Kindern mit und ohne Erosionen

\begin{tabular}{|c|c|c|c|c|c|c|c|c|c|c|c|c|}
\hline & \multicolumn{2}{|c|}{$\begin{array}{l}\text { Speichel- } \\
\text { fließrate } \\
{[\mathrm{ml}] \text { in }} \\
\text { Ruhe }\end{array}$} & \multicolumn{2}{|c|}{$\begin{array}{c}\text { Stimulierte } \\
\text { Speichel- } \\
\text { fließrate } \\
\text { [ml] }\end{array}$} & \multicolumn{2}{|c|}{$\begin{array}{l}\text { Speichel- } \\
\text { pH-Wert in } \\
\text { Ruhe }\end{array}$} & \multicolumn{2}{|c|}{$\begin{array}{l}\text { Stimulierter } \\
\text { Speichel- } \\
\text { pH-Wert }\end{array}$} & \multicolumn{2}{|c|}{$\begin{array}{c}\text { Pufferkapa- } \\
\text { zität in } \\
\text { Ruhe }\end{array}$} & \multicolumn{2}{|c|}{$\begin{array}{c}\text { Stimulierte } \\
\text { Pufferkapa- } \\
\text { zität }\end{array}$} \\
\hline & $\begin{array}{l}\frac{2}{2} \\
\frac{2}{2} \\
\frac{7}{0}\end{array}$ & $\begin{array}{l}3 \\
1+ \\
0\end{array}$ & 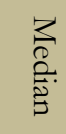 & $\begin{array}{l}3 \\
1+ \\
0\end{array}$ & 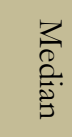 & $\begin{array}{l}3 \\
1+ \\
6\end{array}$ & $\begin{array}{l}\frac{2}{2} \\
\frac{2}{2} \\
\frac{2}{5}\end{array}$ & $\begin{array}{l}2 \\
1+ \\
6\end{array}$ & 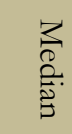 & $\begin{array}{l}3 \\
1+ \\
0\end{array}$ & $\begin{array}{l}\stackrel{2}{2} \\
\stackrel{2}{2} \\
\stackrel{0}{0}\end{array}$ & $\begin{array}{l}2 \\
1+ \\
0\end{array}$ \\
\hline $\begin{array}{l}\text { Kinder mit } \\
\text { Erosionen } \\
(\mathrm{n}=37)\end{array}$ & 0,6 & $\begin{array}{l}0,6 \\
\pm \\
0,3\end{array}$ & 1,2 & $\begin{array}{l}1,3 \\
\pm \\
0,5\end{array}$ & 7,3 & $\begin{array}{l}7,2 \\
\pm \\
0,3\end{array}$ & 7,4 & $\begin{array}{l}7,5 \\
\pm \\
0,3\end{array}$ & 8,0 & $\begin{array}{l}7,5 \\
\pm \\
2,2\end{array}$ & 12,0 & $\begin{array}{l}10,3 \\
\pm \\
2,1\end{array}$ \\
\hline $\begin{array}{l}\text { Kinder ohne } \\
\text { Erosionen } \\
(\mathrm{n}=38)\end{array}$ & 0,6 & $\begin{array}{l}0,8 \\
\pm \\
0,5\end{array}$ & 1,4 & $\begin{array}{l}1,5 \\
\pm \\
0,6\end{array}$ & 7,3 & $\begin{array}{l}7,3 \\
\pm \\
0,4\end{array}$ & 7,4 & $\begin{array}{l}7,4 \\
\pm \\
0,3\end{array}$ & 8,0 & $\begin{array}{l}8,1 \\
\pm \\
2,5\end{array}$ & 12,0 & $\begin{array}{c}10,1 \\
\pm \\
2,6\end{array}$ \\
\hline
\end{tabular}

M: Mittelwert; SD: Standardabweichung

Eine weiterführende Analyse der Speichelproben war aufgrund der geringen Anzahl betroffener Patienten in der Gruppe normalgewichtiger Kinder (Erosionen $n=6$, Karies $\left.\mathrm{n}_{\mathrm{d} 1-6 \mathrm{mft}}=2\right)$ nicht möglich. 


\section{Diskussion}

\subsection{Diskussion der Methode}

\subsubsection{Indizes}

Zur Diagnostik und Klassifikation von Karies und dentalen Erosionen stehen eine Vielzahl verschiedener Indizes zur Verfügung. Die große Bandbreite verwendeter epidemiologischer Indizes aus bereits publizierten Studien erschwert die Vergleichbarkeit der in der Literatur beschriebenen Prävalenzraten. Ein Index sollte sich durch seine einfache Anwendung und Reproduzierbarkeit auszeichnen und die Beschreibung von Häufigkeiten, Verteilungen und Ursachen von Erkrankungen einer Population ermöglichen. Die klinische Untersuchung der Teilnehmer wurde mit Hilfe von Indizes durchgeführt, welche international für zahnärztliche Untersuchungen empfohlen wurden (Bartlett et al. 2008; Bourgeois et al. 2008).

In der vorliegenden Studie erfolgte die Einschätzung kariöser Läsionen neben dem visuellen Kariesdiagnosesystem ICDAS-II auch mit Hilfe des DMFT-/dmft- bzw. des DT-/dt-Index nach Klein et al. (1938). Erosive Läsionen wurden mit Hilfe des BEWE-Index klassifiziert (Bartlett et al. 2008). Die Intra- und Interobserverreliabilitäten waren moderat bis hoch und bestätigten die Reproduzierbarkeit der Messungen.

Mit Hilfe von ICDAS-II ist sowohl die Diagnostik initialer als auch manifester kariöser Veränderungen an Okklusal- und Glattflächen möglich.

Jablonski-Momeni et al. (2008) untersuchten an 100 extrahierten humanen Zähnen die Reproduzierbarkeit und Genauigkeit des visuellen Kariesdiagnosesystems ICDAS-II in der Diagnostik einer okklusalen Karies und verglichen die Ergebnisse mit denen einer elektrischen Widerstandsmessung und fiberoptischen Transillumination. Das ICDAS-II-System bewährte sich in seiner Reproduzierbarkeit und Diagnosegenauigkeit für den Nachweis einer okklusalen Karies in verschiedenen Stadien des Krankheitsprozesses. Die visuelle Inspektion mit Hilfe des ICDAS-II stellt dabei ein probates Mittel zur genauen, reproduzierbaren und schnellen Kariesdiagnostik dar.

Der DMFT- bzw. DT-Index summiert die zerstörten, fehlenden oder restaurativ versorgten Zahnflächen. ICDAS-II erfasst zusätzlich den Kariesprozess bezüglich seiner Ausdehnung (Kavität ja/nein) und seiner Aktivität (aktiv oder arretiert) und ermöglicht die Einteilung verschiedener Cut-Off-Punkte für D/d des DMFT/dmft. 
Der BEWE-Index stellt einen gebräuchlichen Index für die Diagnose und den Umgang mit dentalen Erosionen bei Kindern dar und fand bereits im Rahmen der Fünften Deutschen Mundgesundheitsstudie Anwendung (Micheelis und Jordan 2016).

\subsubsection{Fragebogen}

Mit Hilfe eines Fragebogens wurden am Untersuchungstag demographische Daten (Alter, Geschlecht, Nationalität, Netto-Haushaltseinkommen), die Ernährungsgewohnheiten, das Zahnputzverhalten sowie das Vorliegen von weiteren möglichen Einflussfaktoren, die potenziell mit Karies und Erosionen assoziiert werden können, erfragt. Die Gestaltung des Fragebogens erfolgte in Anlehnung an den Fragebogen der Vierten Deutschen Mundgesundheitsstudie (Micheelis und Schiffner 2006).

Anamnesebögen stellen ein probates Mittel der Datenerhebung dar und fanden bereits in zahlreichen epidemiologischen Studien bei Kindern Anwendung (Tong et al. 2014; Tschammler et al. 2016; Wiegand et al. 2006; Willershausen et al. 2007).

Bei der Auswertung eines Fragebogens bleibt jedoch immer ungewiss, ob alle Eltern die Beantwortung der Fragen wahrheitsgemäß ausgeführt haben oder ob zur Verdeckung des eigenen Fehlverhaltens, insbesondere bei den Fragen zu Ernährungs- und Zahnputzgewohnheiten, nicht doch häufig bessere Angaben gemacht wurden. Einige Kinder und Jugendliche hatten ihre Ernährung bereits im Hinblick auf die Behandlung ihrer Fettleibigkeit geändert, sodass die Ernährungsweise, welche potenziell zu Karies oder dentalen Erosionen führte, nicht herausgearbeitet werden konnte.

Insbesondere für Familien mit Migrationshintergrund kann die Beantwortung eines Fragebogens auch eine sprachliche Barriere darstellen, die es zu berücksichtigen gilt. Bei der Erstellung des Fragebogens wurde daher auf eine leichte Verständlichkeit der Fragen geachtet. Zudem fand im Rahmen dieser Studie die Beantwortung der Fragen parallel zur Untersuchung des Kindes statt, sodass Unklarheiten seitens der Eltern jederzeit mit der Zahnärztin besprochen werden konnten. Die Erstellung eines mehrsprachigen Fragebogens, wie er mittlerweile auch in zahlreichen Kliniken und Zahnarztpraxen zur Anwendung kommt, könnte die Durchführung zukünftiger Studien jedoch zusätzlich erleichtern.

Die anfängliche Befürchtung, dass die Frage über das monatliche Netto-Haushaltseinkommen bei den Eltern auf Ablehnung stoßen würde, hat sich im Laufe der Studie nicht bewahrheitet. Sie wurde von der Mehrzahl der Eltern beantwortet (78,5\%). 


\subsubsection{Speichelprobe}

Die Entnahme einer unstimulierten und stimulierten Speichelprobe diente der Untersuchung von Speichelfließrate, Speichel-pH-Wert und Pufferkapazität.

Bisher gibt es nur eine geringe Anzahl epidemiologischer Studien, welche die Speichelparameter bei Kindern sowie deren Einfluss auf das Vorkommen von Karies und dentalen Erosionen untersucht haben (Jaeggi und Lussi 2004; Modeer et al. 2010; Tong et al. 2014; Wang et al. 2011; Wiegand et al. 2006). Eines der Hauptprobleme stellt dabei die Gewinnung einer Speichelprobe insbesondere bei jüngeren Kindern dar.

Aufgrund dieses Problems konnten im Rahmen der vorliegenden Studie nur bei einem geringen Anteil (33,6\%) an Kindern und Jugendlichen Speichelproben gewonnen werden. Die erhobenen Speichelparameter mussten deswegen aus der multifaktoriellen Analyse ausgeschlossen werden. Es war lediglich eine deskriptive Analyse möglich.

Die Menge des gesammelten Speichels wurde durch das Wiegen der mit Speichel gefüllten kalibrierten Plastikbecher auf einer Waage in g ermittelt. Zum Erhalt der Fließrate in $\mathrm{ml} / \mathrm{min}$ erfolgte die Multiplikation des Gewichts mit der Dichte des Speichels.

Die Dichte des Speichels ist ein in der Literatur kontrovers diskutierter Wert mit einer Schwankung von 1,0024 bis 1,012 (Shannon 1973). Im Rahmen dieser Studie wurde die Dichte entsprechend der Autoren Jenkins und Edgar (1989) und Jensen et al. (1998) gleich $1 \mathrm{~g} / \mathrm{ml}$ gesetzt.

Die Untersuchung des Speichel-pH-Werts erfolgte direkt im Anschluss an die Entnahme der Speichelprobe unter Verwendung eines kalibrierten $\mathrm{pH}-$ Meters.

Zur Bestimmung der Pufferkapazität des Speichels fanden industriell genormte Teststreifen (Saliva-Check BUFFER, GC Germany, Bad Homburg, Deutschland) Verwendung. Maldupa et al. (2011) testeten die Genauigkeit dieser Teststreifen und der des CRT® Buffer Strips und verglichen die Ergebnisse mit dem Goldstandard der Speichel-pH-Wert-Messung, der labortechnischen Titration nach Ericsson. Der im Rahmen der vorliegenden Studie verwendete Saliva-Check BUFFER gehört zu den kolorimetrischen Testverfahren und zeichnet sich insbesondere durch seine einfache Handhabung aus. Maldupa et al. (2011) ermittelten insbesondere für den GC Saliva-Check BUFFER eine positive Korrelation mit dem labortechnischen Verfahren der Titration (Spearman Rank, $\mathrm{r}_{\mathrm{s}}=0,837$ ) und eine hohe Genauigkeit, weshalb wir uns für die Verwendung dieser Teststreifen entschieden haben. Die Saliva-Check BUFFER Teststreifen zur Messung der Pufferkapazität des Speichels fanden auch in einer kariesepidemiologischen Studie von Singh et al. (2015) Anwendung. 


\subsection{Diskussion der Ergebnisse}

\subsubsection{Ergebnisse der zahnärztlichen Untersuchung}

\subsubsection{Karies im Milchgebiss}

\subsection{Kariesprävalenz}

Die Kariesprävalenz der untersuchten Kinder mit Milchzähnen lag bei 57,1 \% in Bezug auf den $\mathrm{d}_{1-6} \mathrm{mft}-$ Index. Invasiv behandlungsbedürftige Läsionen fanden sich bei 44,3 \% der untersuchten Kinder $\left(\mathrm{d}_{3-6} \mathrm{mft}>0\right)$.

Betrachtet man ausschließlich die Gruppe der normalgewichtigen Kinder mit Milchzähnen ( $\mathrm{n}=38$; Durchschnittsalter 7,6 $\pm 2,6)$ lag die Kariesprävalenz bei 50,0 \% ( $\left.\mathrm{d}_{1-6 \mathrm{mft}}>0\right)$. Bei $39,5 \%$ der untersuchten normalgewichtigen Kinder lagen invasiv behandlungsbedürftige kariöse Läsionen vor. Diese Daten liegen im Einklang mit anderen deutschen Studien:

Im Rahmen der epidemiologischen Begleituntersuchungen zur Gruppenprophylaxe wurden 151.555 6- bis 7-jährige Kinder untersucht. Die Prävalenz für kariöse Läsionen lag bei 43,6 \%, unter Berücksichtigung initialkariöser Läsionen bei 50,1 \%. Betrachtet man ausschließlich die Ergebnisse für Niedersachsen, lag die Kariesprävalenz für 2.281 untersuchte 6- bis 7-jährige Kinder mit Milchzähnen bei 43,2\%. Unter Berücksichtigung der initialkariösen Läsionen reduzierte sich der Prozentsatz kariesfreier Gebisse auf 50,9 \% (Basner et al. 2017).

Sabel (2012) untersuchte 1.643 3- bis 6-jährige Kinder in Hamburg. Unter Berücksichtigung von $\mathrm{d}_{1^{-}}$(initiale Schmelzläsionen) und $\mathrm{d}_{2^{-}}$(geringe, auf den Schmelz beschränkte Kavitation) Läsionen wiesen 50,8 \% kariöse Zahnhartsubstanzdefekte auf.

In einer Studie aus dem Nordosten Italiens wurden 260 5-jährige Kinder untersucht und der Zahnstatus der eingeborenen Kinder mit dem der eingewanderten Kinder mit Migrationshintergrund verglichen. Die Kariesprävalenz lag bei 34,2 \%. Von den Kindern mit Migrationshintergrund waren durchschnittlich nur 25,0\% der Gebisse frei von Karies $(p<0,001)$, verglichen mit 65,8 \% unter den italienischen Kindern (Ferro et al. 2007).

In der vorliegenden Studie wurden lediglich acht Kinder mit Milchgebiss und Migrationshintergrund untersucht. Insofern sind die Aussagen zur Kariesprävalenz (50,0 \%, $\left.\mathrm{d}_{1-6 \mathrm{mft}}>0\right)$ limitiert. 


\subsection{Karieserfahrung}

Das Ausmaß der Karieserfahrung wurde anhand des $\mathrm{d}_{1-6} \mathrm{mft}-$ und $\mathrm{d}_{3-6} \mathrm{mft}-$ Index analysiert. Der durchschnittliche $\mathrm{d}_{1-6} \mathrm{mft}-$ Wert lag innerhalb der Gruppe der normalgewichtigen Kinder mit Milchzähnen bei 1,4 \pm 2,2 Zähnen, der durchschnittliche $\mathrm{d}_{3-6} \mathrm{mft}$-Wert bei $0,9 \pm 1,9$.

Eine höhere Karieserfahrung verglichen mit den Ergebnissen der vorliegenden Arbeit zeigten 2.281 6- bis 7-jährige Kinder in Niedersachsen, welche 2016 im Rahmen der DAJ-Studie untersucht wurden. Für die Milchzähne ergab sich ein mittlerer dmft-Wert von 1,78. Betrachtet man ausschließlich die Gruppe der 7-Jährigen lag der mittlere dmft-Wert bei 1,99 für die Milchzähne (Basner et al. 2017).

Die geschlechtsspezifischen Mittelwerte des Kariesbefalls fielen in der vorliegenden Studie zugunsten der Mädchen geringer aus. Ursächlich hierfür könnte das höhere Gesundheitsbewusstsein der Mädchen sein. Zahnpflegegewohnheiten variieren geschlechtsabhängig. So zeigt eine Untersuchung im Rahmen der KiGGS-Studie, welche von 2003 bis 2006 an 17.641 Kindern und Jugendlichen im Alter von 0 bis 17 Jahren vom Robert Koch-Institut durchgeführt wurde, dass ein Drittel der Jungen (33,2 \%) weniger als zweimal täglich ihre Zähne putzen, verglichen mit nur einem Viertel (25,0 \%) bei den Mädchen (Schenk und Knopf 2007).

\subsection{Prävalenz und Schweregrad von Karies in Abhängigkeit vom Körpergewicht}

In der zahnbasierten Auswertung zeigten adipöse und extrem adipöse Kinder sowohl auf dem Cut-Off-Point d1 als auch d3 eine signifikant höhere Prävalenz für kariöse Läsionen $\left(\mathrm{d}_{1-6} \mathrm{mft}>0\right.$ : Adipositas: 55,7\%; extreme Adipositas: 71,1\%; $\mathrm{d}_{3-6 \mathrm{mft}}>0$ : Adipositas 45,9\%; extreme Adipositas: 57,7\%) als normalgewichtige Kinder $\left(\mathrm{d}_{1-6} \mathrm{mft}>0: 50,0 \% ; \mathrm{d}_{3-6} \mathrm{mft}>0\right.$ : $39,5 \%$ ). In der Regressionsanalyse erzielte dies ein Odds Ratio von 1,02. Demnach stieg das Risiko für initialkariöse und invasiv behandlungsbedürftige kariöse Läsionen pro BMIPerzentile für adipöse und extrem adipöse Kinder und Jugendliche um den Faktor 1,02 an.

Diese Beobachtung ließen bereits die Ergebnisse von Azrak et al. (2006) vermuten, welche 638 Mainzer Kindergarten- und Vorschulkinder im Alter von 2 bis 6 Jahren (364 Jungen und 274 Mädchen) untersuchten. Bei 70,0 \% der untersuchten adipösen Kinder lag ein erheblicher Kariesbefall vor (dmft-Index von $\geq 9,0)$.

Einen deutlichen Zusammenhang zwischen dem Auftreten dentaler Karies und Übergewicht zeigen auch vergangene deutsche Studien (Haas et al. 2004; Moschos et al. 2006; Willershausen et al. 2004).

Moschos et al. (2006) konnten bei der Untersuchung von 1.942 6- bis 10-jährigen Grundschulkindern einen signifikanten Zusammenhang zwischen der Kariesprävalenz und einem 
erhöhten BMI nachweisen. Während ein niedriger BMI dabei signifikant mit der Kariesfreiheit korrelierte $(\mathrm{p}<0,0001)$, stand ein hoher BMI für einen hohen Kariesbefall $((\mathrm{df}-\mathrm{t} / \mathrm{DF}$ T)-Werte; $\mathrm{p}=0,0021)$.

In der Studie von Willershausen et al. (2004) stand die Prävalenz dentaler Karies ebenfalls in signifikantem Zusammenhang mit dem Körpergewicht. Der mittlere df-t-Wert lag bei den normalgewichtigen Kindern bei 2,09 (DF-T = 0,57), übergewichtige Kinder verzeichneten einen mittleren df-t-Wert von 2,48 (DF-T $=0,91)$ und adipöse Kinder einen mittleren df-tWert von 3,3 (DF-T = 0,88). Der Prozentsatz kariesfreier Gebisse sank von 35,5 \% für normalgewichtige Kinder auf 27,5 \% für die Gruppe der übergewichtigen Kinder.

\subsubsection{Karies im bleibenden Gebiss}

\subsection{Kariesprävalenz}

Für normalgewichtige Kinder mit bleibenden Zähnen ( $\mathrm{n}=46$; Durchschnittsalter 10,1 \pm 3,5 Jahre) lag die Kariesprävalenz bei 34,8 \% (D 1 -6 MFT > 0). Bei 21,7 \% der untersuchten normalgewichtigen Kinder lagen invasiv behandlungsbedürftige kariöse Läsionen $\left(\mathrm{D}_{3-6} \mathrm{MFT}>0\right)$ vor.

Die Prävalenzraten der vorliegenden Arbeit sind vergleichbar mit den Ergebnissen anderer deutscher Studien:

Im Rahmen der epidemiologischen Begleituntersuchungen zu Gruppenprophylaxe (DAJ 2016) wurden 55.002 12-jährige Kinder mit bleibenden Zähnen untersucht. Die Prävalenz für kariöse Läsionen lag bei 21,2 \%, unter Berücksichtigung initialkariöser Läsionen bei $34,5 \%$. Betrachtet man ausschließlich die Ergebnisse für Niedersachsen lag die Kariesprävalenz für 1.479 untersuchte 12-jährige Kinder mit bleibenden Zähnen bei 21,7 \%. Unter Berücksichtigung der initialkariösen Läsionen reduzierte sich der Prozentsatz kariesfreier Gebisse auf 66,4 \% (Basner et al. 2017).

Auch Willershausen et al. (2004) kamen zu vergleichbaren Ergebnissen wie die vorliegende Studie für Kinder und Jugendliche mit bleibenden Zähnen. Bei 33,7 \% der untersuchten Kinder im Alter von 6 bis 11 Jahren lagen kariesfreie Gebisse vor. Die Kariesprävalenz (DFT-/df-t-Wert) für normalgewichtige Kinder lag jedoch bei 64,5 \% und damit deutlich höher als in der vorliegenden Studie $\left(34,8 \%\right.$ für $\left.\mathrm{D}_{1-6} \mathrm{MFT}>0\right)$.

Jungen verzeichneten in 32,1 \% der Fälle kariöse Läsionen $\left(\mathrm{d}_{1-6 \mathrm{mft}}>0\right)$, bei den Mädchen lag die Kariesprävalenz bei $38,9 \%\left(\mathrm{~d}_{1-6} \mathrm{mft}>0\right)$. 


\subsection{Karieserfahrung}

Der durchschnittliche $\mathrm{D}_{1-6} \mathrm{MFT}$-Wert lag innerhalb der Gruppe der normalgewichtigen Kinder mit bleibenden Zähnen bei 1,5 \pm 3,3 Zähnen, der durchschnittliche $\mathrm{D}_{3-6} \mathrm{MFT}$-Wert bei 0,7 $\pm 2,0$. Für die kleine Gruppe normalgewichtiger 12-jähriger Kinder mit bleibenden Zähnen $(n=6)$ konnte gezeigt werden, dass diese durchschnittlich weniger als einen kariös zerstörten, fehlenden oder gefüllten Zahn aufwiesen. Die mittlere Karieserfahrung machte gemäß $\mathrm{D}_{3-6}$ MFT-Index $0,8 \pm 1,6$ Zähne aus.

Im Rahmen der 2016 von der Deutschen Arbeitsgemeinschaft für Jugendzahnpflege e. V. durchgeführten epidemiologischen Begleituntersuchungen zur Gruppenprophylaxe lagen die mittleren DMFT-Werte in allen Bundesländern unter 1. Die beste Mundgesundheit verzeichneten 12-Jährige in Rheinland-Pfalz (DMFT-Wert = 0,24). Der höchste mittlere DMFTWert wurde in Berlin (DMFT-Wert $=0,76)$ registriert (Basner et al. 2017). Auf der Grundlage dieser Zahlen wurden Mittelwerte für Gesamtdeutschland errechnet. Für 12-Jährige lag der mittlere DMFT-Wert 2004 noch bei 0,98, 2009 nur noch bei 0,72 und 2016 bei nur 0,44. Das Ergebnis der vorliegenden Studie liegt damit über den Mittelwerten für Gesamtdeutschland. Bei alleiniger Betrachtung der DMFT-Entwicklungen verdeutlichen die Ergebnisse der DAJStudie der letzten Jahre eine deutliche Verbesserung der Zahngesundheit 12-Jähriger in Deutschland. Die möglichen Ursachen für diesen Rückgang wurden u. a. in den DAJ-Gutachten von 2000 und 2004 bereits ausführlich diskutiert. So werden insbesondere die regelmäßige Zahnpflege mit fluoridhaltigen Zahnpasten, die Fissurenversiegelungen an den bleibenden Molaren, Lokalfluoridierungsmaßnahmen im Rahmen der Gruppen- und Individualprophylaxe oder auch die verstärkte Verwendung fluoridhaltigen Speisesalzes als Haupteinflussfaktoren diskutiert (Pieper 2005).

\subsection{Prävalenz und Schweregrad von Karies in Abhängigkeit vom Körpergewicht}

Im Rahmen der vorliegenden Studie konnte ein signifikanter Zusammenhang zwischen der Karieserfahrung und dem Körpergewicht für die bleibende Dentition ermittelt werden. Qadri et al. (2015), von Bremen et al. (2015) und Willershausen et al. (2007) fanden bei der Untersuchung von deutschen Kindern ebenfalls einen signifikanten Zusammenhang zwischen einem erhöhten BMI und der Kariesprävalenz sowohl für die erste als auch für die bleibende Dentition, wobei höhere BMI-Werte mit einer höheren Kariesprävalenz einhergingen. Bailleul-Forestier et al. (2007) bestätigten dies für eine Gruppe französischer Jugendlicher. Untersucht wurden 41 adipöse Jugendliche und eine Vergleichsgruppe aus 41 normalgewichtigen Jugendlichen. In der Gruppe der adipösen Probanden bestand ein signifikanter 
Zusammenhang zwischen BMI und DMFT-Index $(\mathrm{p}=0,01)$. Demnach hatten adipöse Jugendliche häufiger Karies als die normalgewichtige Vergleichsgruppe.

Willershausen et al. (2007) untersuchte den möglichen Zusammenhang von Körpergewicht und dentaler Gesundheit an 1.290 Schulkindern im Alter von 6 bis 11 Jahren. Die Ergebnisse der Studie zeigten eine signifikante Assoziation zwischen hohem Gewicht und Kariesprävalenz sowohl für die erste $(p=0,007)$ als auch für die zweite Dentition $(p<0,001)$. Die Anzahl naturgesunder Zähne nahm mit steigendem Alter $(p=0,001)$ und steigendem BMI $(p=0,006)$ ab. Während in der Altersgruppe der 6-Jährigen noch $53 \%$ der Gebisse kariesfrei waren, verzeichneten 7-jährige Kinder nur noch in 39 \% ein Gebiss frei von Karies und 10jährige Kinder nur noch in $30 \%$. Gleichzusetzen war dies mit einem Anstieg der Kariesprävalenz um ca. $10 \%$ pro Lebensjahr.

In einer Studie von Qadri et al. (2015) wurden 694 Kinder im Alter von 9 bis 12 Jahren untersucht (Altersdurchschnitt: 10,3 \pm 0,6 Jahre; 48,0 \% Mädchen). Das Körpergewicht war signifikant mit der Prävalenz und dem Schweregrad für Karies in der bleibenden Dentition assoziiert $(p=0,039)$. Normalgewichtige Kinder hatten demnach einen niedrigeren mittleren DMFT-Wert $(0,56)$ als ihre übergewichtigen/adipösen Altersgenossen $(0,70)$.

In der vorliegenden Studie konnte für Kinder mit bleibenden Zähnen (Durchschnittsalter 10,6 \pm 3,1 Jahre) ebenfalls ein signifikanter Zusammenhang zwischen Kariesprävalenz und einem erhöhten BMI nachgewiesen werden, wenn D1 als Cut-Off-Punkt galt. Adipöse und extrem adipöse Kinder und Jugendliche hatten demnach ein signifikant höheres Risiko für initialkariöse Läsionen als ihre normalgewichtigen Altersgenossen (Zahn- und Patientenebene, $\mathrm{p}=0,006$ und $\mathrm{p}=0,007$ ). Diese Beobachtung bestätigen auch Regressionsanalysen, die zeigen, dass ein steigender BMI ein Hauptrisikofaktor für die Prävalenz und den Schweregrad von kariösen Läsionen ist.

Im Vergleich dazu stehen die Ergebnisse anderer Studien, welche eine inverse Beziehung zwischen Körpergewicht und dentaler Karies (Kopycka-Kedzierawski et al. 2008) oder keinen signifikanten Einfluss des Körpergewichts auf das Auftreten dentaler Karies ermitteln konnten (Granville-Garcia et al. 2008).

Kopycka-Kedzierawski et al. (2008) untersuchten anhand einer national repräsentativen Stichprobe von Kindern zwischen zwei und 18 Jahren einen möglichen Zusammenhang zwischen Übergewicht und dem Auftreten von Karies sowohl für die primäre als auch für die bleibende Dentition. Mittels logistischer Regression wurden die Daten von 10.180 Kindern des NHANES III von 1988 bis 1994 und die Daten von 7.568 Kindern des NHANES von 1999 bis 2002 statistisch analysiert. Die Daten von NHANES III und NHANES liefern keinen Hinweis darauf, dass übergewichtige Kinder ein erhöhtes Risiko für Karies haben. 
Obwohl bei jüngeren Kindern keine Unterschiede bei der Kariesprävalenz in Abhängigkeit vom Gewicht festgestellt wurden, legen die Ergebnisse von NHANES III interessanterweise nahe, dass Übergewicht mit einer geringeren Kariesprävalenz bei älteren Kindern in Verbindung gebracht werden kann.

Granville-Garcia et al. (2008) untersuchten 2.651 Vorschulkinder in Brasilien. Im Rahmen ihrer Studie konnten sie keinen signifikanten Zusammenhang zwischen dem Körpergewicht und Auftreten dentaler Karies ermitteln.

\subsubsection{Erosionen im Milchgebiss}

\subsection{Prävalenz dentaler Erosionen}

Von 140 untersuchten Kindern und Jugendlichen mit Milchzähnen zeigten 75,0 \% Anzeichen dentaler Erosion. Betrachtet man ausschließlich die Gruppe der normalgewichtigen Kinder und Jugendlichen $(\mathrm{n}=38)$ mit Milchzähnen konnte eine Prävalenzrate von 63,2 \% ermittelt werden. In den vergangenen Jahren wurde im Rahmen verschiedener epidemiologischer Studien das Auftreten von erosiven Zahnhartsubstanzdefekten bei Kindern untersucht. Die Ergebnisse der vorliegenden Studie sind vergleichbar mit denen von Millward et al. (1994), Jaeggi und Lussi (2004), Luo et al. (2005), Wiegand et al. (2006) und Tschammler et al. (2016), welche in der Altersgruppe von zwei bis neun Jahren Prävalenzraten von 5,7 \% bis $100 \%$ festgestellt haben. Ein uneingeschränkter Vergleich der verschiedenen Studienergebnisse ist allerdings aufgrund des unterschiedlichen Durchschnittsalters der untersuchten Probanden sowie der Verwendung unterschiedlicher Indizes erschwert. Millward et al. (1994) untersuchten 4-jährige Kinder, Wiegand et al. (2006) solche im Alter zwischen zwei und sieben Jahren. Die Probandengruppen beider Studien waren damit jünger als die der vorliegenden Studie mit Milchzähnen (Durchschnittsalter 7,6 Jahre).

Bei der geschlechtsspezifischen Differenzierung waren Jungen mit 78,3 \% signifikant häufiger betroffen als Mädchen mit 40,0 \%. Auf Zahnebene zeigten die Milchzähne der Mädchen ein 0,7-fach geringeres Risiko erosive Läsionen aufzuweisen als die Milchzähne der Jungen $(\mathrm{p}=0,001)$.

Tschammler et al. (2016) bestätigten dies für 775 untersuchte 3- bis 6-jährige Kinder aus Göttingen. Jungen wiesen auch hier gegenüber Mädchen signifikant mehr Erosionen auf. 


\subsection{Schweregrad, Lokalisation und Verteilung dentaler Erosionen}

Bei Kindern und Jugendlichen mit Milchzähnen verteilten sich 50,7 \% aller erosiven Läsionen auf den Oberkiefer und 49,3\% auf den Unterkiefer.

Am häufigsten waren die oberen Eckzähne (Zahn 53: 65,7 \%; Zahn 63: 61,9 \%) betroffen, gefolgt von den zweiten unteren Milchmolaren (Zahn 75: 50,5\%). Zu berücksichtigen ist dabei, dass ein Großteil der untersuchten Probanden ein Wechselgebiss aufwies, vor allem zahlreiche Milchfrontzähne waren zum Zeitpunkt der Untersuchung bereits herausgefallen und somit nicht mehr beurteilbar.

Wiegand et al. (2006) untersuchten 463 Göttinger Kindergartenkinder im Alter von zwei bis sieben Jahren. Erosive Zahnhartsubstanzdefekte wurden am meisten an den ersten und zweiten Oberkieferschneidezähnen (15,5- 25,0 \%) beobachtet, gefolgt von den Oberkiefereckzähnen (10,5-12,0\%).

\subsection{Prävalenz und Schweregrad dentaler Erosionen in Abhängigkeit vom Körpergewicht}

Die vorliegende Studie ist bislang die einzige, welche den Zusammenhang von Übergewicht und (extremer) Adipositas mit dem Auftreten dentaler Erosionen für Kinder mit Milchgebiss untersucht hat. Für die erste Dentition konnte ein signifikanter Zusammenhang zwischen dem Auftreten und dem Schweregrad dentaler Erosionen und Körpergewicht (BMI) ermittelt werden.

Gründe für das erhöhte Erosionsrisiko bei (extrem) adipösen Kindern und Jugendlichen können in bisherigen Ernährungsgewohnheiten (häufiger Konsum gesüßter kohlensäurehaltiger Getränke), in der gezielten Umstellung der bisherigen Ernährungsgewohnheiten (u. U. häufiger Konsum von Zitrusfrüchten und Säften) während der Betreuung im AdipositasProgramm oder in intrinsischen Faktoren, wie dem Vorliegen einer gastroösophagealen Refluxkrankheit, als Komorbidität der Adipositas, liegen (Kendrick und Houghton 2006; Tong et al. 2014). Auch die Einnahme verschiedener Medikamente, wie z. B. Antihypertonika zur Therapie einer arteriellen Hypertonie wie sie häufig als Begleiterkrankung der Adipositas vorliegt, können die Entstehung erosiver Zahnhartsubstanzdefekte beeinflussen. Antihypertonika gehören zu den Parasympatholytika und hemmen so die Speichelproduktion (Porter et al. 2004). Järvinen et al. (1991) konnten in der Vergangenheit einen Zusammenhang zwischen dem Auftreten erosiver Zahnhartsubstanzdefekte und einer verminderten Speichelfließrate nachweisen. 


\subsubsection{Erosionen im bleibenden Gebiss}

Prävalenz dentaler Erosionen

Von 207 untersuchten Kindern und Jugendlichen mit bleibenden Zähnen (4 - 17 Jahre; Durchschnittsalter: 10,6 \pm 3,1 Jahre) zeigten 17,4 \% Anzeichen dentaler Erosion. Betrachtet man ausschließlich die Gruppe der normalgewichtigen Patienten mit bleibenden Zähnen wird eine Erosionsprävalenz von 4,3 \% verzeichnet.

Auch für Patienten mit bleibenden Zähnen sind im vergangenen Jahrzehnt diverse Prävalenzstudien durchgeführt worden.

Bereits 1994 untersuchten Milosevic et al. (1994) 1.035 14-jährige Jugendliche in Liverpool und fanden bei allen mindestens einen erosiv geschädigten Zahn. Auch die Erosionsprävalenz der 12- bis 14-Jährigen in der Studie von Al-Majed et al. (2002) ist auffallend hoch. Bei $95 \%$ der 862 untersuchten Jugendlichen konnten erosive Zahnhartsubstanzveränderungen diagnostiziert werden, von denen $26 \%$ bis in das Dentin reichten.

In den Studien von Al-Dlaigan et al. (2001) und Dugmore und Rock (2004) sind ebenfalls in etwa die Hälfte aller untersuchten 14- bzw. 12-Jährigen von Erosionen betroffen (48 \% und 59,7 \%). Betrachtet man die Prävalenzraten für 22 untersuchte 14-jährige Jugendliche dieser Studie, so wird ein Ergebnis im niedrig-prävalenten Bereich verzeichnet (31,8 \%).

Deutsche Studien zur Prävalenz dentaler Erosionen bei Kindern und Jugendlichen beobachten vergleichbare Ergebnisse wie die vorliegende Arbeit. So wiesen 12-jährige Kinder, welche im Rahmen der Fünften Deutschen Mundgesundheitsstudie untersucht wurden, in 17,9 \% der Fälle Anzeichen dentaler Erosionen auf. Ein signifikanter Unterschied in der Prävalenzrate von Jungen und Mädchen war nicht zu beobachten (Micheelis und Jordan 2016).

Ganss et al. (2001) untersuchten das Auftreten von dentalen Erosionen bei Kindern und Jugendlichen anhand von 1.000 Situationsmodellen (Durchschnittsalter der Kinder und Jugendlichen: 11,4 \pm 3,3 Jahre). Sie ermittelten eine Erosionsprävalenz von 11,6 \% für die bleibende Dentition.

Ein direkter Vergleich der verschiedenen Studienergebnisse ist allerdings aufgrund der Verwendung unterschiedlicher Indizes limitiert.

In fast allen Prävalenzstudien weisen Jungen häufiger Erosionen auf als Mädchen (AlDlaigan et al. 2001; Dugmore und Rock 2004; Larsen et al. 2005; Peres et al. 2005). Es bleibt jedoch unklar, ob die geschlechtsspezifischen Unterschiede auf biologische oder verhaltensbedingte Risikofaktoren zurückzuführen sind. 
Einen signifikanten Unterschied der Erosionsprävalenz bei Mädchen und Jungen liefert die Studie von Dugmore und Rock (2004). Hier waren Jungen (63,9 \%) deutlich häufiger betroffen als Mädchen (55,3\%). Milosevic et al. (1994) fanden bei Jungen auch signifikant mehr Dentinerosionen als bei Mädchen.

Die Studie von Wang et al. (2010) ist eine der wenigen Studien, welche für Mädchen (29,9\%) eine höhere Erosionsprävalenz ermittelte als für Jungen (25,7\%).

Mulic et al. (2012) fanden für Jungen und Mädchen unterschiedliche Risikofaktoren für das Auftreten dentaler Erosionen. So zeigten sich für Jungen die Faktoren „Besuch einer berufsbildenden Sekundarschule“ und „häufiger Konsum von zuckerhaltigen Erfrischungsgetränken“ als signifikante Einflussfaktoren auf das Auftreten dentaler Erosionen. Für Mädchen wurden die Faktoren „Erbrechen“, „Reflux“ sowie „Fruchtsaftkonsum“ signifikant mit dem Auftreten von dentalen Erosionen assoziiert. Al-Dlaigan et al. (2001) und Hasselkvist et al. (2010) haben gezeigt, dass Jungen häufiger Erfrischungsgetränke konsumieren als Mädchen. Andere Studien zeigten, dass Mädchen tendenziell mehr Obst und Säfte konsumieren (Bere et al. 2008; Wang et al. 2010) und dass Essstörungen, welche mit häufigem Erbrechen einhergehen, häufiger bei Mädchen auftreten (Kjelsas et al. 2004).

\subsection{Schweregrad, Lokalisation und Verteilung dentaler Erosionen}

Bei Patienten mit bleibenden Zähnen waren Unterkieferzähne geringfügig häufiger betroffen als Oberkieferzähne. Während 50,3 \% ( $\mathrm{n}=273$ betroffene Zähne) aller Unterkieferzähne Erosionen aufwiesen, waren es im Oberkiefer 49,7\%.

In der vorliegenden Studie waren bei den bleibenden Zähnen im Oberkiefer die Schneidezähne (2,6- 5,9 \%) am häufigsten betroffen. Im Unterkiefer waren die Eckzähne (4,5- 7,6 \%) und die Molaren (3,5- 4,6 \%) die Zähne, welche die meisten erosiven Läsionen zeigten. Die physiologischen Durchbruchszeiten der 6-Jahr-Molaren sowie der bleibenden Inzisivi erklären die Prädisposition für erosive Zahnhartsubstanzdefekte. Frontzähne brechen eher in die Mundhöhle durch als die Prämolaren und sind somit länger sauren Getränken und Nahrungsmitteln ausgesetzt. Je länger ein Zahn potenziell erosiven Angriffen ausgesetzt ist, desto höher ist die Wahrscheinlichkeit, dass erosive Zahnhartsubstanzdefekte ausgebildet werden. Zu ähnlichen Ergebnissen wie die vorliegende Studie kamen auch Dugmore und Rock (2004) bei der Untersuchung von 1.753 Zwölfjährigen in England. Sie fanden die höchste Erosionsprävalenz an Palatinalflächen der Oberkieferfrontzähne (49 \%) und Oberkiefermolaren (49 \%) sowie den Vestibulärflächen der Unterkiefermolaren (50\%). Die Unterkieferschneidezähne waren in dieser Studie lediglich in 13,5 \% der Fälle betroffen. 
Larsen et al. (2005) untersuchten die Prävalenz und Lokalisation erosiver Zahnhartsubstanzdefekte bei 558 Jugendlichen im Alter zwischen 15 und 17 Jahren. Die am häufigsten betroffenen Stellen waren die lingualen Oberflächen der Oberkieferschneidezähne. Al-Dlaigan et al. (2001) ermittelten das höchste Erosionsvorkommen an den Frontzähnen des Unterkiefers, Vargas-Ferreira et al. (2011) an denen des Oberkiefers.

Aus vergangenen Studien geht hervor, dass Frontzähne häufiger Erosionen aufweisen als Seitenzähne (Dugmore und Rock 2004; Larsen et al. 2005). Die Vestibulärflächen der Unterkieferschneidezähne werden bei eugnather Bisslage durch die Oberkieferfrontzähne geschützt. Des Weiteren können durch die unmittelbare Nähe zu den Ausführungsgängen der Glandulae submandibularis und sublingualis erosive Nahrungsmittelbestandteile schneller neutralisiert werden.

\subsection{Prävalenz und Schweregrad dentaler Erosionen in Abhängigkeit vom Körpergewicht}

Im Rahmen der vorliegenden Studie konnte ein signifikanter Zusammenhang zwischen dem Auftreten und dem Schweregrad dentaler Erosionen und dem Körpergewicht (BMI) für die bleibende Dentition ermittelt werden.

Demnach konnten für adipöse und extrem adipöse Kinder mit bleibenden Zähnen (Patientenebene) ein stark erhöhtes Erosionsrisiko, höhere Schweregrade und ein höherer Prozentsatz betroffener Zähne aufgezeigt werden.

Tong et al. (2014) zeigten im Rahmen einer univarianten Analyse, dass adipöse Kinder und Jugendliche im Alter von 7 bis 15 Jahren mehr Erosionen in Bezug auf den Schweregrad und die betroffene Fläche ( $\mathrm{p}<0,0001)$, nicht aber in Bezug auf die Anzahl betroffener Flächen hatten $(\mathrm{p}=0,167)$. Adipöse Kinder und Jugendliche hatten demnach 26-mal häufiger erosiv geschädigte Zähne als die gesunde normalgewichtige Kontrollgruppe.

McGuire et al. (2009) ermittelten für 13- bis 19-jährige Jugendliche eine Erosionsprävalenz von $46 \%$. Übergewichtige Jugendliche hatten verglichen mit normalgewichtigen Jugendlichen tendenziell höhere Prävalenzraten. Der Unterschied war jedoch statistisch nicht signifikant.

Ebenso wie in der Studie von Tong et al. (2014) erfolgte die Rekrutierung des Studienkollektivs aus der Adipositas-Sprechstunde. Gründe für das signifikant höhere Auftreten erosiver Zahnhartsubstanzdefekte bei (extrem) adipösen Kindern und Jugendlichen können daher im bisherigen Konsum gesüßter kohlensäurehaltiger Getränke, in der gezielten Umstellung der bisherigen Ernährungsgewohnheiten (u. U. häufiger Konsum von Zitrusfrüchten und Säf- 
ten) während der Betreuung im Adipositas-Programm des Sozialpädiatrischen Zentrums oder in intrinsischen Faktoren, wie z. B. dem Vorliegen einer gastroösophagealen Refluxkrankheit, als Komorbidität der Adipositas, liegen.

\subsubsection{Assoziation zwischen Karies und dentalen Erosionen}

Dentale Erosionen und Karies haben einige ätiologische Faktoren gemeinsam, was darauf hindeuten könnte, dass beide Krankheiten korreliert sein könnten. Zu den gemeinsamen ätiologischen Faktoren zählen u. a. ein hoher Konsum von sauren und kohlenhydratreichen Erfrischungsgetränken, bestimmte Ernährungsgewohnheiten sowie quantitative und qualitative Veränderungen der Speichelzusammensetzung.

In einer Reihe von Querschnittsstudien, welche in der Vergangenheit einen möglichen Zusammenhang zwischen dentalen Erosionen und Karies bei Kindern untersuchten, blieben die Ergebnisse jedoch widersprüchlich. Während einige Studien über einen signifikanten Zusammenhang berichteten (Al-Malik et al. 2002; Dugmore und Rock 2004; Zhang et al. 2014), konnten die Studien von Auad et al. (2009) und Huew et al. (2012) diesen nicht bestätigen. Al-Malik et al. (2002), welche 2- bis 5-jährige Kinder in Saudi-Arabien untersuchten, konnten höhere Prävalenzraten für erosive Läsionen (33 \%) bei Kindern mit Karieserfahrung verglichen zu Kindern ohne Karieserfahrung (27\%) nachweisen.

Dieser Zusammenhang bestätigte sich in der vorliegenden Studie für die Milchzähne. Für (extrem) adipöse Kinder und Jugendliche wurde ein schwacher Zusammenhang zwischen dentalen Erosionen und Karies sowohl auf Zahn- als auch auf Patientenebene ermittelt $\left(\mathrm{p}<0,001 ; \mathrm{r}_{\mathrm{Sp}}=-0,144\right)$.

Für normal- und übergewichtige Kinder und Jugendliche konnte kein oder nur ein geringer direkter Zusammenhang zwischen dentalen Erosionen und Karies ermittelt werden $\left(\mathrm{D}_{1-6} \mathrm{MFT}>0, \mathrm{p}=0,008\right)$. Betrachtet man die bleibenden Zähne, waren für Kinder und Jugendliche mit (extremer) Adipositas sowohl auf Zahn- als auch auf Patientenebene dentale Erosionen und Karies assoziiert ( $\mathrm{p} \leq 0,005 ; \phi=0,110$ bis 0,267).

Dugmore und Rock (2004) untersuchten in Großbritannien 1.753 12-jährige Jugendliche und konnten feststellen, dass das Risiko für dentale Erosionen an Frontzähnen und 6-Jahr-Molaren mit erhöhten DMFT-Werten dieser Zähne ansteigt ( $p=0,002$, OR: 1,48). 


\subsubsection{Ergebnisse des Fragebogens}

Ergänzend zur dentalen Untersuchung wurden verschiedene Mundhygiene- und Ernährungsgewohnheiten sowie sozioökonomische Faktoren mittels eines Anamnesebogens abgefragt und der mögliche Einfluss dieser Parameter auf die Prävalenz und den Schweregrad von Karies und dentalen Erosionen überprüft.

\subsubsection{Ernährungsgewohnheiten}

Zahlreiche vergangene Studien untersuchten bereits einen möglichen Zusammenhang verschiedener Ernährungsgewohnheiten mit dem Auftreten und der Schwere kariöser sowie erosiver Läsionen (Al-Malik et al. 2001; Alm et al. 2008; Harding et al. 2003; Millward et al. 1994; Tschammler et al. 2016; Wiegand et al. 2006).

Als Risikofaktor für das Auftreten kariöser Läsionen wurde im Rahmen der vorliegenden Studie bei der zahnbezogenen Auswertung sowohl für die primäre Dentition $\left(\mathrm{d}_{3-6} \mathrm{mft}>3\right)$ als auch für die bleibende Dentition $\left(\mathrm{D}_{1-6} \mathrm{MFT}>0\right)$ der häufige Verzehr kariogener Getränke beschrieben. In der bleibenden Dentition zeigte sich der häufige Konsum kariogener Getränke ebenfalls auf die Schwere kariöser Läsionen (ICDAS) als signifikanter Risikofaktor.

Als Hauptrisikofaktoren für die Entstehung extrinsischer Erosionen wurden der Konsum kohlensäurehaltiger und säurehaltiger Getränke, der nächtliche Konsum von Fruchtsäften und Fruchtschorlen, die Verweildauer der Getränke im Mund, die Frequenz oder die Art des Trinkverhaltens (Einnahme von Fruchtsaftgetränken mit einem Fläschchen) beschrieben (Al-Majed et al. 2002; Al-Malik et al. 2001; Harding et al. 2003; Luo et al. 2005; Lussi et al. 1991; Millward et al. 1994; Milosevic et al. 1997). Die bekannten Risikofaktoren konnten in der vorliegenden Studie abermals bestätigt werden. Demnach führte der mehrmals wöchentliche Konsum erosiver Getränke und der Konsum erosiver Zwischenmahlzeiten zu höheren Prävalenzraten für erosive Zahnhartsubstanzdefekte, insbesondere für die bleibenden Zähne (zahnbezogen) und für Kinder mit bleibenden Zähnen (patientenbezogen).

\subsubsection{Sozioökonomische Faktoren}

Ebenso wie in der vorliegenden Studie wurde bereits in zahlreichen anderen Studien ein möglicher Zusammenhang zwischen sozioökonomischen Faktoren (Nationalität, sozialer Schichtzugehörigkeit) und der Prävalenz von Karies und Erosionen untersucht (Al-Dlaigan et al. 2001; Harding et al. 2003; Vargas-Ferreira et al. 2011). Bei genauer Betrachtung der Studienergebnisse zeigt sich jedoch eine kontroverse Studienlage.

Entsprechend einer Hochrechnung des Statistischen Bundesamtes aus dem Jahre 2011 ist die Verteilung des monatlichen Netto-Haushaltseinkommens innerhalb der deutschen All- 
gemeinbevölkerung vergleichbar mit der innerhalb der Gruppe normalgewichtiger Probanden. Gemessen an den Angaben von 36.701 deutschen Haushalten verzeichnen 51,6 \% ein monatliches Netto-Haushaltseinkommen unter $2.600 €$ und 48,3 \% über $2.600 €$ (Bundeszentrale für politische Bildung).

Mit steigenden BMI-Perzentil-Werten war im vorliegenden Studienkollektiv ein sinkender Anteil von Probanden aus der oberen Sozialschicht zu beobachten. Während in der Gruppe der normalgewichtigen Kinder und Jugendlichen noch 40,4 \% der Familien ein monatliches Haushaltseinkommen über $2.750 €$ verzeichneten, wiesen in der Gruppe der extrem adipösen Kinder und Jugendlichen nur noch knapp die Hälfte der Familien (19,6 \%) ein solch hohes Netto-Haushaltseinkommen auf.

Für das Auftreten und den Schweregrad kariöser Läsionen im Milchgebiss und bleibenden Gebiss (Zahn- und Patientenebene) konnte für Kinder aus Familien mit höherem monatlichen Netto-Haushaltseinkommen ein geringeres Risiko für das Auftreten kariöser Läsionen $\left(\mathrm{d}_{1-6} \mathrm{mft} / \mathrm{D}_{1-6} \mathrm{MFT}>0\right)$, ein geringeres Risiko für das Auftreten invasiv behandlungsbedürftiger kariöser Läsionen $\left(\mathrm{D}_{3-6} \mathrm{MFT} / \mathrm{d}_{3-6} \mathrm{mft}>3\right)$ und ein geringeres Risiko für schwerere kariöse Läsionen ermittelt werden.

Dies deckt sich mit den Beobachtungen von Städtler et al. (2003) und Oliveira et al. (2008). Städtler et al. (2003) konnten bei der Untersuchung von 516 australischen Kindern im Alter von sechs Jahren ebenfalls einen signifikanten Zusammenhang zwischen der Kariesprävalenz und dem Familieneinkommen nachweisen. Die Prävalenz dentaler Karies war umgekehrt proportional zum Familieneinkommen ( $\mathrm{p}<0,001 ; \mathrm{r}=-0,173)$.

Oliveira et al. (2008) ermittelten ebenfalls einen Zusammenhang zwischen sozioökonomischen Faktoren (niedrigem Einkommen) und dem Auftreten kariöser Zahnhartsubstanzdefekte.

Betrachtet man die Erosionsprävalenz in den verschiedenen sozialen Schichten in Abhängigkeit des monatlichen Netto-Haushaltseinkommens, zeigten die Daten der vorliegenden Studie keine signifikanten Unterschiede. So wiesen durchschnittlich 82,2 \% der unteren, 81,8 \% der mittleren und 79,4 \% der oberen Sozialschicht Anzeichen dentaler Erosionen auf. Das Ergebnis deckt sich somit mit den Beobachtungen von Vargas-Ferreira et al. (2011), die bei der Untersuchung von 11- bis 14-jährigen Schülern in Brasilien ebenfalls keinen statistisch signifikanten Zusammenhang zwischen sozialem Status und dem Auftreten dentaler Erosionen feststellen konnten.

In den Studien von Peres et al. (2005) und Luo et al. (2005) konnte hingegen eine höhere Prävalenz für erosive Läsionen insbesondere bei Kindern aus einkommensstarken Familien 
festgestellt werden. Al-Dlaigan et al. (2001) und Harding et al. (2003) ermittelten einen niedrigeren soziökonomischen Status als Risikofaktor für erosive Zahnhartsubstanzdefekte.

In Bezug auf den Migrationshintergrund konnte für das Auftreten und die Schwere erosiver Läsionen an den Milchzähnen und bleibenden Zähnen (Zahnebene) für Kinder und Jugendliche, welche einen Migrationshintergrund aufwiesen, ein höheres Erosionsrisiko für die Milchzähne $(p=0,010)$ und für die bleibenden Zähne $(p=0,010)$ sowie schwerere erosive Läsionen an den bleibenden Zähnen $(p<0,001)$ ermittelt werden. Kinder mit Milchzähnen (Patientenebene), welche einen Migrationshintergrund vorweisen konnten, hatten einen signifikant höheren Prozentsatz betroffener Zähne ( $\mathrm{p}=0,017)$.

$\mathrm{Zu}$ gleichem Ergebnis kam eine Untersuchung von 5- bis 7-jährigen Kindern in Griechenland. Gatou und Mamai-Homata (2012) fanden heraus, dass die untersuchten Kinder mit Migrationshintergrund höhere Prävalenzraten für dentale Erosionen verzeichneten, verglichen mit der griechischen Vergleichsgruppe. Auch in einer chinesischen Studie von Tao et al. (2015) konnte festgestellt werden, dass der Geburtsort einen signifikanten Einfluss auf das Vorkommen von dentalen Erosionen hat $(p<0,05)$.

Ernährungs- und Mundhygienegewohnheiten von Kindern und Jugendlichen werden häufig von ihrem sozioökonomischen Hintergrund geprägt. Das Gesundheitsbewusstsein bzw. der Umgang mit Gesundheitsfragen variieren innerhalb der sozialen Schichten der Gesellschaft und in Abhängigkeit vom Migrationshintergrund. Eine mögliche Erklärung für die gesundheitliche Benachteiligung von Kindern und Jugendlichen aus Migrantenfamilien ist deren häufige Zugehörigkeit zur unteren Sozialschicht. Ferner können sprachliche Barrieren zum Missverständnis ärztlicher/zahnärztlicher Hinweise führen und den Zugang zu Präventionsprogrammen erschweren.

In der KiGGS-Studie konnte gezeigt werden, dass der Anteil der Kinder und Jugendlichen mit geringer Zahnputzfrequenz umso höher ist, je niedriger deren sozioökonomischer Status ist. Noch deutlicher waren die Unterschiede zwischen Kindern und Jugendlichen ohne Migrationshintergrund und solchen aus Migrantenfamilien (26,1\% versus 45,0 \%). Kinder und Jugendliche aus Migrantenfamilien, insbesondere aus arabischislamischen Ländern und der Türkei, nahmen außerdem weniger oft zahnärztliche Kontrolluntersuchungen in Anspruch (Schenk und Knopf 2007).

Auch migrationsbezogene Besonderheiten im Ernährungsverhalten, wie die Art und die Zubereitung der Lebensmittel, sollten Berücksichtigung finden. Der Stellenwert von Ernährung und Mahlzeitenstrukturen variiert innerhalb verschiedener Kulturen. Mit der Einwanderung 
nach Deutschland verändert sich häufig das Ernährungsmuster hin zu zucker- und/oder fetthaltigen Nahrungsmitteln. So überwiegt beispielsweise bei Kindern und Jugendlichen aus russisch- oder türkischstämmigen Familien der Konsum von Erfrischungsgetränken, Weißbrot, frittierten oder gebratenen Kartoffeln und Schokolade. Gleichzeitig zum häufigeren Konsum dieser Nahrungsmittel ist das Bewusstsein für deren erosive und kariogene Wirkung gering (Schenk et al. 2008).

\subsubsection{Mundhygienegewohnheiten}

Der Einfluss der Mundhygiene auf die Prävalenz von Karies und Erosionen wurde bereits in einigen Studien untersucht (Al-Malik et al. 2001; Millward et al. 1994):

Al-Malik et al. (2001) konnten für die Faktoren „Wer putzt“ sowie „Häufigkeit des Zähneputzens" keinen signifikanten Zusammenhang zur Erosionsprävalenz ermitteln. Zwischen Kindern, die sich selbst die Zähne putzten und Kindern, deren Eltern sie beim Zähneputzen unterstützten sowie Kindern, welche täglich oder gelegentlich Zähne putzten, wurden kaum Unterschiede in der Erosionsprävalenz ermittelt. Auch in der Studie von Millward et al. (1994) zeigten Mundhygienegewohnheiten, wie „Dauer des Zähneputzens“, „Frequenz des Zähneputzens“, „Borstenhärte der Zahnbürste“ oder „Zähneputzen direkt nach den Mahlzeiten“, keinen signifikanten Einfluss auf das Auftreten von Erosionen.

Dem gegenüber stehen die Ergebnisse der vorliegenden Studie. Sowohl für Erosionen als auch für Karies konnten Mundhygienemaßnahmen als signifikante Einflussfaktoren auf das Risiko für die Entstehung bzw. den Schweregrad dentaler Erosionen und Karies ermittelt werden.

Für das Auftreten und den Schweregrad von erosiven Zahnhartsubstanzdefekten konnten im Rahmen der vorliegenden Studie weitere signifikante Risikofaktoren ermittelt werden. So verzeichneten Kinder mit Milchzähnen bei Verwendung einer Zahnpasta mit unzureichender Fluoridkonzentration signifikant höhere BEWE-Summenwerte und das Auftreten erosiver Läsionen an den bleibenden Zähnen (zahnbezogene Auswertung) war beim Zähneputzen mit Handzahnbürste und elektrischer Zahnbürste signifikant erhöht ( $\mathrm{p}=0,021)$.

Sowohl für die Milchzähne und bleibenden Zähne (zahnbezogen) als auch für Kinder mit Milchzähnen (patientenbezogen) konnten Mundhygienefaktoren wie „Dauer des Zähneputzens“, „Frequenz des Zähneputzens“, „Art der Zahnbürste“ und „Art der Zahnpasta“ als signifikante Einflussfaktoren auf das absolute Auftreten kariöser Läsionen $\left(\mathrm{D}_{1-6} \mathrm{MFT} / \mathrm{d}_{1-6} \mathrm{mft}>0\right)$, das Auftreten behandlungsbedürftiger kariöser Läsionen $\left(\mathrm{D}_{3-6} \mathrm{MFT} / \mathrm{d}_{3-6} \mathrm{mft}>3\right)$ und den Schweregrad kariöser Läsionen (ICDAS) ermittelt werden. 
In der zahn- und patientenbezogenen Auswertung für die Milchzähne spielten dabei insbesondere schlechte Zahnputzgewohnheiten (Dauer des Zähneputzens weniger als zwei Minuten; Häufigkeit des Zähneputzens weniger als zweimal täglich) und die Verwendung einer Zahnpasta, welche eine niedrigere Fluoridkonzentration hatte als von der DGZMK empfohlen eine entscheidende Rolle. Demnach zeigten Kinder, welche eine Zahnpasta mit unzureichender Fluoridkonzentration verwendeten ein 3,6-fach höheres Risiko für das Auftreten kariöser Läsionen $\left(\mathrm{d}_{1-6} \mathrm{mft}>0\right)$ und ein 2,9-fach höheres Risiko für das Auftreten invasiv behandlungsbedürftiger kariöser Läsionen $\left(\mathrm{d}_{3-6} \mathrm{mft}>3\right)$ im Vergleich zu Kindern welche eine Zahnpasta mit ausreichender Fluoridkonzentration verwendeten.

Die kariesprophylaktische Wirksamkeit fluoridierter Zahnpasta wurde in den letzten Jahren vielfach belegt. In einer Cochrane-Meta-Analyse von 75 klinischen Studien, welche 40.000 Kinder und Jugendliche im Alter von 5 bis 16 Jahren einschlossen, zeigten Kinder, welche mindestens einmal täglich mit fluoridhaltiger Zahnpasta die Zähne putzten, eine Kariesreduktion um $24 \%$. Die zweimal tägliche Anwendung der fluoridhaltigen Zahnpasta erhöhte den kariespräventiven Effekt (Walsh et al. 2010). Die kariesprophylaktische Wirksamkeit ist für Fluoridkonzentrationen von $\geq 1.000$ ppm eindeutig belegt. Fluoridkonzentrationen von $\leq 550$ ppm zeigten keinen statistisch signifikanten kariesprophylaktischen Effekt (Rasines 2010).

Ein aktueller Bericht, welcher die Meta-Analyse von 96 klinischen Studien zwischen 1955 und 2014 einschließt, bestätigt das Ergebnis von 2010 (Walsh et al. 2019).

\subsubsection{Ergebnisse der Speichelprobe}

Entsprechend Hara und Zero (2014) stellen der Speichelfluss und die Zusammensetzung des Speichels signifikante Kofaktoren bei der Entwicklung von dentalen Erosionen und Karies dar. Der Speichelfluss und die Zusammensetzung des Speichels können bei Kindern und Jugendlichen mit Adipositas im Vergleich zu Normalgewichtigen verändert sein (Modeer et al. 2010).

Auf der Annahme dieser Tatsache wurde in zahlreichen in-vitro-Studien der protektive Einfluss von Speichel auf die Entstehung von dentalen Erosionen und Karies untersucht. Die vorliegende Studie ist bislang die einzige Studie in Deutschland, welche die Speichelfließrate, den $\mathrm{pH}$-Wert und die Pufferkapazität bei Kindern mit bzw. ohne Erosionen und Karieserfahrung untersucht hat.

Insgesamt konnte jedoch lediglich von 75 Kindern und Jugendlichen eine Speichelprobe gewonnen werden. Die erhobenen Speichelparameter mussten aufgrund der geringen Stichprobengröße aus der multifaktoriellen Analyse ausgeschlossen werden. 
Jaeggi und Lussi (2004) und Bartlett et al. (1998) konnten entgegen der These von Hara und Zero (2014) im Rahmen ihrer Studien keinen signifikanten Zusammenhang zwischen dem Auftreten und dem Schweregrad dentaler Erosionen und der Fließrate sowie Pufferkapazität des Ruhespeichels finden.

Auch Wang et al. (2011) fanden keinen signifikanten Unterschied in der Fließrate, dem pHWert sowie der Pufferkapazität im nicht stimulierten und stimulierten Speichel zwischen Probanden mit und ohne dentale Erosionen. Sie untersuchten 60 Schulkinder im Alter von 12 bis 13 Jahren.

Tong et al. (2014) untersuchten die stimulierte Speichelfließrate, die Pufferkapazität sowie den Gehalt an koloniebildenden Einheiten von Streptococcus mutans und Laktobazillen des Speichels adipöser Kinder und Jugendlicher und verglichen diese Parameter mit denen von gesunden normalgewichtigen Kindern. Sie konnten zeigen, dass adipöse Kinder keine signifikanten Unterschiede der genannten Parameter verglichen mit denen normalgewichtiger Kinder aufwiesen. Dieses Ergebnis konnte auch für die in der vorliegenden Studie getestete stimulierte Speichelfließrate und Pufferkapazität bestätigt werden.

$\mathrm{Zu}$ den gleichen Ergebnissen kommt auch eine 2010 in Brasilien durchgeführte Studie an einem Probandengut von 90 Schulkindern im Alter von 7 bis 10 Jahren. Es konnte kein signifikanter Unterschied in der stimulierten Speichelfließrate zwischen übergewichtigen, adipösen und normalgewichtigen Kindern herausgefunden werden (Pannunzio et al. 2010). Eine Fall-Kontroll-Studie von Järvinen et al. (1991) dagegen ermittelte eine niedrige unstimulierte Speichelfließrate als signifikanten Risikofaktor für das Auftreten erosiver Läsionen. Auch der Einfluss anderer Speichelparameter, wie der Kalzium- und Phosphatkonzentration, werden in der Literatur diskutiert (Anderson et al. 2001; Ben-Aryeh et al. 1984; Wiegand et al. 2006).

Die unterschiedlichen Ergebnisse auf die Frage der protektiven Wirkung des Speichels in Bezug auf die Entstehung von dentalen Erosionen und Karies beweisen dessen Vielschichtigkeit. So zeigt Speichel eine vom zirkadianen Rhythmus abhängige Zusammensetzung. Während noch am Morgen der muköse Speichel überwiegt, nimmt der Anteil des serösen Speichels tagsüber zu.

Möglicherweise spielen auch interindividuelle Differenzen oder auch unterschiedliche Speichelqualitäten / -quantitäten an verschiedenen Stellen der Mundhöhle eine Rolle, welche es noch weiter zu erforschen gilt. 


\subsection{Ausblick}

Die aktuellen Zahlen der Deutschen Arbeitsgemeinschaft für Jugendzahnpflege e. V. (DAJ) zur Kariesprävalenz sprechen nur noch für einen minimalen Kariesrückgang, insbesondere im Milchgebiss. Trotz verbesserter zahnmedizinischer Versorgungskonzepte bleiben immer noch 43 \% der Milchzähne 6- bis 7-jähriger Kinder unversorgt (Basner et al. 2017).

Auch in der vorliegenden Studie verzeichnete nahezu jedes zweite Kind ein Gebiss mit Karieserfahrung $\left(\mathrm{D}_{1-6} \mathrm{MFT}>0\right)$. Die Gesamtprävalenz für kariöse Läsionen lag auch hier bei $43,5 \%$.

Auch in Hinblick auf erosive Läsionen mussten im Rahmen dieser Studie hohe Prävalenzraten verzeichnet werden. Dabei wiesen mehr als die Hälfte der untersuchten Kinder und Jugendlichen erosive Läsionen an mindestens einem Zahn auf. Die Gesamtprävalenz für dentale Erosionen ( $\mathrm{n}=130 ; 58,3 \%$; Durchschnittsalter 10,2 \pm 3,4 Jahre) stimmt mit den Prävalenzraten anderer Studien in Deutschland überein, in denen Werte zwischen 52 \% für 4bis 6- jährige Kinder (Tschammler et al. 2016) und $71 \%$ für die erste Dentition (mittleres Alter: 11,4 Jahre) sowie $12 \%$ (Ganss et al. 2001) bis $18 \%$ (12-Jährige) (Micheelis und Jordan 2016) für Kinder mit bleibenden Zähnen ermittelt wurden.

Die Schweregrade von dentalen Erosionen bei Kindern und Jugendlichen mit Milchzähnen $(3,5 \pm 3,1)$ oder bleibenden Zähnen $(0,4 \pm 1,3)$ sind ebenfalls mit kürzlich veröffentlichten Studien vergleichbar (Micheelis und Jordan 2016; Tschammler et al. 2016).

In Anbetracht der hohen Prävalenzraten überrascht wenig, dass diese Thematik zu einem wichtigen Thema in der Zahnheilkunde geworden ist.

Die Korrelation zwischen Übergewicht und (extremer) Adipositas mit einem erhöhten Risiko für Karies und erosive Zahnhartsubstanzdefekte legt für Pädiater und Zahnärzte die Notwendigkeit nahe, die Implementierung von Präventionsstrategien weiter fortzusetzen und Eltern bereits frühzeitig über die Entstehung von dentalen Erosionen und Karies sowie den möglichen Zusammenhang mit Übergewicht und (extremer) Adipositas aufzuklären.

Regelmäßige Ernährungsberatung und Schulungen der Kinder und Jugendlichen sowie deren Familien können das Bewusstsein für den eigenen Körper erhöhen und somit die langfristigen gesundheitlichen Folgen der Fettleibigkeit begrenzen und die Zahngesundheit verbessern. 


\section{$5 \quad$ Zusammenfassung}

In der vorliegenden Studie wurde erstmals die Prävalenz, der Schweregrad und die Lokalisation von Karies und dentalen Erosionen an einem Probandengut von übergewichtigen und adipösen Kindern und Jugendlichen in der Altersgruppe der 4- bis 17-Jährigen in Deutschland untersucht und mit normalgewichtigen Kindern verglichen.

Ziel der Studie: Ziel dieser Studie war es, einen möglichen Zusammenhang zwischen BodyMass-Index-Perzentilen und einem erhöhten Auftreten von Erosionen und Karies bei Kindern und Jugendlichen nachzuweisen. Ein besonderes Augenmerk sollte dabei auf potenzielle Einflussfaktoren wie Ernährungsgewohnheiten der Probanden (Häufigkeit und Art der Zwischenmahlzeiten, bevorzugte Getränke), sozioökonomischer Hintergrund und das Vorliegen von Allgemeinerkrankungen, die potenziell mit Erosionen und Karies assoziiert werden könnten, gelegt werden.

Methode: Insgesamt nahmen 223 Kinder (112 Mädchen; Altersdurchschnitt: 10,2 Jahre) im Alter zwischen 4 und 17 Jahren an der Studie teil. Kariöse Läsionen wurden mit Hilfe des DMFT-/dmft- und DT/dt-Index sowie des Kariesdiagnosesystems International Caries Detection and Assessement System II erfasst, erosive Läsionen wurden anhand des BEWEIndex klassifiziert. Mit Hilfe eines Anamnesebogens wurden Allgemeinerkrankungen sowie Mundhygiene- und Ernährungsgewohnheiten der Kinder am Tag der Untersuchung ermittelt. Die Gewichtsklassifikation basierte auf der Verwendung von alters- und geschlechtsspezifischen Perzentilkurven. Statistische Analysen wurden mit Chi ${ }^{2}$-Tests, Kruskal-Wallis-Tests sowie logistischen und linearen Regressionsanalysen durchgeführt. Um einen möglichen Zusammenhang zwischen dentalen Erosionen und Karies festzustellen, wurden $\mathrm{Chi}^{2}$-Tests (Prävalenz zu Prävalenz) und Spearman-Korrelationen (Schweregrad zu Schweregrad) verwendet. Das Signifikanzniveau wurde auf $\mathrm{p}<0,05$ festgelegt.

Ergebnisse: Adipöse und extrem adipöse Kinder und Jugendliche zeigten im Vergleich zu normalgewichtigen Kindern und Jugendlichen eine signifikant höhere Prävalenz für Karies und dentale Erosionen sowohl für die Zähne der ersten Dentition als auch für die bleibende Dentition. Als Risikofaktoren für dentale Erosionen wurden ein höherer Body-Mass-Index, Alter, Geschlecht und der Konsum von erosiven Zwischenmahlzeiten/Getränken identifiziert. Ein höherer Body-Mass-Index, das Alter, sozioökonomische Faktoren, ungünstige Zahnputzgewohnheiten und der Konsum kariogener Getränke wurden als Kariesrisikofaktoren identifiziert. Dentale Erosionen und Karies zeigten bei (extrem) adipösen Kindern und Jugendlichen eine schwache Korrelation $(\phi=0,110$ bis 0,267$)$. 
Schlussfolgerung: Die vorliegende Studie konnte einen signifikanten Einfluss des Körpergewichts auf die Prävalenz und den Schweregrad von Erosionen und Karies bei Kindern und Jugendlichen nachweisen. 


\section{Anhang}

\subsection{Fragebogen (Version 2)}

\section{UNIVERSITÄTSMEDIZIN "
GÖTTINGEN " $\mathbf{M G}$}

Zentrum Zarn; Mund- und Kefertelkunde

Prodoriologe und Karologie

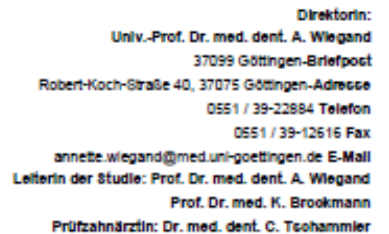

Studientitel:

\section{Zahngesundheit bei übergewichtigen und adipösen Kindern und Jugendlichen}

Fragebogen (Version 2)

Studienteilnehmer-Nr.:

Heutiges Datum:

Bitte fülle diesen Fragebogen alleine oder mit Hilfe eines Erwachsenen aus. Wenn du Fragen hast, kannst du dich jederzeit an unsere(n) Mitarbeiter/in wenden.

Vielen Dank für Deine Mitarbeit!

Wann wurdest du geboren? am

Dein Geschlecht?

$\square$ männlich a weiblich

Wie oft isst du außerhalb der Hauptmahlzeiten (also außer Frūhstück, Mittag- und Abendessen) irgendwelche Kleinigkeiten? Schätze bitte ungefähr, wie oft das jeden Tag ist.

1- bis 2-mal am Tag (2.B. 1. und 2. Pause)

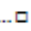

3- bis 4-mal am Tag (2.B. Pausen, 1x am Nachmittag und 1x abends) .......................................................

5-mal am Tag.

Fast jede Stunde

Mindestens $1 \mathrm{x}$ pro Stund

Ich esse nur zu den Hauptmahlzeiten

Was isst du zwischendurch besonders gerne? Du kannst auch mehrere Antworten ankreuzen

Ich esse zwischendurch nichts

Brot, Brötchen oder ähnliches (oä) .

Wurst, Schinken, Käse o.ã.

Rohes Gemūse (Paprika, Tomaten, Karotten usw.)

Zitrusfrüchte (Orangen, Äpfel usw.)

Süßigkeiten (Bonbons, Schokolade, Schokoriegel, Gummibärchen usw.) ...............................................

Kuchen, Kekse, Waffeln, Brot mit Marmelade/Honig, Müsliriegel, Eis, Pudding, Grießbrei, Milchreis o.ä. .............. ․

Ungesüßten weißen Joghurt, Quark

Gesüßten/ nicht weißen Joghurt, Quark, Müsli (mit Zucker, Honig od. Obst)

Trockenfrüchte, Rosinen

Sonstiges, nämlich: 


\section{$7 \quad$ Literaturverzeichnis}

Al-Dlaigan YH, Shaw L, Smith A (2001): Dental erosion in a group of British 14-year-old, school children. Part I: Prevalence and influence of differing socioeconomic backgrounds. Br Dent J 190, 145-149

Al-Majed I, Maguire A, Murray JJ (2002): Risk factors for dental erosion in 5-6 year old and 12-14 year old boys in Saudi Arabia. Community Dent Oral Epidemiol 30, 38-46

Al-Malik MI, Holt RD, Bedi R (2001): The relationship between erosion, caries and rampant caries and dietary habits in preschool children in Saudi Arabia. Int J Paediatr Dent 11, 430-439

Al-Malik MI, Holt RD, Bedi R (2002): Erosion, caries and rampant caries in preschool children in Jeddah, Saudi Arabia. Community Dent Oral Epidemiol 30, 16-23

Alberti G, Zimmet P, Shaw J, Bloomgarden Z, Kaufman F, Silink M (2004): Type 2 diabetes in the young: the evolving epidemic: the international diabetes federation consensus workshop. Diabetes Care 27, 1798-1811

Alm A, Fahraeus C, Wendt LK, Koch G, Andersson-Gare B, Birkhed D (2008): Body adiposity status in teenagers and snacking habits in early childhood in relation to approximal caries at 15 years of age. Int J Paediatr Dent $\underline{18}, 189-196$

Anderson P, Hector MP, Rampersad MA (2001): Critical pH in resting and stimulated whole saliva in groups of children and adults. Int J Paediatr Dent 11, 266-273

Attin T (1999): Erosion und Abrasion von Zahnhartsubstanz-Einflußfaktoren, Pathogenese und Therapie. Dtsch Zahnärztekal 토, 1-31

Auad SM, Waterhouse PJ, Nunn JH, Moynihan PJ (2009): Dental caries and its association with sociodemographics, erosion, and diet in schoolchildren from southeast Brazil. Pediatr Dent $\underline{31}, 229-235$

Azrak B, Huyer S, Pistorius A, Willerhausen B (2006): Kariesprävalenz und

Gewichtszustand von 638 Vorschulkindern mit zahnärztlichem Sanierungsbedarf. Dtsch Zahnärztl Z $\underline{61}, 564-567$

Bailleul-Forestier I, Lopes K, Souames M, Azoguy-Levy S, Frelut ML, Boy-Lefevre ML (2007): Caries experience in a severely obese adolescent population. Int J Paediatr Dent $17,358-363$

Bartlett D, Ganss C, Lussi A (2008): Basic Erosive Wear Examination (BEWE): a new scoring system for scientific and clinical needs. Clin Oral Investig 12 Suppl 1, 65-68

Basner R, Santamaria RM, Schmoeckel J, Schüler E, Splieth CH: Epidemiologische Begleituntersuchungen zur Gruppenprophylaxe 2016. Deutsche Arbeitsgemeinschaft für Jugendzahnpflege (DAJ), Bonn 2017

Bawa S (2005): The role of the consumption of beverages in the obesity epidemic. J R Soc Promot Health $\underline{125}$, 124-128 
Ben-Aryeh H, Lapid S, Szargel R, Benderly A, Gutman D (1984): Composition of whole unstimulated saliva of human infants. Arch Oral Biol 29, 357-362

Bender GR, Sutton SV, Marquis RE (1986): Acid tolerance, proton permeabilities, and membrane ATPases of oral streptococci. Infect Immun 53, 331-338

Bere E, Brug J, Klepp K-I (2008): Why do boys eat less fruit and vegetables than girls? Public Health Nutr 11, 321-325

Block G (2004): Foods contributing to energy intake in the US: data from NHANES III and NHANES 1999-2000. J Food Compost Anal 17, 439-447

Bourgeois DM, Llodra JC, Christensen LB, Pitts N, Ottolenghi L, Senekola E: Health Surveillance in Europe: European Global Oral Health Indicators Development Program (Egohid II). Oral Health Interviews and Clinical Surveys: Guidelines. Universität Lyon, Lyon 2008

Bundeszentrale für politische Bildung (2013): Einkommen privater Haushalte. http://www.bpb.de/nachschlagen/zahlen-und-fakten/siziale-situation-indeutschland/61754/einkommen-privater-haushalte; abgerufen am 06.04.2017

Buzalaf MA, Hannas AR, Kato MT (2012): Saliva and dental erosion. J Appl Oral Sci 20 , 493-502

Cohen J: Statistical power analysis for the behavioral sciences. 2. Auflage; Lawrence Erlbaum Associates, Hillsdale 1988

Dawes C (1996): Factors influencing salivary flow rate and composition. In: Edgar WE, O’Mullane DM (Hrsg.): Saliva and Oral Health. 3. Auflage; British Dental Association, London 1996, 27-41

de Onis M, Blossner M, Borghi E (2010): Global prevalence and trends of overweight and

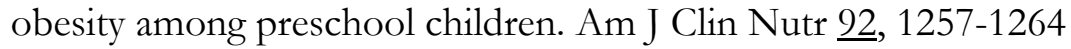

Dugmore CR, Rock WP (2004): The prevalence of tooth erosion in 12-year-old children. Br Dent J 196, 279-282; discussion 273

Dye BA, Shenkin JD, Ogden CL, Marshall TA, Levy SM, Kanellis MJ (2004): The relationship between healthful eating practices and dental caries in children aged 25 years in the United States, 1988-1994. J Am Dent Assoc 135, 55-66

Edgar WM (1990): Saliva and dental health. Clinical implications of saliva: report of a consensus meeting. Br Dent J $\underline{169}$, 96-98

Fadel HT, Pliaki A, Gronowitz E, Marild S, Ramberg P, Dahlen G, Yucel-Lindberg T, Heijl L, Birkhed D (2014): Clinical and biological indicators of dental caries and periodontal disease in adolescents with or without obesity. Clin Oral Investig $\underline{18}$, 359-368

Ferro R, Besostri A, Meneghetti B, Stellini E (2007): Prevalence and severity of dental caries in 5- and 12-year old children in the Veneto Region (Italy). Community Dent Health $24,88-92$ 
Fox S, Meinen A, Pesik M, Landis M, Remington PL (2005): Competitive food initiatives in schools and overweight in children: a review of the evidence. WMJ 104, 38-43

Ganss C (2014): Is erosive tooth wear an oral disease? Monogr Oral Sci $\underline{25}, 16-21$

Ganss C, Lussi A (2014): Diagnosis of erosive tooth wear. Monogr Oral Sci 25, 22-31

Ganss C, Klimek J, Giese K (2001): Dental erosion in children and adolescents - a crosssectional and longitudinal investigation using study models. Community Dent Oral Epidemiol 29, 264-271

Ganss C, Lussi A, Schlueter N (2014): The histological features and physical properties of eroded dental hard tissues. Monogr Oral Sci 25, 99-107

Gatou T, Mamai-Homata E (2012): Tooth wear in the deciduous dentition of 5-7-year-old children: risk factors. Clin Oral Investig $\underline{16}, 923-933$

Genco RJ, Grossi SG, Ho A, Nishimura F, Murayama Y (2005): A proposed model linking inflammation to obesity, diabetes, and periodontal infections. J Periodontol $\underline{76}$, 2075-2084

Gerdin EW, Angbratt M, Aronsson K, Eriksson E, Johansson I (2008): Dental caries and body mass index by socio-economic status in Swedish children. Community Dent Oral Epidemiol 36, 459-465

Gibbons RJ, Fitzgerald RJ (1969): Dextran-induced agglutination of Streptococcus mutans, and its potential role in the formation of microbial dental plaques. J Bacteriol $\underline{98}$, 341-346

Granville-Garcia AF, de Menezes VA, de Lira PI, Ferreira JM, Leite-Cavalcanti A (2008): Obesity and dental caries among preschool children in Brazil. Rev Salud Publica (Bogota) 10, 788-795

Haas G, Willershausen B, Hohenfellner K, Koppelmann S (2004): Zusammenhang zwischen Kariesvorkommen und Übergewicht bei Grundschulkindern. Dtsch Zahnärtzl Z $\underline{59}, 111-115$

Hamada S, Slade HD (1980): Biology, immunology, and cariogenicity of Streptococcus mutans. Microbiol Rev $\underline{44}, 331-384$

Hannig M, Balz M (2001): Protective properties of salivary pellicles from two different intraoral sites on enamel erosion. Caries Res $\underline{35}, 142-148$

Hannig M, Hannig C (2014): The pellicle and erosion. Monogr Oral Sci 25, 206-214

Hara AT, Zero DT (2014): The potential of saliva in protecting against dental erosion. Monogr Oral Sci 25, 197-205

Harding MA, Whelton H, O'Mullane DM, Cronin M (2003): Dental erosion in 5-year-old Irish school children and associated factors: a pilot study. Community Dent Health $\underline{20}, 165-170$

Hasselkvist A, Johansson A, Johansson A-K (2010): Dental erosion and soft drink consumption in Swedish children and adolescents and the development of a 
simplified erosion partial recording system. A longitudinal study of dental erosion and associated lifestyle factors in a group of Swedish children and adolescents. Swed Dent J $\underline{34}$, 187-195

Hayden C, Bowler JO, Chambers S, Freeman R, Humphris G, Richards D, Cecil JE (2013): Obesity and dental caries in children: a systematic review and meta-analysis. Community Dent Oral Epidemiol 41, 289-308

Hellström I (1977): Oral complications in anorexia nervosa. Scand J Dent Res $\underline{8}$, 71-86

Hellwig E, Lussi A (2014): Oral hygiene products, medications and drugs - hidden aetiological factors for dental erosion. Monogr Oral Sci 25 , 155-162

Hoffmann-Axthelm W: Lexikon der Zahnmedizin. Quintessenz Verlag, Berlin 2000

Hooley M, Skouteris H, Boganin C, Satur J, Kilpatrick N (2012): Body mass index and dental caries in children and adolescents: a systematic review of literature published 2004 to 2011. Syst Rev 1, 57

Hotz PR (1987): Erosion des Zahnschmelzes. Schweiz Monatsschr Zahnmed 97, 219-222

Huew R, Waterhouse P, Moynihan P, Kometa S, Maguire A (2012): Dental caries and its association with diet and dental erosion in Libyan schoolchildren. Int J Paediatr Dent 22, 68-76

Humphrey SP, Williamson RT (2001): A review of saliva: normal composition, flow, and function. J Prosthet Dent $\underline{85}, 162-169$

Ismail AI, Sohn W, Tellez M, Amaya A, Sen A, Hasson H, Pitts NB (2007): The International Caries Detection and Assessment System (ICDAS): an integrated system for measuring dental caries. Community Dent Oral Epidemiol 35, 170-178

Jablonski-Momeni A, Stachniss V, Ricketts DN, Heinzel-Gutenbrunner M, Pieper K (2008): Reproducibility and accuracy of the ICDAS-II for detection of occlusal caries in vitro. Caries Res $\underline{42}, 79-87$

Jaeggi T, Lussi A (2004): Erosionen bei Kindern im frühen Schulalter. Schweiz Monatsschr Zahnmed 114, 876-881

Jaroch M, Kielbassa A (2009): Der dentale Biofilm - Voraussetzung dentaler und parodontaler Erkrankung. Dentalhyg J 2, 10-14

Järvinen VK, Rytömaa, II, Heinonen OP (1991): Risk factors in dental erosion. J Dent Res 70, $942-947$

Jenkins GN, Edgar WM (1989): The effect of daily gum-chewing on salivary flow rates in man. J Dent Res $\underline{68}$, 786-790

Jensen JL, Karatsaidis A, Brodin P (1998): Salivary secretion: stimulatory effects of chewing-gum versus paraffin tablets. Eur J Oral Sci 106, 892-896

Kendrick ML, Houghton SG (2006): Gastroesophageal reflux disease in obese patients: the role of obesity in management. Dis Esophagus $\underline{19}, 57-63$ 
Kjelsas E, Bjornstrom C, Gotestam KG (2004): Prevalence of eating disorders in female and male adolescents (14-15 years). Eat Behav $\underline{5}, 13-25$

Klein H, Palmer CE, Knutson JW (1938): Studies on dental caries: I. Dental status and dental needs of elementary school children. Public Health Rep $\underline{53}$, 751-765

Klimek J (2008): Saliva \& Oral Health. Lecture Handout for Undergraduate Students of Dentistry, 3-46

Kopycka-Kedzierawski DT, Auinger P, Billings RJ, Weitzman M (2008): Caries status and overweight in 2- to 18-year-old US children: findings from national surveys. Community Dent Oral Epidemiol 36, 157-167

Kromeyer-Hauschild K, Wabitsch M, Kunze D, Geller F, Geiß HC, Hesse V, von Hippel A, Jaeger U, Johnsen D, Korte W et al. (2001): Perzentile für den Body-mass-Index für das Kindes-und Jugendalter unter Heranziehung verschiedener deutscher Stichproben. Monatsschr Kinderheilkd 149, 807-818

Kuramitsu HK (1993): Virulence factors of mutans streptococci: role of molecular genetics. Crit Rev Oral Biol Med 4 , 159-176

Kurth BM, Schaffrath Rosario A (2007): The prevalence of overweight and obese children and adolescents living in Germany. Results of the German Health Interview and Examination Survey for Children and Adolescents (KiGGS). Bundesgesundheitsblatt Gesundheitsforschung Gesundheitsschutz 무, 736-743

Larsen MJ, Nyvad B (1999): Enamel erosion by some soft drinks and orange juices relative to their $\mathrm{pH}$, buffering effect and contents of calcium phosphate. Caries Res $\underline{33}, 81$ 87

Larsen MJ, Poulsen S, Hansen I (2005): Erosion of the teeth: prevalence and distribution in a group of Danish school children. Eur J Paediatr Dent $\underline{6}, 44-47$

Lenander-Lumikari M, Loimaranta V (2000): Saliva and dental caries. Adv Dent Res $\underline{14}$, 4047

Levine RS (1973): Fruit juice erosion--an increasing danger? J Dent $\underline{2}$, 85-88

Lobstein T, Baur L, Uauy R (2004): Obesity in children and young people: a crisis in public health. Obes Rev $\underline{5 \text { Suppl 1 }}$, 4-104

Luo Y, Zeng XJ, Du MQ, Bedi R (2005): The prevalence of dental erosion in preschool children in China. J Dent $\underline{33}, 115-121$

Lussi A (1996): Dental erosion clinical diagnosis and case history taking. Eur J Oral Sci 104, 191-198

Lussi A, Jaeggi T (2006): Dental erosion in children. Monogr Oral Sci 20, 140-151

Lussi A, Schaffner M, Hotz P, Suter P (1991): Dental erosion in a population of Swiss adults. Community Dent Oral Epidemiol 19, 286-290

Lussi A, Jaeggi T, Zero D (2004): The role of diet in the aetiology of dental erosion. Caries

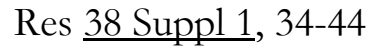


Lussi A, Schaffner M, Jaeggi T, Grüninger A (2005): Erosionen. Schweiz Monatsschr Zahnmed 115, 917-935

Maldupa I, Brinkmane A, Mihailova A (2011): Comparative analysis of CRT Buffer, GC saliva check buffer tests and laboratory titration to evaluate saliva buffering capacity. Stomatologija $\underline{13}, 55-61$

Marcotte H, Lavoie MC (1998): Oral microbial ecology and the role of salivary immunoglobulin A. Microbiol Mol Biol Rev 62, 71-109

Marsicano JA, Sales-Peres A, Ceneviva R, de CS-PSH (2012): Evaluation of oral health status and salivary flow rate in obese patients after bariatric surgery. Eur J Dent $\underline{6}$, 191-197

McGuire J, Szabo A, Jackson S, Bradley TG, Okunseri C (2009): Erosive tooth wear among children in the United States: relationship to race/ethnicity and obesity. Int J Paediatr Dent 19, 91-98

Meurman JH, Drysdale T, Frank RM (1991): Experimental erosion of dentin. Scand J Dent Res $\underline{99}, 457-462$

Micheelis W, Schiffner U (Hrsg.): Vierte Deutsche Mundgesundheitsstudie (DMS IV). Institut der Deutschen Zahnärzte (IDZ). Deutscher Zahnärzte Verlag DÄV, Köln 2006

Micheelis W, Jordan RA (Hrsg.): Fünfte Deutsche Mundgesundheitsstudie (DMS V). Institut der Deutschen Zahnärzte (IDZ). Deutscher Zahnärzte Verlag DÄV, Köln 2016

Millward A, Shaw L, Smith A (1994): Dental erosion in four-year-old children from differing socioeconomic backgrounds. ASDC J Dent Child 61, 263-266

Milosevic A, Young PJ, Lennon MA (1994): The prevalence of tooth wear in 14-year-old school children in Liverpool. Community Dent Health $\underline{11}$, 83-86

Milosevic A, Lennon MA, Fear SC (1997): Risk factors associated with tooth wear in teenagers: a case control study. Community Dent Health $\underline{14}$, 143-147

Modeer T, Blomberg CC, Wondimu B, Julihn A, Marcus C (2010): Association between obesity, flow rate of whole saliva, and dental caries in adolescents. Obesity (Silver Spring) $\underline{18}, 2367-2373$

Moschos D, Willershausen B, Blettner M, Azrak B (2006): Korrelation zwischen Mundgesundheit und Body-Mass-Index (BMI) bei Grundschülern. Dtsch Zahnärtzl Z $\underline{61}, 627-631$

Moura-Grec PG, Marsicano JA, Carvalho CA, Sales-Peres SH (2014): Obesity and periodontitis: systematic review and meta-analysis. Cien Saude Colet $\underline{19}, 1763-1772$

Mulic A, Skudutyte-Rysstad R, Tveit AB, Skaare AB (2012): Risk indicators for dental erosive wear among 18-yr-old subjects in Oslo, Norway. Eur J Oral Sci $\underline{120}$, 531 538 
Nadeau KJ, Maahs DM, Daniels SR, Eckel RH (2011): Childhood obesity and cardiovascular disease: links and prevention strategies. Nat Rev Cardiol $\underline{8}$, 513-525

Nishida N, Tanaka M, Hayashi N, Nagata H, Takeshita T, Nakayama K, Morimoto K, Shizukuishi S (2005): Determination of smoking and obesity as periodontitis risks using the classification and regression tree method. J Periodontol $\underline{76}$, 923-928

Ochoa MC, Moreno-Aliaga MJ, Martinez-Gonzalez MA, Martinez JA, Marti A (2007): Predictor factors for childhood obesity in a Spanish case-control study. Nutrition $\underline{23}, 379-384$

Ogden CL, Carroll MD, Kit BK, Flegal KM (2012): Prevalence of obesity and trends in body mass index among US children and adolescents, 1999-2010. JAMA $\underline{307}$, 483490

Ohrn R, Enzell K, Angmar-Mansson B (1999): Oral status of 81 subjects with eating disorders. Eur J Oral Sci 107, 157-163

Oliveira LB, Sheiham A, Bonecker M (2008): Exploring the association of dental caries with social factors and nutritional status in Brazilian preschool children. Eur J Oral Sci $116,37-43$

Page RC, Kornman KS (1997): The pathogenesis of human periodontitis: an introduction. Periodontol 2000 14, 9-11

Pannunzio E, Amancio OM, Vitalle MS, Souza DN, Mendes FM, Nicolau J (2010): Analysis of the stimulated whole saliva in overweight and obese school children. Rev Assoc Med Bras 므, 32-36

Peres KG, Armenio MF, Peres MA, Traebert J, De Lacerda JT (2005): Dental erosion in 12-year-old schoolchildren: a cross-sectional study in Southern Brazil. Int J Paediatr Dent $\underline{15}, 249-255$

Pieper K: Epidemiologische Begleituntersuchungen zur Gruppenprophylaxe 2004. Deutsche Arbeitsgemeinschaft für Jugendzahnpflege (DAJ), Bonn 2005

Pindborg JJ: Pathology of dental hard tissues. Munksgaard Verlag, Kopenhagen 1970

Porter SR, Scully C, Hegarty AM (2004): An update of the etiology and management of xerostomia. Oral Surg Oral Med Oral Pathol Oral Radiol Endod 97, 28-46

Poskitt EM (1995): Defining childhood obesity: the relative body mass index (BMI). European Childhood Obesity group. Acta Paediatr $\underline{84}$, 961-963

Preshaw PM, Seymour RA, Heasman PA (2004): Current concepts in periodontal pathogenesis. Dent Update $\underline{31}$, 570-572, 574-578

Qadri G, Alkilzy M, Feng YS, Splieth C (2015): Overweight and dental caries: the association among German children. Int J Paediatr Dent 25, 174-182

Quetelet A: Physique sociale: Ou, Essai Sur Le Développement Des Facultés de l'Homme. 1. Auflage; C. Muquardt, Brüssel 1869 
Rasines G (2010): Fluoride toothpaste prevents caries in children and adolescents at fluoride concentrations of 1000 ppm and above. Evid Based Dent 11, 6-7

Robb ND, Smith BG, Geidrys-Leeper E (1995): The distribution of erosion in the dentitions of patients with eating disorders. Br Dent J $\underline{178}, 171-175$

Sabel C (2012): Karies bei Hamburger Kindern im Alter von 3 bis 6 Jahren im Jahr 2006: Eine Erhebung in Kindergärten und Kindertagesstätten unter Berücksichtigung der sozialen Schichtzugehörigkeit. Med. Diss. Hamburg 2012

Sanchez-Perez L, Irigoyen ME, Zepeda M (2010): Dental caries, tooth eruption timing and obesity: a longitudinal study in a group of Mexican schoolchildren. Acta Odontol Scand $\underline{68}, 57-64$

Schenk L, Knopf H (2007): Mundgesundheitsverhalten von Kindern und Jugendlichen in Deutschland. Bundesgesundheitsblatt-Gesundheitsforschung-Gesundheitsschutz $\underline{50}, 653-658$

Schenk L, Neuhauser H, Ellert U, Poethko-Müller C, Kleiser C, Mensink G: Kinder- und Jugendgesundheitssurvey (KiGGS) 2003-2006: Kinder und Jugendliche mit Migrationshintergrund in Deutschland. Robert Koch-Institut, Berlin 2008

Schlueter N, Ganss C, Klimek J, Zeeck A (2006): Zahnhartsubstanzschäden bei Essstörungen. Psychotherapeut 51, 465-474

Schlueter N, Tveit AB (2014): Prevalence of erosive tooth wear in risk groups. Monogr Oral Sci 25, 74-98

Shannon IL (1973): Reference table for human parotid saliva collected at varying levels of exogenous stimulation. J Dent Res $\underline{52}, 1157$

Sharma A, Hegde AM (2009): Relationship between body mass index, caries experience and dietary preferences in children. J Clin Pediatr Dent $\underline{34}$, 49-52

Shellis RP: Äthiologie und Pathogenese der Karies. In: Meyer-Lückel H, Paris S, Ekstrand K (Hrsg.): Karies: Wissenschaft und Klinische Praxis. Georg Thieme Verlag, Stuttgart 2012, 23-38

Shellis RP, Featherstone JD, Lussi A (2014): Understanding the chemistry of dental erosion. Monogr Oral Sci 25, 163-179

Shiboski CH, Hodgson TA, Ship JA, Schiodt M (2007): Management of salivary hypofunction during and after radiotherapy. Oral Surg Oral Med Oral Pathol Oral Radiol Endod 103 Suppl, S66.e61-19

Singh S, Sharma A, Sood PB, Sood A, Zaidi I, Sinha A (2015): Saliva as a prediction tool for dental caries: An in vivo study. J Oral Biol Craniofac Res $\underline{5}, 59-64$

Splieth CH, Treuner A, Berndt C (2009): Orale Gesundheit im Kleinkindalter. Prävent Gesundheitsförd 4, 119-124

Städtler P, Bodenwinkler A, Sax G (2003): Prevalence of caries in 6-year-old Austrian children. Oral Health Prev Dent $1,179-183$ 
Tao DY, Hao G, Lu HX, Tian Y, Feng XP (2015): Dental erosion among children aged 3-6 years and its associated indicators. J Public Health Dent $\underline{75}$, 291-297

Ten Bruggen Cate HJ (1968): Dental erosion in industry. Br J Ind Med 25, 249-266

Tong HJ, Rudolf MC, Muyombwe T, Duggal MS, Balmer R (2014): An investigation into the dental health of children with obesity: an analysis of dental erosion and caries status. Eur Arch Paediatr Dent 15, 203-210

Treuner A, Splieth CH (2013): Gebissdestruktion im Kleinkindalter - Frühkindliche Karies - Fakten und Prävention. Zahnärztl Mitt 17, 44-51

Tschammler C, Müller-Pflanz C, Attin T, Müller J, Wiegand A (2016): Prevalence and risk factors of erosive tooth wear in 3-6 year old German kindergarten children-A comparison between 2004/05 and 2014/15. J Dent $\underline{52}$, 45-49

Uhlen MM, Tveit AB, Stenhagen KR, Mulic A (2014): Self-induced vomiting and dental erosion-a clinical study. BMC Oral Health $\underline{14}, 92$

Vargas-Ferreira F, Praetzel JR, Ardenghi TM (2011): Prevalence of tooth erosion and associated factors in 11-14-year-old Brazilian schoolchildren. J Public Health Dent $\underline{71}, 6-12$

von Bremen J, Lorenz N, Ruf S (2015): Impact of body mass index on oral health during orthodontic treatment: an explorative pilot study. Euro J Orthodontics $\underline{38}$, 386-392

Wabitsch M (2004): Obese children and adolescents in Germany. A call for action. Bundesgesundheitsblatt Gesundheitsforschung Gesundheitsschutz 47, 251-255

Wabitsch M, Kunze D (2015): Konsensbasierte (S2) Leitlinie zur Diagnostik, Therapie und Prävention von Übergewicht und Adipositas im Kindes- und Jugendalter. S2Leitlinie der Arbeitsgemeinschaft Adipositas im Kindes- und Jugendalter; https://aga.adipositasgesellschaft.de/fileadmin/PDF/Leitlinien/AGA_S2_Leitlinie.pdf; abgerufen am 08.09.2019

Walsh T, Worthington HV, Glenny AM, Appelbe P, Marinho VC, Shi X (2010): Fluoride toothpastes of different concentrations for preventing dental caries in children and adolescents. Cochrane Database Syst Rev 1 , Cd007868

Walsh T, Worthington HV, Glenny AM, Marinho VC, Jeroncic A (2019): Fluoride toothpastes of different concentrations for preventing dental caries. Cochrane Database Syst Rev $\underline{3}$, Cd007868

Wang P, Lin HC, Chen JH, Liang HY (2010): The prevalence of dental erosion and associated risk factors in 12-13-year-old school children in Southern China. BMC Public Health $\underline{10}, 478$

Wang P, Zhou Y, Zhu YH, Lin HC (2011): Unstimulated and stimulated salivary characteristics of 12-13-year-old schoolchildren with and without dental erosion. Arch Oral Biol 56, 1328-1332

Wiegand A, Schlueter N (2014): The role of oral hygiene: does toothbrushing harm? Monogr Oral Sci $\underline{25}, 215-219$ 
Wiegand A, Müller J, Werner C, Attin T (2006): Prevalence of erosive tooth wear and associated risk factors in 2-7-year-old German kindergarten children. Oral Dis $\underline{12}$, $117-124$

Willershausen B, Haas G, Krummenauer F, Hohenfellner K (2004): Relationship between high weight and caries frequency in German elementary school children. Eur J Med Res $\underline{9}, 400-404$

Willershausen B, Blettner M, Kasaj A, Hohenfellner K (2007): Association between body mass index and dental health in 1,290 children of elementary schools in a German city. Clin Oral Investig 11, 195-200

Williams RC (1990): Periodontal disease. N Engl J Med 322, 373-382

Wood N, Johnson RB, Streckfus CF (2003): Comparison of body composition and periodontal disease using nutritional assessment techniques: Third National Health and Nutrition Examination Survey (NHANES III). J Clin Periodontol 30, 321-327

Young JA, Schneyer CA (1981): Composition of saliva in mammalia. Aust J Exp Biol Med Sci $\underline{59}, 1-53$

Young WG, Khan F (2002): Sites of dental erosion are saliva-dependent. J Oral Rehabil 29, $35-43$

Zahradnik RT, Moreno EC, Burke EJ (1976): Effect of salivary pellicle on enamel subsurface demineralization in vitro. J Dent Res $\underline{55}$, 664-670

Zentner A, Duschner H (1996): Structural changes of acid etched enamel examined under confocal laser scanning microscope. J Orofac Orthop 프, 202-209

Zero DT (1996): Etiology of dental erosion-extrinsic factors. Eur J Oral Sci 104, 162-177

Zhang S, Chau AM, Lo EC, Chu CH (2014): Dental caries and erosion status of 12-yearold Hong Kong children. BMC Public Health $\underline{14}, 7$ 


\section{Danksagung}

An dieser Stelle möchte ich meinen besonderen Dank nachstehenden Personen entgegenbringen, ohne deren Mithilfe diese Promotionsschrift niemals zustande gekommen wäre:

Frau Prof. Dr. Annette Wiegand, Direktorin der Poliklinik für Präventive Zahnmedizin, Parodontologie und Kariologie des Zentrums Zahn-, Mund- und Kieferheilkunde der Universitätsmedizin Göttingen, gilt mein besonderer Dank für die Überlassung des Themas und für die vielfältige Unterstützung und Förderung dieser Arbeit.

Bedanken möchte ich mich ebenfalls bei Frau Dr. Claudia Tschammler, Zahnärztin in der oben genannten Poliklinik, für ihre Betreuung bei der Durchführung der Studie und die Anregungen während der gesamten Arbeit.

Weiterhin danke ich dem Sozialpädiatrischen Zentrum der Universitätsmedizin Göttingen, im Besonderen Herrn Prof. Dr. Knut Brockmann und Herrn Dr. Markus Röbl, für die großartige organisatorische Hilfe.

Bedanken möchte ich mich auch bei den Kindern und ihren Eltern für ihre Teilnahme an der Studie. 